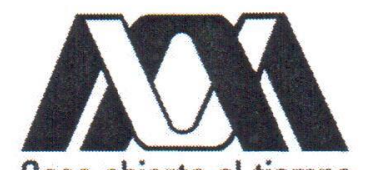

Casa abierta al tiempo UNVERSIDAD AUTÓNOMA METROPOLITANA
UNIVERSIDAD AUTÓNOMA METROPOLITANA IZTAPALAPA

DIVISIÓN DE CIENCIAS BÁSICAS E INGENIERÍA

\title{
ESTUDIO EXPERIMENTAL Y MODELADO \\ DEL SECADO DEL JITOMATE TOMANDO \\ EN CUENTA EL ENCOGIMIENTO
}

\author{
TESIS \\ Para obtener el grado de: \\ Maestra en Ciencias en Ingeniería Química \\ Que presenta: \\ I.Q. Rocío de los Ángeles García Hernández
}

Directores de Tesis:
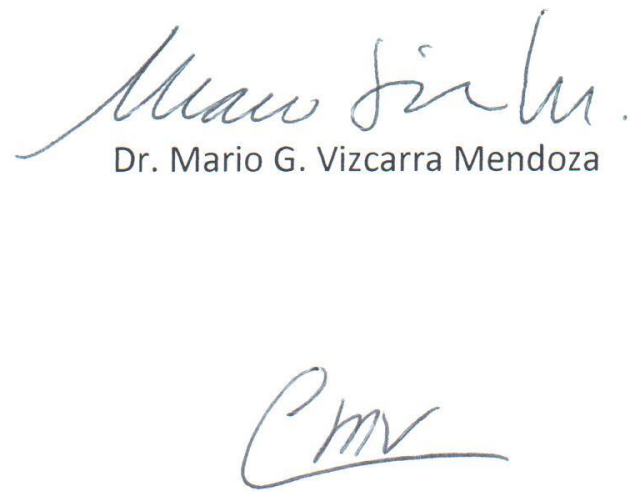

Dr. Carlos Martínez Vera

México Distrito Federal, Diciembre de 2013 


\section{ÍNDICE}

RESUMEN

CAPÍTULO I

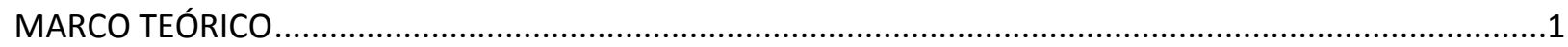

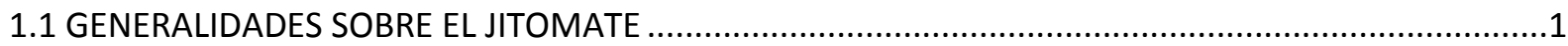

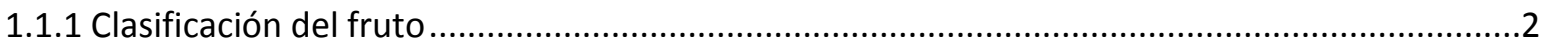

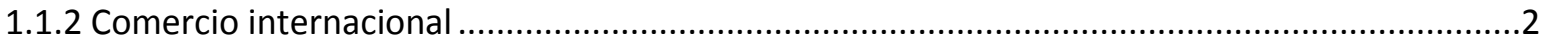

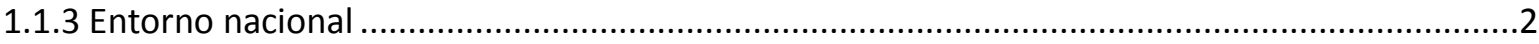

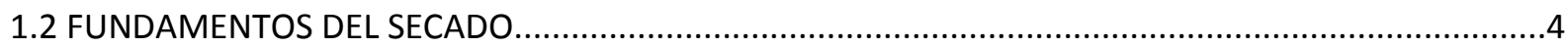

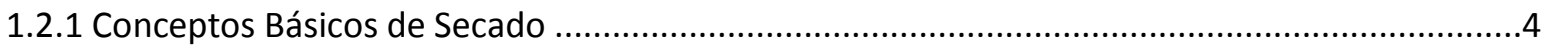

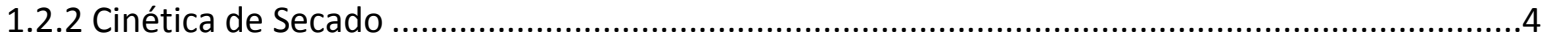

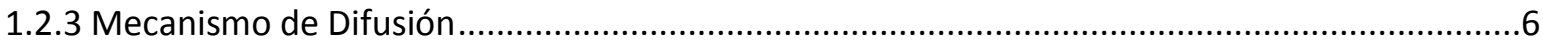

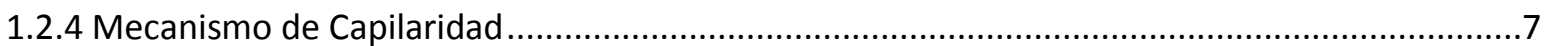

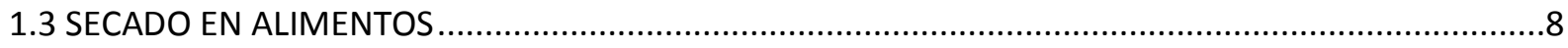

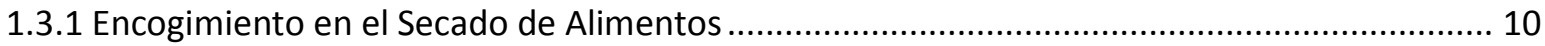

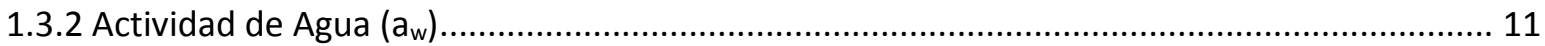

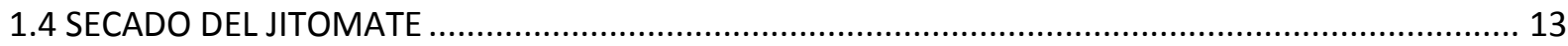

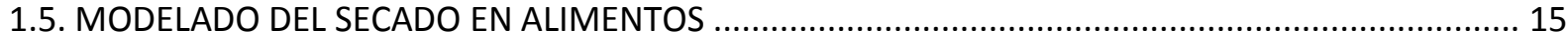

CAPÍTULO II

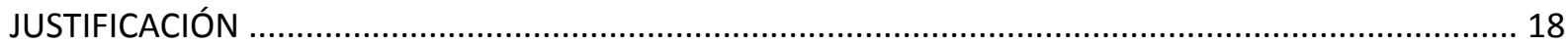

OBJETIVOS

General:

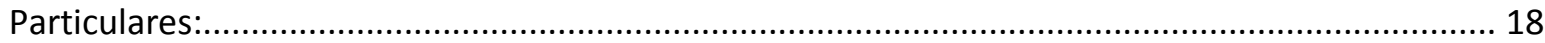

CAPÍTULO III

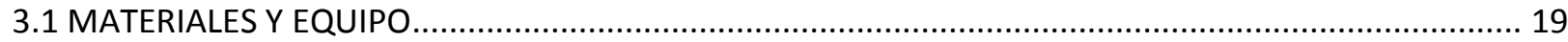

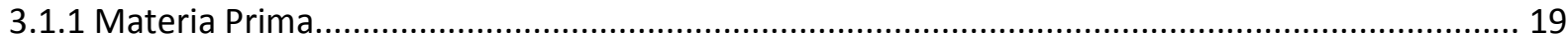

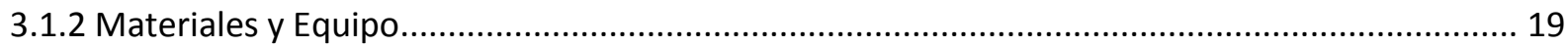

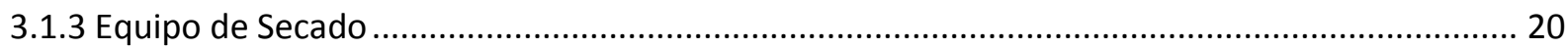

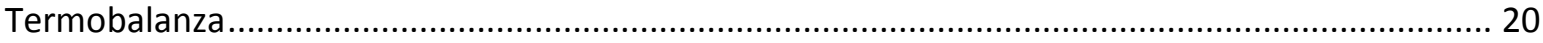

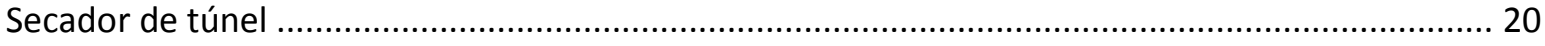

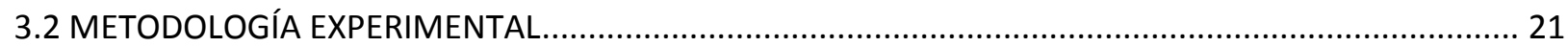

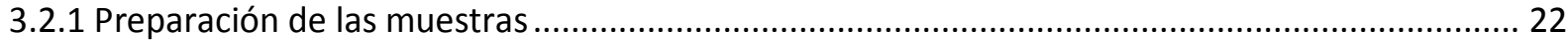




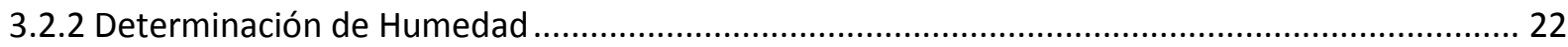

3.2.3 Determinación de volumen de los cubos de tomate ............................................................ 22

3.2.4 Determinación del Radio Equivalente .................................................................................. 23

3.2.5 Proceso de Secado de los Cubos de Tomate........................................................................... 23

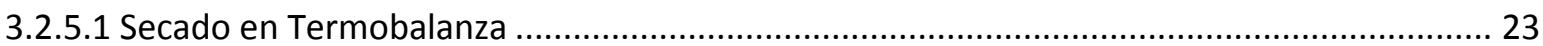

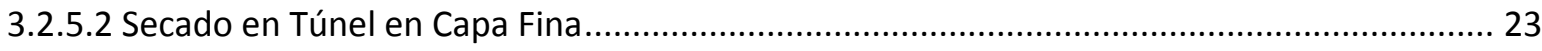

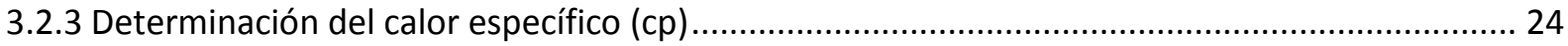

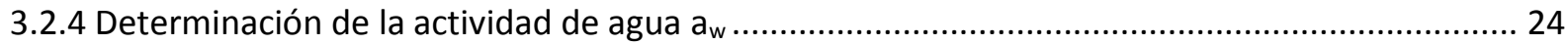

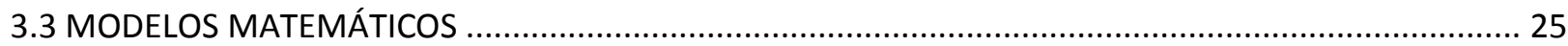

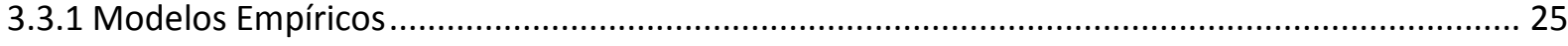

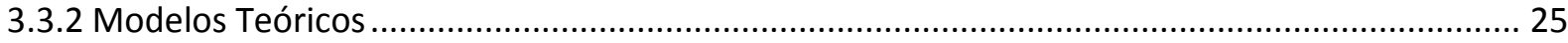

3.3.2.1 Solución de la 2a․ Ley de Fick con Coeficiente de Difusión constante ................................ 25

3.3.2.2 Solución de la 2ª. Ley de Fick con Coeficiente de Difusión Variable.................................... 26 CAPÍTULO IV

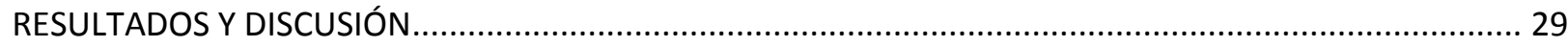

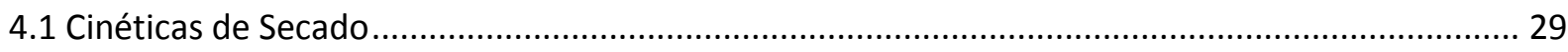

4.2 Modelo para el cálculo del radio equivalente durante el proceso de encogimiento .................... 32

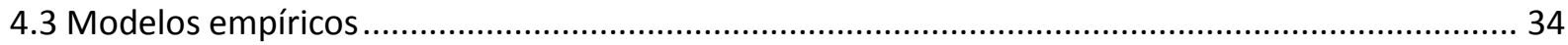

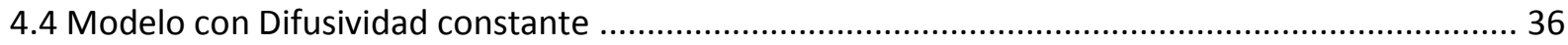

4.5 Modelo con la Difusividad en función del contenido de humedad ............................................... 38

4.5.1 Curvas de Secado y Perfiles de Concentración ....................................................................... 40

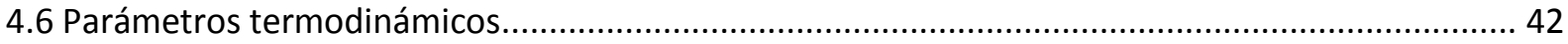

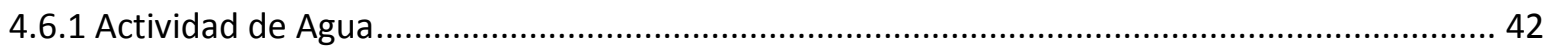

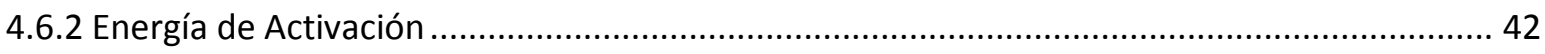

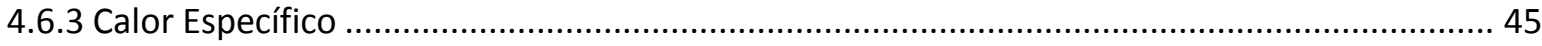

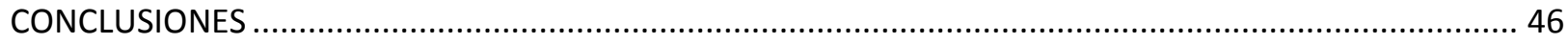

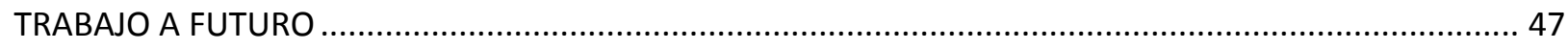

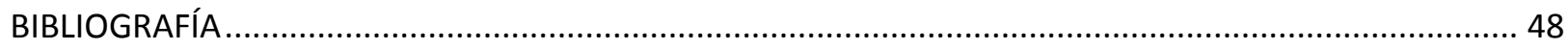

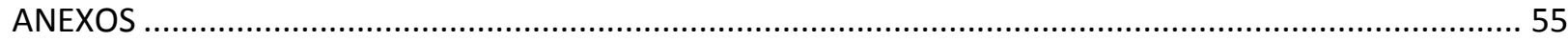

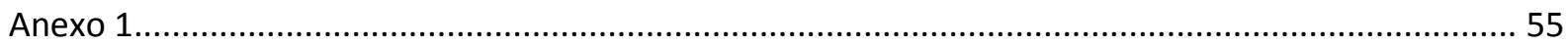

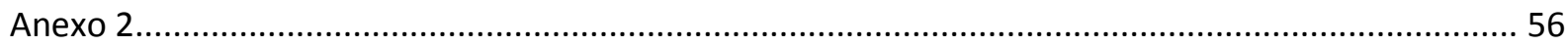

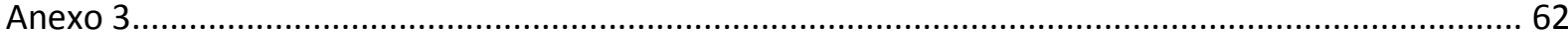


Anexo 4 .

Anexo 5

Anexo 6

Anexo 7.

\section{ÍNDICE DE FIGURAS}

- Figura 1. Participación de la producción mundial (FAO, 2008).......................................2

- Figura 2. Producción de tomate en México. Fuente: SAGARPA, DGAFR - SIAP (2008)......3

- Figura 3. Curva de Secado (Geankoplis, 1998)............................................................5

- Figura 4. Esquema del equipo experimental del secador de túnel. ...............................20

- Figura 5. Diseño Factorial $2^{2}$ con repeticiones en el punto central para el secado en

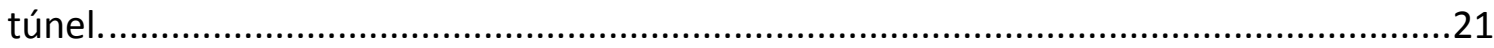

- Figura 6. Curvas de secado en termobalanza (a) y en túnel de viento (b).....................29

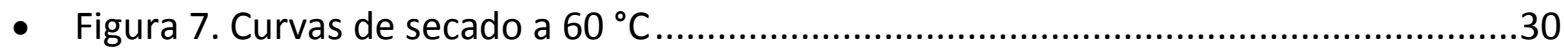

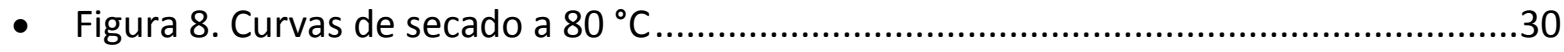

- Figura 9. Curvas de secado a 60 y $80^{\circ} \mathrm{C}$ con un flujo de $150 \mathrm{~L} / \mathrm{min}$..............................31

- Figura 10. Curvas de secado a 60 y $80{ }^{\circ} \mathrm{C}$ con un flujo de $250 \mathrm{~L} / \mathrm{min}$...........................31

- Figura 11. Ajuste modelo tipo potencia para flujo de $150 \mathrm{~L} / \mathrm{min}$. ..............................32

- Figura 12. Ajuste modelo tipo potencia para flujo de $200 \mathrm{~L} / \mathrm{min}$. ...............................32

- Figura 13. Ajuste modelo tipo potencia con flujo de $250 \mathrm{~L} / \mathrm{min}$..................................32

- Figura 14. Datos Experimentales $\left(60^{\circ} \mathrm{C}, 150 \mathrm{~L} / \mathrm{min}\right)$ ajustados a los modelos de Newton y Page

- Figura 15. Datos Experimentales $\left(60^{\circ} \mathrm{C}, 250 \mathrm{~L} / \mathrm{min}\right.$ ) ajustados a los modelos de Newton y Page.

- Figura 16. Datos Experimentales $\left(70^{\circ} \mathrm{C}, 200 \mathrm{~L} / \mathrm{min}\right)$ ajustados a los modelos de Newton y Page.

- Figura 17. Datos Experimentales $\left(80^{\circ} \mathrm{C}, 150 \mathrm{~L} / \mathrm{min}\right.$ ) ajustados a los modelos de Newton y Page.

- Figura 18. Datos Experimentales $\left(80^{\circ} \mathrm{C}, 250 \mathrm{~L} / \mathrm{min}\right.$ ) ajustados a los modelos de Newton y Page.

- Figura 19. Datos Experimentales $\left(60^{\circ} \mathrm{C}, 150 \mathrm{~L} / \mathrm{min}\right)$ ajustados a los modelos de Hawlader y propuesto.

- Figura 20. Datos Experimentales $\left(60^{\circ} \mathrm{C}, 250 \mathrm{~L} / \mathrm{min}\right.$ ) ajustados a los modelos de Hawlader y propuesto.

- Figura 21. Datos Experimentales $\left(70^{\circ} \mathrm{C}, 200 \mathrm{~L} / \mathrm{min}\right.$ ) ajustados a los modelos de Hawlader y propuesto.

- Figura 22. Datos Experimentales $\left(80^{\circ} \mathrm{C}, 150 \mathrm{~L} / \mathrm{min}\right.$ ) ajustados a los modelos de Hawlader y propuesto 
- Figura 23. Datos Experimentales $\left(80^{\circ} \mathrm{C}, 250 \mathrm{~L} / \mathrm{min}\right.$ ) ajustados a los modelos de Hawlader y propuesto.

- Figura 24. Coeficiente de difusión para $60{ }^{\circ} \mathrm{C}-150 \mathrm{~L} / \mathrm{min}$, para tres puntos del sólido. ..39

- Figura 25. Simulación y datos experimentales de las curvas de secado a $60^{\circ} \mathrm{C}-150$ L/min .40

- Figura 26. Perfiles de contenido de humedad (b.vol.) $60{ }^{\circ} \mathrm{C}-150 \mathrm{~L} / \mathrm{min}$.

- Figura 27 .Perfiles de contenido de humedad (b.s.) a $60{ }^{\circ} \mathrm{C}-150 \mathrm{~L} / \mathrm{min}$

- Figura 28. Simulación y datos experimentales de la curva de secado a $60^{\circ} \mathrm{C}-250 \mathrm{~L} / \mathrm{min}$.

- Figura 29. Simulación y datos experimentales de la curva de secado a $70^{\circ} \mathrm{C}-200 \mathrm{~L} / \mathrm{min}$.

- Figura 30. Simulación y datos experimentales de la curva de secado a $80^{\circ} \mathrm{C}-150 \mathrm{~L} / \mathrm{min}$.

- Figura 31. Simulación y datos experimentales ......................................................41

- Figura 32. Isoterma del secado a $70{ }^{\circ} \mathrm{C}, 200 \mathrm{~L} / \mathrm{min}$ ajustada al modelo de GAB. ...........42

- Figura 33. Efecto de la temperatura en el valor de la Difusividad Efectiva. ...................43

- Figura 34. Efecto de la temperatura .......................................................................44

- Figura 35. Efecto de la temperatura......................................................................44

- Figura 36. Gráfica del calor específico en función de la Temperatura............................45

- Figura 37. Perfiles de contenido de humedad (b.s.) a $60^{\circ} \mathrm{C}-250 \mathrm{l} / \mathrm{min}$........................63

- Figura 38. Perfiles de contenido de humedad .........................................................63

- Figura 39. Coeficiente de difusión (función continua) para $60{ }^{\circ} \mathrm{C}-250 \mathrm{~L} / \mathrm{min}$, para tres puntos del sólido.

- Figura 40. Coeficiente de difusión (función continua) para $70^{\circ} \mathrm{C}-200 \mathrm{~L} / \mathrm{min}$, para tres puntos del sólido.

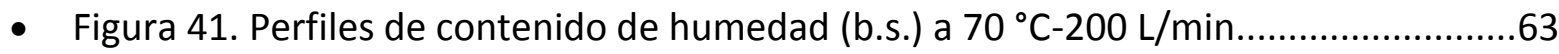

- Figura 42. Perfiles de contenido de humedad (b. vol.) $70^{\circ} \mathrm{C}-200 \mathrm{~L} / \mathrm{min}$.....................63

- Figura 43. Perfiles de contenido de humedad (b.s.) a $80^{\circ} \mathrm{C}-150 \mathrm{l} / \mathrm{min}$........................64

- Figura 44. Perfiles de contenido de humedad ..........................................................64

- Figura 45. Coeficiente de difusión para $80^{\circ} \mathrm{C}-150 \mathrm{l} / \mathrm{min}$, para tres puntos del sólido....64

- Figura 46. Coeficiente de difusión (función continua) para $80^{\circ} \mathrm{C}-250 \mathrm{l} / \mathrm{min}$, para tres puntos del sólido. .64

- Figura 47. Perfiles de contenido de humedad (b.s.) a $80^{\circ} \mathrm{C}-250 \mathrm{l} / \mathrm{min}$........................64

- Figura 48 . Perfiles de contenido de humedad ..........................................................64

- Figura 49. Isoterma del secado a $60^{\circ} \mathrm{C}, 150-250 \mathrm{l} / \mathrm{min}$ ajustada al modelo de...............65

- Figura 50. Isoterma del secado a $80^{\circ} \mathrm{C}, 150-250 \mathrm{l} / \mathrm{min}$ ajustada al modelo de GAB.......65 


\section{ÍNDICE DE TABLAS}

- Tabla 1. Modelos Empíricos Lineales y No Lineales. ...................................................17

- Tabla 2. Diseño factorial $2^{2}$ factorial con tres repeticiones en el punto central...............21

- Tabla 3. Modelos empíricos para la cinética de secado ...................................................25

- Tabla 4. Humedad de equilibrio para las diferentes condiciones de secado ......................31

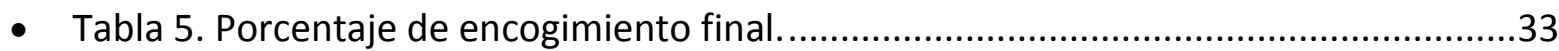

- Tabla 6. Valores de las constantes de la ecuación (22).....................................................33

- Tabla 7. Fotografías de cubos de tomate secados a $250 \mathrm{I} / \mathrm{min}$ a 60 y $80^{\circ} \mathrm{C} \ldots \ldots \ldots \ldots \ldots \ldots . . . . . .33$

- Tabla 8. Valores de la constante y correlación para el Modelo de Newton a diferentes

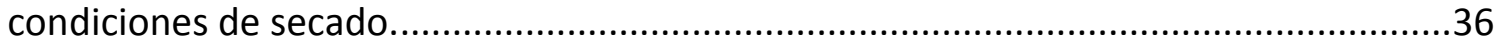

- Tabla 6. Valores de la constante y correlación para el Modelo de Page a diferentes

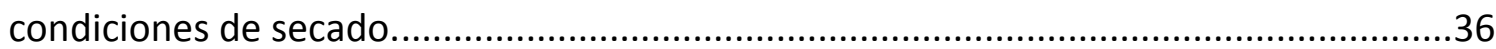

- Tabla 10. Valores de la $D_{\text {ef }}$ para las diferentes condiciones de secado............................38

- Tabla 11. Constantes para la ecuación de Def para diferentes condiciones de operación.

.

- Tabla 12. Coeficiente de $D_{\text {ef }}$ y $R^{2}$ para la simulación de las curvas de secado..................39

- Tabla 13. Valores de las constantes del modelo de GAB para el secado a $70^{\circ} \mathrm{C}$ y 200

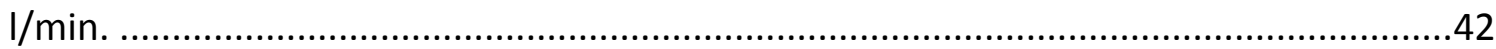

- Tabla 14. Valores de la $D_{\text {ef }}$ a diferentes temperatura con un flujo de $250 \mathrm{l} / \mathrm{min}$. ............43

- Tabla 15. Valores de la $D_{\text {ef }} f(X)$ a dos temperatura con un flujo de $250 \mathrm{l} / \mathrm{min}$..................44

- Tabla 15 . Valores de las constantes del modelo de GAB para el secado a 60 y $80^{\circ} \mathrm{C}$ y $150-250 \mathrm{l} / \mathrm{min}$. 


\section{NOMENCLATURA}

A Área efectiva para transferencia $\left(\mathrm{m}^{2}\right)$.

$a, b, c \quad$ Constantes en modelos.

$A_{s} \quad$ Área superficial de la partícula $\left(\mathrm{m}^{2}\right)$.

Aw Actividad de agua.

$\mathrm{C}, \mathrm{K} \quad$ Constantes relacionadas con la temperatura.

$\mathrm{c}, \mathrm{k} \quad$ Factores de acomodamiento entrópico.

D Coeficiente de difusión $\left(\mathrm{m}^{2} / \mathrm{s}\right)$.

Do $\quad$ Factor pre-exponencial para la difusividad ef $\left(\mathrm{m}^{2} / \mathrm{s}\right)$.

$D_{A B} \quad$ Coeficiente de difusión de un componente $A$ en otro $B\left(\mathrm{~m}^{2} / \mathrm{s}\right)$.

$D_{\text {ef }} \quad$ Difusividad efectiva $\left(\mathrm{m}^{2} / \mathrm{s}\right)$.

$D_{\text {eq }} \quad$ Diámetro equivalente al de una esfera $(m)$.

$\mathrm{E}_{\mathrm{a}} \quad$ Energía de activación para la difusión de la humedad $(\mathrm{kJ} / \mathrm{mol})$.

$\mathrm{h}_{\mathrm{m}}, \mathrm{h}_{\mathrm{n}} \quad$ Entalpías molares de sorción de la monocapa y multicapa (kJ/mol).

$k, k_{1}, k_{2}$ Constantes en modelos.

L $\quad$ Espesor,(longitud) (m).

n Número de observaciones.

P Presión de vapor de agua ejercida por el alimento (atm).

Po Presión de vapor de agua (atm).

Q Flujo de aire (L/min).

$r, R \quad$ Radio de la partícula (m).

$R \quad$ Constante de los gases ideales (J/mol K).

$r^{\prime} \quad$ Radio corregido considerando el encogimiento $(m)$.

$\mathrm{RH} \quad$ Humedad relativa (\%).

T Temperatura $\left({ }^{\circ} \mathrm{C}\right)$.

$V_{0} \quad$ Volumen inicial $\left(\mathrm{m}^{3}\right)$.

$X \quad$ Contenido de humedad base seca a un tiempo $\mathrm{t}\left(\mathrm{kg}_{\mathrm{w}} / \mathrm{kg}_{\mathrm{ss}}\right)$

$\mathrm{X}_{0} \quad$ Contenido de humedad en la monocapa $\left(\mathrm{kg}_{\mathrm{w}} / \mathrm{kg}_{\mathrm{ss}}\right)$

$\mathrm{X}_{\mathrm{A}} \quad$ Contenido de Humedad base seca del componente $\mathrm{A}\left(\mathrm{kg}_{\mathrm{w}} / \mathrm{kg}_{\mathrm{ss}}\right)$

$\mathrm{X}_{\mathrm{e}} \quad$ Humedad de equilibrio en base seca $\left(\mathrm{kg}_{\mathrm{w}} / \mathrm{kg}_{\mathrm{ss}}\right)$

Ys Humedad del aire a la temperatura en el secador $\mathrm{T}_{S}\left({ }^{\circ} \mathrm{C}\right)$.

$\mathrm{Y}_{\mathrm{W}} \quad$ Humedad absoluta de saturación a condición de bulbo húmedo del aire $\left(\mathrm{kg}_{\mathrm{w}} / \mathrm{m}^{3}\right)$

Z Dirección $Z$ en el eje de las coordenadas. 


\section{RESUMEN}

Se realizó el secado de cubos de jitomate por dos métodos, el primero se llevó a cabo en termobalanza a tres temperaturas: 60,70 y $80^{\circ} \mathrm{C}$. EL segundo fue un secador de túnel de viento, para el cual se realizó un diseño factorial 22 con repeticiones en el punto central. Los parámetros de estudio fueron, la temperatura de alimentación del aire: 60,70 y $80{ }^{\circ} \mathrm{C}$ y el flujo de aire: 150, 200 y 250 L/min. En ambos casos se monitoreó, cada minuto, la variación del peso del sólido, hasta que las muestras llegaron a un contenido de humedad de equilibrio. Con esto se obtuvieron las respectivas curvas de secado. En el caso del secado en túnel, se siguió el encogimiento de los sólidos durante el secado, midiendo el aceite desplazado por las muestras de sólidos sujetas a diferentes tiempos de secado, el de encogimiento varió entre el 60 y el $87 \%$ en volumen.

Las curvas de secado, obtenidas en el secador de túnel, se ajustador a dos modelos propuestos en la literatura, el de Newton (Westerman y col., 1973) y el de Page (1949). También, utilizando el modelo difusivo correspondiente a la $2 \underline{\text { a }}$ Ley de Fick se modelaron las curvas de secado, considerando el efecto del encogimiento, por medio del modelo propuesto por Hawlader (1999) y, tomando en cuenta la relación propuesta en este trabajo. En éste último se incluyó una modificación para el cálculo de la variación del radio del sólido, la cual se obtuvo de forma experimental y con ella se logró un mejor ajuste. Para el último caso el valor de $D_{\text {ef, }}$ para las diferentes condiciones de secado, fue de $7.892 \times 10^{-10}$ a $1.330 \times 10^{-9}$.

El mismo modelo de difusión de Fick también se resolvió considerando las variaciones de la difusividad efectiva $\left(D_{\text {ef }}\right)$ en el contenido de humedad y del encogimiento, lo que constituye un modelo de frontera móvil que considera intervalos de valor de $D_{\text {ef }}$ por medio de una función continua tipo sigmoidea. Se logró un ajuste superior a una $\mathrm{R}^{2}=0.998$. Se obtuvieron los perfiles de concentración en diferentes puntos del sólido para cada caso experimental.

Por último, se obtuvieron y ajustaron datos experimentales de la actividad de agua al modelo de Guggenheim-Anderson-de Boer, (GAB) con sus parámetros correspondientes. Con la calorimetría diferencial de barrido (DSC) se determinó la ecuación, en función de la temperatura, para el calor específico. 


\section{CAPÍTULO I}

En este capítulo se presenta la información sobre las características el sólido de estudio, el jitomate, el cual posee un alto contenido de humedad (cerca del $90 \%$ ). Se incluyen fundamentos del secado en general, y en específico de esta operación con relación a la conservación de alimentos, considerando el caso particular del jitomate, así como el estado del arte concerniente a esta operación. Finalmente se muestran evidencias del modelado del secado en alimentos y los tipos de modelos presentes en la literatura, y se hace el desarrollo de las ecuaciones de trabajo que serán utilizadas en este trabajo, las cuales están basadas en la 2a Ley de Fick de la Difusión.

\section{MARCO TEÓRICO}

\subsection{GENERALIDADES SOBRE EL JITOMATE}

El tomate (Lycopersicon esculentum Mill.) es uno de los cultivos más importantes en el mundo. En el contexto de la salud humana, esta fruta es un componente importante de la dieta diaria en varios países y conforma una fuente importante de minerales, vitaminas y antioxidantes (Rajkumar y col., 2007) (Toor y Savage, 2006).

Por otra parte, el tomate es altamente sensible al deterioro y descomposición provocando pérdidas en los periodos de cosecha y poscosecha, por lo que su conservación es de gran interés, sobre todo cuando existe un desequilibrio de la oferta y demanda fuera de la temporada de cosecha lo cual incide en los precios al consumidor. Estas crecientes oportunidades en el mercado hacen necesario que el tomate sea accesible en la forma más conveniente, y esto ha impulsado el desarrollo de tecnologías para el procesamiento, la conservación y venta del producto, en especial, en su forma seca (St. George y col.,2004).

El jitomate es originario de la América del Sur, de la región andina, particularmente de Perú, Ecuador, Bolivia y Chile. Sin embargo, su domesticación fue llevada a cabo en México. El nombre de jitomate procede del náhuatl xictli, ombligo y tomatl, tomate, que significa "tomate de ombligo".

La planta es de porte erecto o semierecto, arbustivo, cultivo de tipo anual. Existen variedades de crecimiento limitado (determinadas) y otras de crecimiento ilimitado (indeterminadas). El fruto es una baya ovalada, redonda o periforme. Su tamaño va desde pequeños frutos del tamaño de una cereza, hasta enormes frutos de 750 gr (SAGARPA, 2010). 


\subsubsection{Clasificación del fruto}

Existen tres maneras de clasificar el tomate, según su forma, madurez y color. De acuerdo a su forma, existen 5 tipos, del más pequeño al más grande: cherry, saladette, tipo pera, bola estándar y bola grande.

Los tomates se clasifican por su grado de madurez considerando el número de días entre que es plantado y su cosecha, así se consideran de madurez temprana cuando se cosechan a los 55-65 días. De mediana maduración se consideran de 66 a 80 días y los de mayor maduración requieren más de 80 días. De la misma manera, pueden clasificarse en función de su color. Existen verde lima, rosa, amarillo, dorado, naranja y rojo (SAGARPA, 2010).

\subsubsection{Comercio internacional}

La producción de tomate en el 2008 se distribuyó de la siguiente manera: China fue el principal productor de jitomate en el mundo, con una participación de 36\%. Le sigue Estados Unidos con 14\%; Turquía, 12\%; India, 11\%; mientras que México ocupó el doceavo lugar, con $3 \%$ de participación en la producción, esta distribución se representa de forma gráfica en la Figura 1.

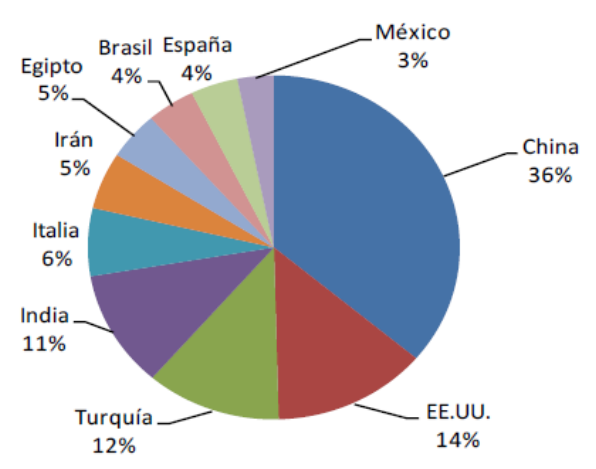

Figura 1. Participación de la producción mundial (FAO, 2008).

\subsubsection{Entorno nacional}

Durante 2008, se produjeron en todo México 2.26 millones de toneladas de tomate, siendo el principal productor el estado de Sinaloa, cuya producción representó el 35\% del total nacional, monto 3.8 veces mayor al producido por el segundo lugar, Baja California, con 9\%. Siguen en la lista los estados de Michoacán, San Luis Potosí y Jalisco con 8\%, 6\% y 5\%, respectivamente. 
La zona productora de mayor importancia es la noroeste. En la Figura 2 se presentan los porcentajes por estado en la producción de tomate.

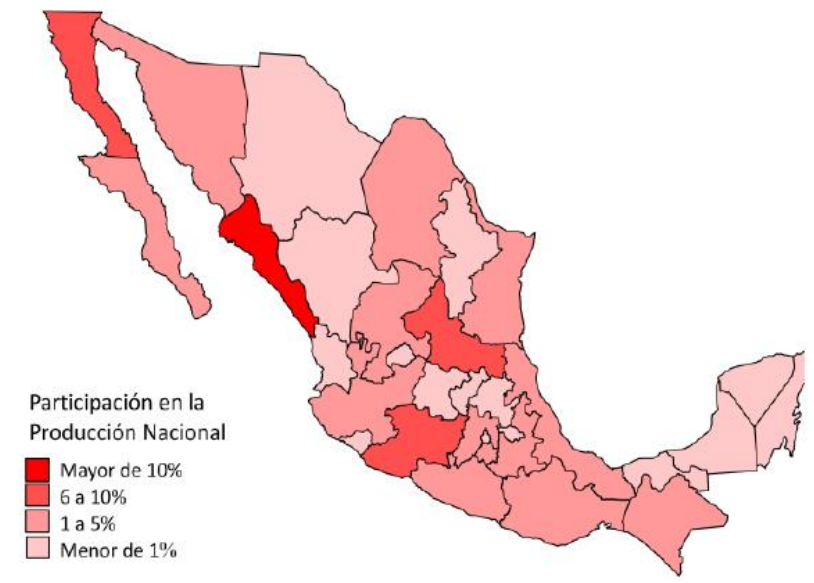

Figura 2. Producción de tomate en México. Fuente: SAGARPA, DGAFR - SIAP (2008).

La producción de tomate es durante todo el año, y en los primeros meses es cuando se genera el tope de producción nacional, principalmente en el estado de Sinaloa, que abastece al mercado nacional y la mitad del norteamericano. Por otro lado, durante el verano, la producción de los estados del centro y de Baja California, es la que abastece la demanda interna y de exportación.

Sin embargo, ante la enorme demanda que tiene este fruto y la vida de anaquel relativamente corta, es importante realizar estudios que permitan alargar su vida de almacenamiento manteniendo altos estándares de calidad en el producto tratado.

Uno de los procedimientos que más se utilizan para estos fines, es el secado. Efectivamente, el producto deshidratado prolonga su vida útil pero la limitante es que el tratamiento térmico que conlleva el proceso. Por esta razón se justifica hacer estudios que permitan encontrar las condiciones adecuadas para obtener un producto seco de calidad. 


\subsection{FUNDAMENTOS DEL SECADO}

\subsubsection{Conceptos Básicos de Secado}

El secado significa la remoción de cantidades de agua relativamente pequeñas de cierto material. La evaporación se refiere a la eliminación de cantidades de agua bastante grandes; además, ahí el agua se elimina en forma de vapor a su punto de ebullición. En el secado, el agua casi siempre se elimina en forma de vapor con aire (Geankoplis, 1998).

Desde el punto de vista de la ingeniería, el secado es una operación típica de contacto entre un sólido húmedo y un gas caliente de manera que cualquier mejora en el contacto entre estas dos fases, hace más rápidos y eficientes los procesos de transferencia de calor y masa que se establecen entre ellas (Geankoplis, 1998) (Félix y col., 1988).

El secado es una operación muy utilizada en el procesamiento de alimentos y se define como una operación unitaria de transferencia simultánea de calor y masa. En la operación básica de secado intervienen dos factores importantes:

1. Trasferencia de calor al material, para suministrar el calor latente de vaporización necesario.

2. Movimiento del agua o del vapor de agua a través del producto (Earle, 1996) (Brennan y col., 1986) (Perry, 1992) (Treybal, 1988).

\subsubsection{Cinética de Secado}

La teoría clásica de secado se basa en las curvas de secado en las que se asocia el contenido de humedad $(\mathrm{X})$ en función del tiempo $(\mathrm{t})$, y otra, por medio de curvas de velocidad de secado (N) en función del contenido de humedad (Foust y Wenzel, 1998).

De acuerdo con la teoría de secado, si se registran los cambios en contenido de humedad de la sustancia a lo largo de todo el proceso de secado y se les presenta de manera gráfica (Figura 3), se pueden reconocer tres etapas o periodos definidos (Brennan y col., 1970) (Perry, 1992) (Treybal, Mass transfer operations, 1988) (Geankoplis, 1998). 


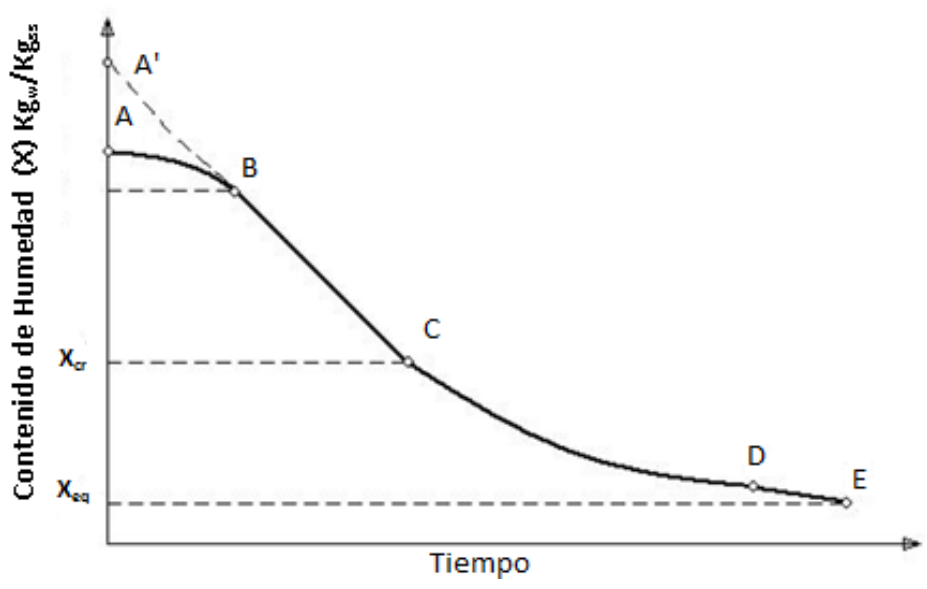

Figura 3. Curva de Secado (Geankoplis, 1998).

Parte $A, A^{\prime}-B$. Este periodo es el de estabilización durante el cual las condiciones de la superficie del sólido se ponen en equilibrio con el aire de secado, en general por ser muy corto es despreciable para fines de cálculo. No se puede modelar.

Parte B-C. Periodo de velocidad constante, durante el cual, la superficie del sólido permanece saturada con agua líquida, el movimiento de agua del interior del sólido a la superficie es prácticamente igual a la velocidad de evaporación en la superficie. La velocidad de secado es función de la velocidad de transmisión de calor a la superficie de secado. La velocidad de transferencia de masa contrarresta la velocidad de transferencia de calor, por lo que la temperatura de la superficie de secado permanece constante. La fuerza motriz que causa el movimiento del vapor a través de la película estacionaria de aire es el gradiente de presión de vapor entre la superficie de secado y la corriente de aire, estableciéndose un estado de equilibrio entre la velocidad de transferencia del calor al producto y la velocidad de transferencia de masa que sale de él.

Parte C-D. A medida que avanza el secado, llega un momento en que el movimiento de la humedad dentro del producto hacia la superficie disminuye hasta el extremo que la superficie empieza a secarse. En el punto $\mathrm{C}$ empieza a disminuir la velocidad de secado, dando comienzo al periodo de velocidad decreciente, el contenido de humedad en este punto se conoce como contenido crítico de humedad, $\mathrm{X}_{\mathrm{C}}$. A partir del punto $\mathrm{C}$ la temperatura de la superficie empieza a elevarse progresivamente conforme progresa el secado, acercándose a la temperatura del bulbo seco del aire. Generalmente, este periodo está compuesto por dos partes conocidas 
como primero y segundo periodo de velocidad decreciente C-E y D-E respectivamente. En el punto E el plano de evaporación se mueve dentro del sólido, descendiendo aún más la velocidad de secado. En los periodos de velocidad decreciente la velocidad de secado está regulada principalmente por la velocidad del movimiento de la humedad del sólido, el efecto de los factores externos, en particular el de la velocidad del aire, resultan disminuidos (Brennan y col.,1970).

En este periodo, la migración de humedad a la superficie del sólido es insuficiente para mantener saturada la película de aire que rodea al sólido. Bajo estas condiciones, la rapidez de secado no depende sólo de las condiciones en la película, sino además, de la estructura interna del sólido y de los mecanismos de migración de la humedad.

En la literatura, Treybal (1988), se plantean mayormente, dos mecanismos uno, el mecanismo difusivo, en donde se considera un gradiente de concentración, tanto para el agua en su forma líquida como para vapor, y el segundo, el mecanismo de capilaridad en donde se contempla un gradiente de presión.

\subsubsection{Mecanismo de Difusión}

La difusión de la humedad líquida puede derivarse de los gradientes de concentración entre el interior del sólido, donde la concentración es alta, y la superficie, donde es baja. Estos gradientes se fijan durante el secado de la superficie. Este método de transporte de la humedad se limita probablemente a los casos en que se forman soluciones sólidas de una sola fase con la humedad, y en ciertos casos en que se esta secando la humedad ligada (Hougen, y col., 1940). Se ha descubierto que la difusividad generalmente decrece al reducirse el contenido de humedad (Treybal, 1988).

La difusividad de la humedad depende de la temperatura, del contenido de humedad y naturaleza del material, la difusividad o coeficiente de difusión $D_{A B}$ de un componente A en B en estado estacionario, es una medida de la movilidad difusiva y se define de acuerdo a la 1 ạ Ley de Fick, como la relación entre el flux $J_{A}$ y su gradiente de concentración $\partial C_{A} / \partial Z$ (Treybal, 1988). 
Para un sistema binario, con difusividad unidireccional constante, esta ley de transferencia se representa por la ecuación (1):

$$
J_{A}=-D_{A B}\left(\frac{\partial C_{A}}{\partial Z}\right)=-c D_{A B}\left(\frac{\partial X_{A}}{\partial Z}\right)
$$

En donde las suposiciones del modelo son:

- La transferencia de masa es controlada por la difusión.

- En la interfase sólido-gas existe equilibrio.

- El coeficiente de difusión es constante.

- Para el caso de ausencia de reacción química, en condiciones de difusión en estado no estacionario, los cuales se presentan con mayor frecuencia durante el secado en materiales sólidos, se utiliza la 2a

\subsubsection{Mecanismo de Capilaridad}

El agua puede fluir desde regiones de concentración elevada hasta las de baja concentración como resultado de una acción capilar en lugar de difusión, cuando el tamaño de los poros de los materiales granulares es adecuado para ello. La teoría capilar (PI) supone que un lecho empacado de esferas no porosas contiene espacios vacíos entre dichas esferas que se llaman poros. A medida que se evapora el agua, las fuerzas capilares actúan debido a la tensión interfacial entre el agua y el sólido. Estas fuerzas dan lugar a la fuerza impulsora para desplazar el agua a través de los poros hasta la superficie de secado. (Geankoplis, 1998).

La humedad no ligada en sólidos granulares y porosos se mueve a través de los capilares e intersticios de los sólidos mediante un mecanismo en que interviene la tensión superficial. Los capilares se extienden desde pequeños recipientes de la humedad en el sólido hasta la superficie que se esta secando. Conforme el secado continúa, al principio la humedad se mueve por capilaridad hasta la superficie, con la suficiente rapidez para mantener una superficie suficientemente humeda; la rapidez de secado es constante. El agua es remplazada por aire que entra en el sólido a través de las relativamente pocas aberturas y rupturas (Treybal, 1993). 


\subsection{SECADO EN ALIMENTOS}

El secado es una de las más antiguas y efectivas operaciones para la conservación de alimentos. Una vez secos, varios tipos de alimentos pueden ser almacenados sin problemas por incluso años sin necesidad de refrigeración si tienen el empaque adecuado (Durance y Wang, 2002). En el caso del secado de materiales de origen biológico, tales como frutas y vegetales, estos tienen un contenido de humedad inicial alto y en general muestran una disminución en su volumen. El encogimiento en este tipo de materiales durante el secado, tiene lugar de forma simultánea con la difusión de la humedad y esto puede afectar la velocidad de secado, siendo así importante el estudio del fenómeno del encogimiento para lograr una mejor comprensión de este proceso de conservación (Liu y col.,2012).

En varios países del mundo la forma tradicional del secado de frutas y vegetales es por medio del sol. Esta técnica tiene como ventajas la simplicidad y los bajos costos de inversión, sin embargo requieren de tiempos largos de secado que pueden tener consecuencias adversas en la calidad del producto final, como es la contaminación con polvo e insectos o, puede haber actividad microbiana y enzimática (Andritsos y col., 2003). Con el propósito de mejorar la calidad, la forma tradicional de secado al sol debe ser remplazada con métodos de secado industriales como secado controlado con aire caliente o radiación (Ertekin y Yaldiz, 2004) para prolongar su vida de anaquel. El principal objetivo en el secado de productos agrícolas es la reducción del contenido de humedad a un nivel en el que puedan ser almacenados de forma segura por un periodo largo de tiempo. De igual forma, se obtiene una reducción en el peso y volumen minimizando así los costos de empaque, almacenaje y transporte (Okos y col.,1992).

Otra forma de secado de alimentos es mediante el uso de hornos el cual es un método aceptable, pero no es eficiente a nivel energético y el alimento no conserva su sabor al final del proceso. Sin embargo hay pocos trabajos sobre el proceso de secado de tomates en horno. Chang y col., 2006, usaron este método para secar rebanadas de tomate a $80^{\circ} \mathrm{C}$ por 2 horas seguido de otro periodo a $60{ }^{\circ} \mathrm{C}$ por 6 horas. El secado por aire caliente es una técnica convencional y una de las más usadas para la producción de frutas y vegetales deshidratados. Sin embargo, esta operación también resulta en una disminución en los niveles nutricionales y organolépticos para productos sensibles al calor. 
Las cinéticas de secado son afectadas en mayor parte por la temperatura y humedad del aire, tamaño del producto, tiempo de secado, entre otras (Rajkumar y col., 2007). Cada uno de estos factores puede tener diferentes efectos en el proceso, los cuales deben ser considerados durante el secado. Esta problemática hace que el control manual de los sistemas de secado sea impráctico, por lo tanto, es importante encontrar un modelo que incorpore un número considerable de variables (Khazaei y col., 2008).

Durante las últimas décadas algunos de los modelos teóricos de secado que han sido ampliamente utilizados para el modelado de las cinéticas de secado de alimentos son presentados en la forma de modelos, principalmente la 2a . Ley de Difusión de Fick, la Función de Distribución de Weibull, los modelos de Peleg y Page y Logarítmicos (Doymaz, 2007) (Machado y col., 1999). A pesar de que estos modelos han explicado satisfactoriamente las cinéticas de secado de productos agrícolas, algunos de ellos solo relacionan el tiempo de secado y no incluyen el efecto de interacción de otros parámetros relacionados, es decir se limitan al uso de parámetros de ajuste que no brindan información referente al proceso.

Los métodos de secado son adecuados para la determinación de la difusividad del agua en los alimentos, debido a que el secado y la rehidratación son procesos comunes aplicados a los alimentos, y las propiedades de transporte del agua son esenciales para realizar el modelo, los cálculos y para el control de estas operaciones (Saravacos y Maroulis, 2001).

La difusividad del agua es una propiedad física que no puede ser estimada directamente, y es necesaria una evaluación experimental. Entre los diferentes mecanismos que han sido propuestos para explicar el transporte del agua en los alimentos, el modelo de difusión arroja resultados satisfactorios para la aplicación ingenieril y tecnológica (Saravacos y Maroulis, 2001).

Hussein (1994) refiere que la $D_{\text {ef }}$ es inherentemente dependiente de la dirección del flujo a menos que el material sea isotrópico. Además del contenido de humedad y la temperatura, $\mathrm{pH}$ y contenido inicial de agua del producto, la velocidad del aire, el encogimiento y la forma afectan la $D_{\text {ef, }}$ Chen (2007) reporta que la difusión de líquidos por sí sola puede no ser suficiente para explicar el proceso de secado en su totalidad ya que eventualmente se establece un perfil de vapor en el producto y su movimiento puede estar restringido en algún 
nivel. Hussein (1994) y Chen (2007) concuerdan en que las descripciones precisas del proceso de encogimiento junto con la caracterización micro estructural de alimentos húmedos, son elementos esenciales para la comprensión de los mecanismos fundamentales de la difusividad del agua.

\subsubsection{Encogimiento en el Secado de Alimentos}

Durante el proceso de secado las matrices de los alimentos experimentan algunas modificaciones que tienen un impacto directo en los atributos de calidad así como en las propiedades del producto final. Por ejemplo, la reducción del tamaño de las muestras secas puede tener un impacto negativo en la percepción de la calidad del producto seco. Publicaciones de datos experimentales (Ratti, 1994; Souraki y Mowla, 2008; Zielinska y Markowski, 2007) muestran que, el volumen final de alimentos, secados por flujo de aire, puede ser reducido a menos de un $20 \%$ del volumen inicial. Por lo tanto, la predicción del encogimiento durante la deshidratación de productos alimenticios, se vuelve un requisito previo para el diseño y optimización del proceso y de las condiciones de secado (Khalloufi y col., 2012).

La estructura particular del material así como las características mecánicas de sus elementos en el equilibrio, definen su volumen y determinan su forma y tamaño. Cuando el agua contenida en el material es removida, se produce un desbalance de presión entre el interior del material y la presión externa, generando así una tensión contractante que conduce al encogimiento o colapso del material, cambios en la forma y algunas veces la formación de grietas en el producto. Esta es una de las razones por las cuales el secado al vacío así como el liofilizado conlleva en general un menor grado de encogimiento (Mayor y Sereno, 2004).

En la literatura existen diferentes propuestas de expresiones matemáticas para la predicción del coeficiente de encogimiento del volumen, en función del contenido de humedad durante el secado. Estos modelos pueden clasificarse en dos grupos: 1) modelos teóricos, basados en la comprensión de los fundamentos de los fenómenos y mecanismos involucrados en el proceso de secado; 2) modelos empíricos, en lo que se unan parámetros para lograr el ajuste con los datos experimentales. Los parámetros de ajuste de los modelos teóricos tienen un 
significado físico, a diferencia de los utilizados en los modelos empíricos que no lo tienen (Khalloufi y col., 2012).

A pesar de que los modelos empíricos han mostrado tener un buen ajuste en general, ofrecen una percepción limitada en los fundamentos básicos involucrados en el secado (Rahman, 2001, 2003). La dependencia de los modelos empíricos en los sistemas específicos utilizados para su obtención, los hace no aplicables a otras matrices o condiciones experimentales. Por lo tanto, es necesaria la construcción de modelos matemáticos que tengan una base y que sirvan como guía para una comprensión amplia de los cambios presentes en los parámetros durante todo el proceso.

\subsubsection{Actividad de Agua $\left(\mathrm{a}_{\mathrm{w}}\right)$}

El conocimiento de las características de adsorción de agua, la humedad crítica y la actividad de agua son de interés en numerosas aplicaciones en la ciencia y tecnología de alimentos. La actividad de agua $\left(\mathrm{a}_{\mathrm{w}}\right)$ es la propiedad más importante del agua en un alimento, ésta describe el estado de energía del agua en el alimento y por lo tanto su disponibilidad para actuar como solvente y participar en reacciones químicas y bioquímicas.

La $a_{w}$ es derivada de los principios fundamentales de termodinámica y fisicoquímica, y se define como la razón de la presión de vapor del agua $(P)$ de un alimento sobre la presión de vapor del agua pura $\left(P_{0}\right)$ a una temperatura dada (Labuza, 1980). La relación anterior se expresa a través de valores adimensionales comprendidos entre 0 y 1 y se presenta en la ecuación (2).

$$
a_{W}=\frac{P}{P_{0}}
$$

La información del contenido de humedad en relación con la $a_{w}$ derivada del comportamiento de sorción es útil en los procesos de concentración y deshidratación, debido a que la facilidad o dificultad de remover agua determina las propiedades de barrera necesarias para envasar el alimento. Así mismo, determina el contenido de humedad necesario para detener el desarrollo bacteriano y predice la estabilidad física y química en función de su contenido acuoso (Fennema, 1996; Kaya y Oner, 1996). 
Las isotermas de sorción de alimentos se han descrito por numerosos modelos (Lewick, 1998), de los cuales el más conocido y básico en la fisisorción es el modelo de Brunauer, Emmett y Teller (BET) (Rizvi y Benado, 1984). Este modelo es apropiado en la determinación de la cantidad de agua en la monocapa (Labuza, 1968) considerado por muchos autores como el punto de máxima estabilidad. La ecuación de Guggenheim-Anderson-de Boer (GAB) también se basa en la teoría de BET, pero introduce una constante $\mathrm{K}$ que corrige las propiedades de las moléculas de agua en la multicapa respecto al agua líquida. GAB se ajusta bien en el intervalo de actividades de agua de 0 a 0.9 y evalúa mejor el valor de monocapa.

El modelo de Guggenheim-Anderson-de Boer, GAB (Bizot y col., 1985) para la adsorción de agua se presenta en la ecuación (3) y los parámetros se presentan en las ecuaciones (4) y (5).

$$
X=\frac{X_{0} C K a_{w}}{\left(1-K a_{w}\right)\left(1-K a_{w}+C K a_{w}\right)}
$$

En donde

$$
\begin{aligned}
& C=c \exp \left[\left(\frac{h_{m}-h_{n}}{R T_{a}}\right)\right] \\
& K=k \exp \left[\left(\frac{h_{m}-h_{n}}{R T_{a}}\right)\right]
\end{aligned}
$$

\subsubsection{Calor específico}

Es la cantidad de energía, en forma de calor, que gana o pierde un sistema por unidad de masa, para que se produzca en él un cambio de temperatura de un grado, sin que haya cambio de estado.

En los alimentos, así como otros compuestos químicos presentan calores específicos variables dependientes de la temperatura y se obtienen mediantes la experimentación. Las ecuaciones del calor específico en función de la temperatura pueden ser de tipo lineal o un polinomio, tal como se presenta en la ecuación (9):

$$
c_{p}=a+b T+c T^{2}+d T^{3}+\ldots
$$




\subsection{SECADO DEL JITOMATE}

La determinación de la calidad de los productos secos así como la predicción de las cinéticas de secado de los productos, bajo diferentes condiciones, son de importancia para el diseño de los sistemas de secado y cumplir con las especificaciones de calidad y conservación de energía. Uno de los aspectos más importantes de la tecnología del secado es el modelado del proceso de secado. El modelado de procesos es de vital importancia para el diseño y operación de los secadores a condiciones óptimas de secado. El secado tiene una influencia fisicoquímica y en las características de la calidad de los productos, así, el modelado de las cinéticas de secado es una herramienta para el control de procesos (Khazaei y col., 2008).

Estudios acerca del secado de tomate están presentes en la literatura, secado en mitades (Giovanelli y col., 2002; Doymaz, 2007; Hossain y Gottschalk, 2009; Askari y col., 2009, secado en rebanadas (Akanbi y col., 2006; Movagharnejad y Nikzad, 2007; Gaware y col., 2010; Kulanthaisami y col., 2010; Abano y col., 2011; Demiray y Tulek, 2012), y secado al sol (Sacilik y col., 2006; Rajkumar y col., 2007), sin embargo estimaciones numéricas de la difusividad del agua durante el secado con aire no estan reportadas. Por otra parte, investigaciones acerca del efecto del pelado en la variación de la difusividad durante el secado son limitadas, y sólo Souza y col., 2007 reportaron valores de difusividad para tomates cortados en cuartos pelados y sin pelar.

Para el secado de tomates a un contenido final de humedad menos al 15\% (base húmeda) generalmente involucra el uso de temperaturas altas de 40 a $110{ }^{\circ} \mathrm{C}$ por periodos de 2 a 35 horas (Toor y Savage, 2006) (Giovanelli y col., 2002) (Doymaz, 2007) (Chang y col., 2006) (Yong y col., 2006).

Hawlader y col. (1999) estudiaron las características de secado bajo diferentes condiciones de operación controladas. Se manejaron diferentes niveles de temperatura y flujo de aire para caracterizar el secado del jitomate. Rebanadas de tomate se colocaron en charolas de malla de alambre para ser secadas, el principal objetivo fue la obtención de los coeficientes de difusión efectiva basada en la resolución de la 2a ley de Fick, usando una correlación para la variación de la longitud presentada en un trabajo anterior (Uddiny col., 1990) la cual relaciona 
el efecto de la temperatura y encogimiento. Los coeficientes de difusión reportados fueron de $1.52 \times 10^{-10}$ a $9.23 \times 10^{-10} \mathrm{~m}^{2} / \mathrm{s}$.

Zanoni y col., (1999) deshidrataron mitades de jitomate a $110{ }^{\circ} \mathrm{C}$ durante 4 horas hasta un contenido de humedad final de $10 \%$, bajo estas condiciones de secado el contenido de licopeno disminuyó un máximo de $10 \%$; cuando la temperatura de secado fue de $80{ }^{\circ} \mathrm{C}$ el tiempo requerido para lograr un contenido de humedad final de $10 \%$ fue de 7 horas y no hubo cambios en el contenido de licopeno. Esos autores de igual forma propusieron para optimizar el secado del tomate, temperaturas bajas, tiempos cortos, reducción del tamaño del sólido (por ejemplo, rebanadas, cuartos o cubos), o removiendo parcialmente el agua antes de proceder al secado.

En el caso de Giovanelli y col., (2002), secaron productos de jitomate colocados en charolas, con cargas de 800 y 1500 g. de pulpa drenada y colocados en charolas con grosores de 15 y 20 $\mathrm{mm}$ respectivamente, el secado se realizó a $70{ }^{\circ} \mathrm{C}$ con flujos de aire de $1.5 \mathrm{~m} / \mathrm{s}$, la humedad final fue de $10 \%$ (b.h.) de igual forma utilizaron 500 g. de tomate rico en sólidos insolubles, con un grosor de $10 \mathrm{~mm}$ y secado a $60^{\circ} \mathrm{C}$ con un flujo de aire de $1.5 \mathrm{~m} / \mathrm{s}$ en este caso el contenido de humedad final fue de $7 \%$. Determinaron valores altos de difusividad del agua en la pulpa de tomate, como resultado de la ausencia de piel, mientras que valores más pequeños fueron determinados para mitades de tomate. Estos valores oscilaron entre $4.01 \times 10^{-9}$ y $2.26 \times 10^{-9} \mathrm{~m}^{2} / \mathrm{s}$ para el secado de mitades de tomate a 110 y $80{ }^{\circ} \mathrm{C}$ respectivamente.

Doymaz (2007) investigó las características del secado de mitades de tomate con y sin pretratamiento (oleato de etilo-carbonato de potasio) con diferentes niveles de temperatura $\left(55,60,65\right.$ y $\left.70{ }^{\circ} \mathrm{C}\right)$ y fijando el flujo de aire a $1.5 \mathrm{~m} / \mathrm{s}$. Se obtuvo que tanto la temperatura como el pretratamiento tienen un efecto significativo en la cinética de secado lo cual se refleja en los coeficientes de difusión efectiva, variando entre $3.91 \times 10^{-10}$ y $7.53 \times 10^{-10} \mathrm{~m}^{2} / \mathrm{s}$. Los datos experimentales fueron ajustados a los modelos de Henderson- Pabis y Page, siendo este último el que tuvo un mejor ajuste. La dependencia del coeficiente de difusión con la temperatura se describe con una correlación tipo Arrhenius obteniendose un rango de energía de activación de 17.40 a $32.94 \mathrm{~kJ} / \mathrm{mol}$. 
Rivera Bahena (2007), trabajo previo a éste, reporta la deshidratación de cubos de tomate en un secador de lecho fluidizado y en un secador piloto de lecho vibrofluidizado, ambos con ciclos de atemperado, a temperaturas de 60,70 y $80{ }^{\circ} \mathrm{C}$. Tomó como parámetro de calidad el porcentaje de retención de licopeno. Se logra una reducción en los tiempos de secado respecto a los tiempos reportados en la literatura, en el caso del atemperado se observó que este favorece la retención de Licopeno. En este trabajo los coeficientes de difusión efectiva entre de $3.1081 \times 10^{-9}$ y $5.2104 \times 10^{-9} \mathrm{~m}^{2} / \mathrm{s}$.

Brooks y col., (2008) estudiaron el efecto de la temperatura ( 55 y $65^{\circ} \mathrm{C}$ ) y la geometría de las piezas para lo cual secaron el jitomate dividido en mitades, cuartos y octavos, el proceso se realizó en un horno de convección forzada. Obtuvieron que al cortar la pieza en pedazos más pequeños y secar a bajas temperaturas es recomendable para lograr una reducción en el tiempo de secado y mantener la calidad del producto.

\subsection{MODELADO DEL SECADO EN ALIMENTOS}

Los modelos matemáticos de los procesos de secado son utilizados para el mejoramiento o diseño de nuevos sistemas de secado o incluso el control del proceso. A pesar de que el proceso de secado y la rehidratación causan disminución y aumento en las dimensiones del producto respectivamente, el tratamiento matemático de los resultados experimentales normalmente incluye supuestos como que el secado es controlado por la difusión interna en un sólido homogéneo e isotrópico que no cambia sus dimensiones. Basándose en estas suposiciones, el proceso de difusión normalmente es descrito por la $2^{a}$ ley de Fick de la Difusión para la cual soluciones analíticas para las tres geometrías más comunes (placa infinita, cilindro y esfera) están disponibles en la literatura (Crank, 1979).

En años recientes, varios investigadores han realizado diferentes estudios sobre el modelado

matemático y las cinéticas de algunos vegetales como el pimiento rojo (Kaleemullah y Kailappan, 2005), berenjena (Ertekin y Yaldiz, 2004) (Akpinar y Bicer, 2005), chicharos (Yaldiz y Ertekin, 2001), okra (Doymaz, 2005) (Maskan y Gogus, 1998), y tomate (Doymaz, 2007) (Sacilik y col., 2006). 
Hatamipour y Mowla (2003) estudiaron los cambios de la densidad, el encogimiento y la difusividad de masa de chícharos y maíz en un lecho fluidizado con y sin el uso de partículas inertes. Schultz y col., (2007) observaron la influencia de diferentes condiciones de operación en el encogimiento de rebanadas de manzana. Wei y col., (2006) hicieron la investigación sobre las características del encogimiento de volumen en jenjibre fresco, zanahoria, papa y platano en el proceso de secado basandose en las definiciones de coeficiente de encogimiento de volumen y isotropicidad del encogimiento.

Durante el desarrollo de los modelos se ha planteado un supuesto importante, que el encogimiento es despreciable, esto es de utilidad para la resoluciones de los modelos pero esto no es compatible con todos los materiales biológicos, en sistemas como los alimentos raramente puede ser despreciable (Mayor y Sereno, 2004).

Una de las primeras investigaciones enfocadas en resolver el problema de difusión en cuerpos que sufren dilatación o encogimiento fue la de Crank (1979). El autor propuso el uso de un marco de referencia fijo para uno de los componentes del sistema para que permaneciera inmovil para poder así resolver la equación de difusión de Fick.

Para tomar en cuenta el efecto del encogimiento en el secado de alimentos en general se hace la resolución de la 2a ley de Fick de la Difusión de forma numérica, teniendo como supuestos que el grosor instantáneo del sólido es proporcional a la cantidad de agua evaporada (Simal y col., 1996). Un procedimiento alternativo, que tiene como supuesto que el fenómeno de encogimiento es equivalente a un flujo convectivo fue empleado por (Hawlader y col., 1999) para la simulación del secado de un sólido en forma de placa, asumiendo variaciones lineales y cuadráticas con el contenido de humedad para la velocidad de encogimiento.

Diferentes modelos de capa fina, disponibles en la literatura, han sido utilizados para explicar las características de secado de productos agrícolas. Estos modelos pueden ser clasificados como teóricos: 2a Ley de Fick; semi-teóricos: Lewis-Page, Page Modificado, Henderson y Pabis, Logarítmico, Dos-términos, Exponencial con dos términos, Aproximación de Difusión, Modelo de Verma y col.; y empíricos: Page (1949), Modelo de Wang y Singh (Ozdemir y Devres, 1999) (McMinn, 2006). 
Los modelos empíricos se obtienen por medio de un análisis de regresión lineal de los datos experimentales; los modelos teóricos están basados en la interpretación física de la estructura de los biomateriales, y tratan de predecir los cambios dimensionales provocados por la variación del volumen de las diferentes fases en el sistema (alimento) a lo largo del proceso de secado.

La forma más simple de modelar el encogimiento durante el secado es mediante la obtención de una correlación empírica entre el encogimiento y el contenido de humedad, incluyendo las condiciones de secado como son la temperatura y humedad del aire. Algunos ejemplos de este tipo de modelos de presentan en la Tabla 1.

Tabla 1. Modelos Empíricos Lineales y No Lineales.

\begin{tabular}{|c|c|c|c|c|}
\hline Modelo & Geometría & Dimensión & Material & Referencia \\
\hline \multicolumn{5}{|l|}{ Modelos Empíricos Lineales } \\
\hline$D_{R 0}=1+\beta X$ & Cubo & Volumen & $\begin{array}{l}\text { Manzana, papa, } \\
\text { zanahoria }\end{array}$ & $\begin{array}{l}\text { (Zogzas y col., } \\
\text { 1994) }\end{array}$ \\
\hline$D_{R 0}=1+\left(k_{1} \exp \left(E_{a} / R T\right)\right) X$ & Esfera & Volumen & Uva & $\begin{array}{l}\text { (Gabas y col., } \\
\text { 1999) }\end{array}$ \\
\hline \multicolumn{5}{|l|}{ Modelos Empíricos No Lineales } \\
\hline$D_{R}=k_{1}+k_{2} X+k_{3} X^{2}+k_{4} X^{3}$ & Cilindro & $\begin{array}{l}\text { Volumen de } \\
\text { cama }\end{array}$ & $\begin{array}{l}\text { Manzana } \\
\text { zanahoria, papa }\end{array}$ & (Ratti, 1994) \\
\hline$D_{R}=k_{1}+k_{2} \exp \left(-k_{3} t\right)$ & Placa & $\begin{array}{l}\text { Área } \\
\text { superficial }\end{array}$ & Papa y chayote & $\begin{array}{l}\text { (Rovedo y col., } \\
\text { 1997) }\end{array}$ \\
\hline
\end{tabular}




\section{CAPÍTULO II}

En esta parte se presenta la justificación del trabajo y los objetivos que se plantearon.

\section{JUSTIFICACIÓN}

El secado es una de las operaciones unitarias de la ingeniería química que más consumen energía en un determinado proceso, lo cual obliga a que constantemente se estén buscando alternativas que permitan optimizarla para así abatir su demanda y costo. La principal motivación para la realización de este trabajo se basa en la importancia de realizar un estudio experimental del secado de jitomate, en donde se considere el efecto del fenómeno de encogimiento del sólido. Ya que para fines de simulación del secado resulta imprescindible tomar en cuenta este fenómeno, debido a que los trozos de jitomate deshidratados presentan tasas de encogimiento de más del $60 \%$ y esto se manifiesta en la determinación de los coeficientes de difusión efectivos.

Los resultados que se obtengan de este trabajo podrán ser usados como parámetros importantes para el establecimiento de procesos de secado con otros vegetales de composición o estructura similar.

\section{OBJETIVOS}

\section{General:}

- Estudiar experimentalmente el proceso de secado en capa delgada de cubos de tomate, considerando el encogimiento; formulación del modelo matemático y simulación del proceso.

\section{Particulares:}

- Obtener las curvas de secado en capa delgada para determinar los parámetros característicos de la cinética de secado.

- Evaluar el encogimiento durante el secado.

- Determinar los parámetros termodinámicos y de transporte: $A_{W}, C_{P}, D_{\text {ef }}(X, T)$

- Modelar las cinéticas de secado con modelos empíricos y teóricos. 


\section{CAPÍTULO III}

En esta sección se presentan los materiales que fueron ocupados para la realización de la parte experimental del proyecto, se presenta una descripción del equipo utilizado. El planteamiento de la metodología experimental propuesta para el estudio de las variables ( $T$ y $Q$ ) presentes en el secado de cubos de jitomate, así como de la descripción de las mediciones que se realizaron para cada condición de operación

\subsection{MATERIALES Y EQUIPO}

\subsubsection{Materia Prima}

Tomate de la variedad Bola (Lycopersicum esculentum) obtenido en un mercado local, en estado de madurez Rojo, en cual al menos un $90 \%$ de la superficie del fruto es roja y su estructura es firme, fue seleccionado debido a que su parte carnosa es de mayor tamaño que el resto de la variedades.

Los frutos fueron seleccionados, lavados, removidos de su semilla y mucílago para ser escaldados en agua destilada a $75^{\circ} \mathrm{C}$ por $60 \mathrm{~s}$. para posteriormente quitarles la piel y cortarlos en cubos de aproximadamente $0.80 \mathrm{~cm}$ de lado (grosor natural de la parte carnosa del tomate).

\subsubsection{Materiales y Equipo}

- Analizador de Humedad MB45, OHAUS.

- Anemómetro DAFM3, UEi.

- Balanza Analítica Pioneer PA1502, OHAUS.

- Computadora para el registro en línea.

- Cronómetro.

- Cuchillo y pinzas de acero inoxidable.

- Differential Scanning Calorimeter (DSC) 2920, TA Instruments.

- Horno de secado, circulación forzada, HCF-48, Riossa.

- Material de vidrio.

- Parilla eléctrica Type 1000 Stir Plate, Thermolyne.

- Termómetro Infrarrojo Raytek Raynger ST20.

- Termómetros Brannam.

- Thermogravimetric Analyzer (TGA) Pyris 1, PerkinElmer.

- Túnel de secado con control de flujo y temperatura para la corriente de aire.

- Water Activity Meter, AguaLab Lite, DECAGON Dev. 


\subsubsection{Equipo de Secado}

\section{Termobalanza}

Se hizo uso de un Analizador de Humedad modelo MB45, marca OHAUS, el cual permite el registro en línea de la temperatura y el peso de la muestra a diferentes intervalos de tiempo.

\section{Secador de túnel en capa fina}

El secador de túnel consiste en un tubo de acrílico de $9 \mathrm{~cm}$ de diámetro por $25 \mathrm{~cm}$ de longitud provisto en la entrada, de un termopar que está conectado a un controlador de temperatura, la salida se encuentra libre para permitir el flujo del aire así como la carga y descarga de los cubos y permitir la medición de las condiciones del aire por medio del anemómetro DAFM3 (UEi), que permite el registro de la humedad relativa, temperatura, punto de rocío, temperatura de bulbo húmedo, velocidad y volumen del aire.

A la mitad del tubo se encuentra en forma perpendicular, una charola circular de $7 \mathrm{~cm}$ de diámetro, que es la encargada de contener la muestra que permite una distribución uniforme para un secado en capa fina, la charola se encuentra colgada y conectada a una Balanza Analítica Pioneer PA1502, OHAUS la cual permite el registro en línea del peso de la muestra (sensibilidad $0.01 \mathrm{~g}$ ). El medidor de flujo de aire permite una velocidad que va desde los 20 hasta los $400 \mathrm{~L} / \mathrm{min}$. El esquema del secador se presenta en la Figura 4.

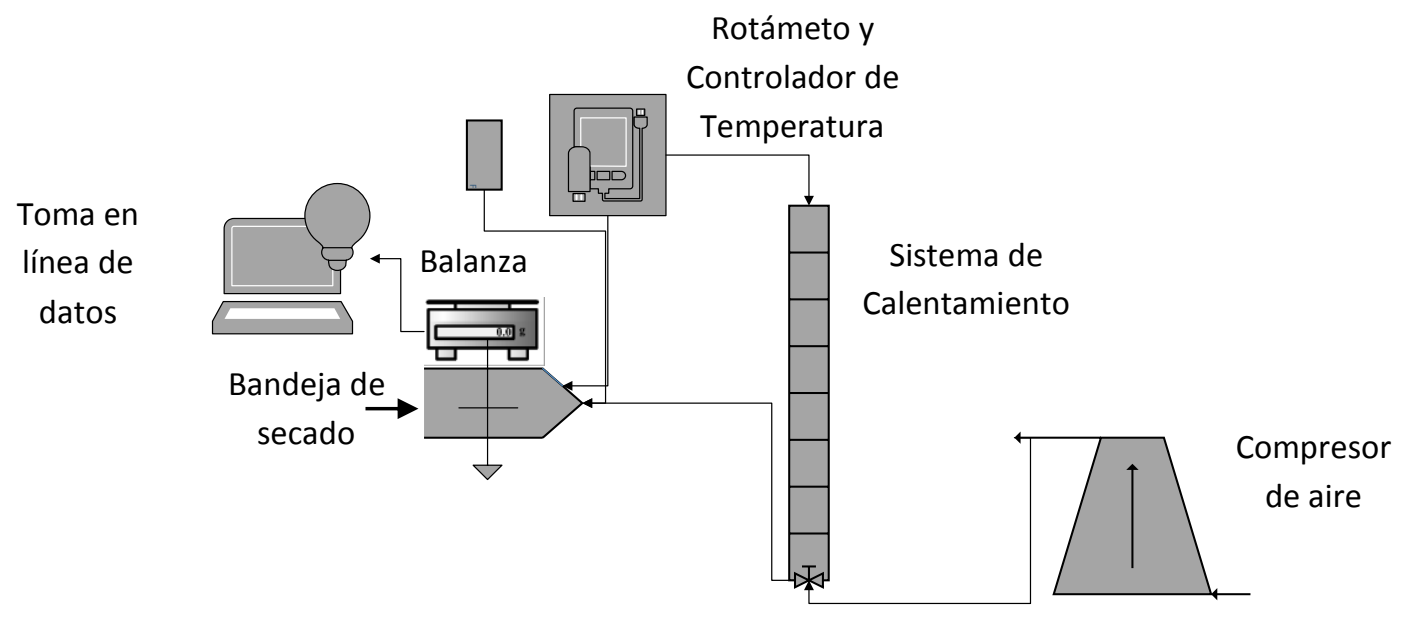

Figura 4. Esquema del equipo experimental del secador de túnel. 


\subsection{METODOLOGÍA EXPERIMENTAL}

Se desarrolló un diseño factorial $2^{2}$, con 2 niveles de temperatura $\left(T=60,80^{\circ} \mathrm{C}\right)$ y dos niveles de flujo de aire $(\mathrm{Q}=150,250 \mathrm{~L} / \mathrm{min})$, con 3 repeticiones en el punto central ( $\left.70{ }^{\circ} \mathrm{C}, 200 \mathrm{~L} / \mathrm{min}\right)$. En donde las unidades experimentales serian lotes de cubos de tomate de $5 \mathrm{~g}$, con dos factores: Temperatura y Flujo de aire, siendo las variables respuesta el contenido de humedad y el volumen de las partículas. Esto permite establecer la siguiente ecuación polinomial:

$$
V=a_{0}+a_{1} X_{1}+a_{2} X_{2}+a_{12} X_{1} X_{2}
$$

donde $\mathrm{V}=\mathrm{X}, \mathrm{V}_{\mathrm{p}}$, corresponden a la variable respuesta; $\mathrm{X}_{1}, \mathrm{X}_{2}$ a los niveles de los factores ( $T$ y $\mathrm{Q}$ ). Los niveles de los parámetros de estudio se como se muestra en la Tabla 2.

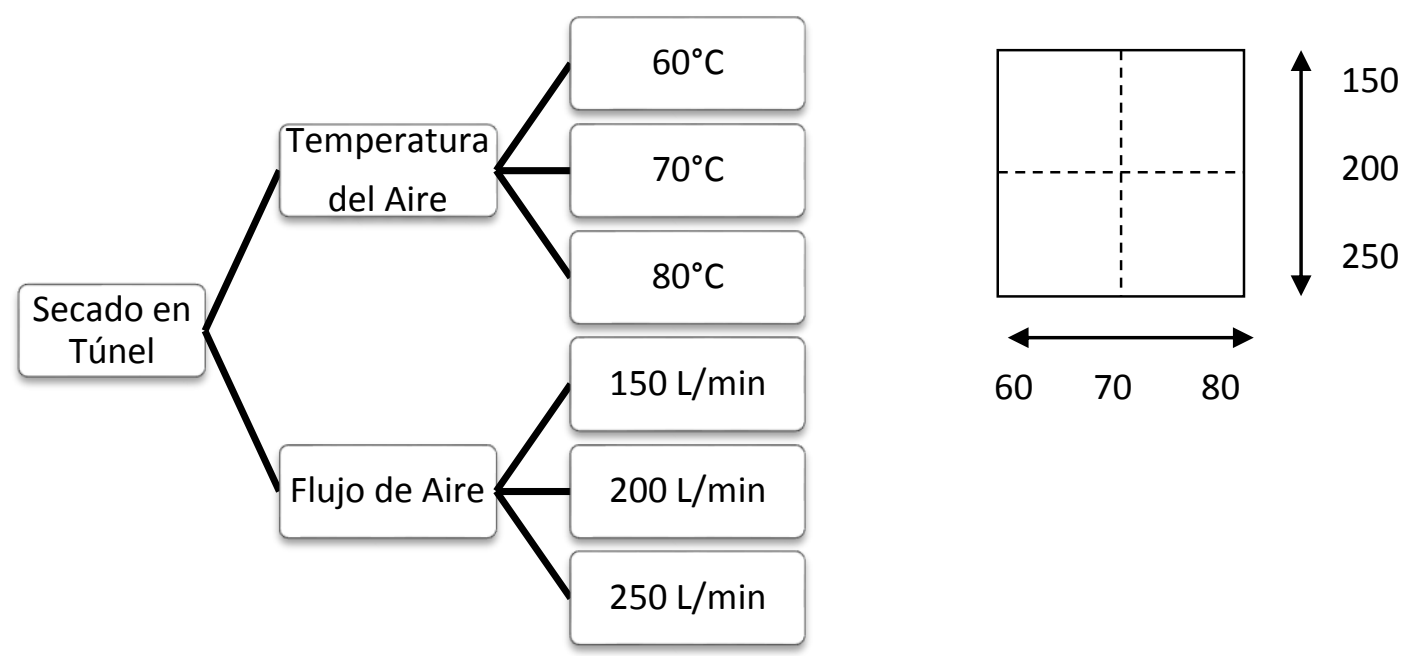

Figura 5. Diseño Factorial $2^{2}$ con repeticiones en el punto central para el secado en túnel.

Tabla 2. Diseño factorial $2^{2}$ factorial con tres repeticiones en el punto central.

\begin{tabular}{|ccc|}
$\begin{array}{c}\text { Corrida } \\
\text { Experimental }\end{array}$ & $\begin{array}{c}\text { Temperatura } \\
\mathbf{X}_{\mathbf{1}}\end{array}$ & $\begin{array}{c}\text { Flujo de Aire } \\
\mathbf{X}_{\mathbf{2}}\end{array}$ \\
\hline $\mathbf{1}$ & -1 & -1 \\
\hline $\mathbf{2}$ & -1 & 1 \\
\hline $\mathbf{3}$ & 1 & -1 \\
\hline $\mathbf{4}$ & 1 & 1 \\
\hline Punto central del dominio experimental \\
\hline $\mathbf{5}$ & 0 & 0 \\
\hline $\mathbf{6}$ & 0 & 0 \\
\hline $\mathbf{7}$ & 0 & 0 \\
\hline
\end{tabular}

Codificación:

$$
X_{i}=\frac{P_{\mp}-\left(\frac{P_{-}+P_{+}}{2}\right)}{\left(\frac{P_{+}-P_{-}}{2}\right)}
$$

$P: T, Q ; i=1,2,1-2$

"_" nivel inferior

"+" nivel superior 
Haciendo uso de programas estadísticos SPSS y el NCSS, se realizó un Análisis de Varianza (ANOVA) para cada una de las variables respuesta para determinar cuál de los factores tiene un efecto significativo, de igual forma se llevaron a cabo las pruebas de normalidad correspondientes.

\subsubsection{Preparación de las muestras}

Los tomates fueron almacenados en refrigeración a una temperatura aproximada a $5{ }^{\circ} \mathrm{C}$, se dejaron reposar unas horas antes del proceso para que llegaran a temperatura ambiente.

Una vez seleccionados al azar y lavados, se procede a hacer dos cortes longitudinal y transversal para obtener cuartos, se separan las semillas y mucílago. Posteriormente se someten a escaldado en agua destilada a $75{ }^{\circ} \mathrm{C}$ durante 60 segundos (condiciones preestablecidas en este trabajo). Después del escaldado se les desprende la piel para dejar sólo el tejido carnoso. Finalmente se cortan cubos de forma manual de aproximadamente 0.80 $\mathrm{cm}$ de lado (grosor natural de la parte carnosa del tomate).

\subsubsection{Determinación de Humedad}

El contenido de humedad del tomate escaldado se determina antes y después del secado. Para la determinación de la masa seca se hace uso del método de horno convectivo (984.25) de la AOAC (1990), a $105^{\circ} \mathrm{C}$ por 16 horas. El contenido de humedad base seca se calcula a partir de la diferencia de pesos.

$$
X_{\text {baseseca }}=\frac{\operatorname{Peso}(t)-\text { Peso }_{\text {seco }}}{\text { Peso }_{\text {seco }}}
$$

\subsubsection{Determinación de volumen de los cubos de tomate}

Para la determinación del volumen de los cubos antes y durante el proceso de secado, se emplea una probeta de $10 \mathrm{ml}$, la cual se llena con aceite de girasol. Se seleccionan y pesan cubos de tomate antes de someterlos al secado, a ciertos intervalos de tiempo para monitorear la variación del volumen (encogimiento), y se adicionan a una probeta con aceite y 
se registra el volumen de aceite que es desplazado por la muestra. Para el cálculo del volumen del sólido se emplea la siguiente ecuación:

$$
\left(V_{s}\right)=\frac{\text { Volumen desplazado de aceite }}{\text { Numero de cubos }}
$$

\subsubsection{Determinación del Radio Equivalente}

Para la obtención del radio equivalente $\left(r_{\text {eq }}\right)$ a partir de la ecuación 9 , se calcula el valor promedio del sólido, tanto de muestra fresca y seca, para los diferentes intervalos de tiempo y condiciones de secado (flujo de aire y temperatura) y así dar seguimiento al porcentaje de encogimiento de los cubos de tomate, se considera que el valor promedio es el correspondiente a una esfera y así se obtiene la siguiente ecuación:

$$
r_{e q}=\sqrt[3]{\frac{3 V_{s}}{4 \pi}}
$$

\subsubsection{Proceso de Secado de los Cubos de Tomate}

\subsubsection{Secado en Termobalanza}

Para conocer las características y comportamiento del sólido se realizó el seguimiento en línea del peso, a cada minuto, de muestras de cubos de tomate con un peso aproximado de $5 \mathrm{~g}$, a tres diferentes temperaturas 60,70 y $80{ }^{\circ} \mathrm{C}$ durante 120 minutos, en el Analizador de Humedad (MB45, OHAUS). El cual se programó para seguir una rampa de calentamiento estándar.

\subsubsection{Secado en Túnel en Capa Fina}

El proceso convectivo de secado fue realizado en el secador de túnel descrito previamente, se inició la carga de muestras a partir de que se lograron condiciones estables de flujo y temperatura de aire. Se colocaron aproximadamente $5 \mathrm{~g}$ de cubos de tomate escaldado de forma uniforme y equidistante en la charola que se encuentra dentro del túnel, la balanza analítica conectada hizo el registro en línea de la pérdida de peso cada minuto. Los experimentos fueron realizados de acuerdo al diseño factorial establecido en este trabajo, a 
tres temperaturas $\left(60,70\right.$ y $\left.80^{\circ} \mathrm{C}\right)$ con tres flujos constantes de aire $(150,200$ y $250 \mathrm{~L} / \mathrm{min})$ durante 60 minutos. Se monitorearon, con el uso del anemómetro, las condiciones del aire a $60{ }^{\circ} \mathrm{C}$ como son velocidad, porcentaje de humedad relativa, temperatura de bulbo seco y punto de rocío.

Para el caso del monitoreo de la variación del volumen, los cubos fueron retirados para ser pesados y poder medir su volumen sin ser devueltos al secador.

\subsubsection{Determinación del calor específico (cp)}

Para la determinación de esta propiedad termodinámica se hizo uso de la Calorimetría Diferencial del Barrido (Differential Scanning Calorimeter - DSC) modelo 2920, TA Instruments, así como de los programas Thermal Advantage y Universal Analysis. Se fijó una rampa de calentamiento modulada en un rango de $30^{\circ} \mathrm{C}$, durante el análisis se monitoreo cada minuto la temperatura y la capacidad calorífica $(C p)$ con la cual se realizó un promedio de los valores para cada temperatura y fue dividida entre el peso inicial de la muestra para obtener el valor del calor específico en cada punto.

\subsubsection{Determinación de la actividad de agua $a_{w}$}

Se realizó una selección de los intervalos de tiempo en los cuales se llevaría a cabo el retiro de la muestra del túnel de secado, para diferentes condiciones de secado. A los diferentes niveles de tiempo se hizo la determinación de la actividad de agua a temperatura ambiente $\left(25^{\circ} \mathrm{C}\right)$, lo cual era necesario para poder realizar el análisis siendo esta medida especificada por los requerimientos del equipo medidor de actividad de agua (AguaLab Lite).

Luego de hacer la calibración correspondiente del equipo se procedió a realizar las mediciones, para las cuales las muestras se colocaron en el recipiente provisto para este fin, se cerró la cámara de análisis y se dio inicio al proceso de detección de la actividad de agua para cada muestra. Entre el análisis de cada muestra se colocó un recipiente con trozos de carbón para extraer la humedad residual en la cámara. 


\subsection{MODELOS MATEMÁTICOS}

\subsubsection{Modelos Empíricos}

Algunos de los modelos empíricos más utilizados para representar sistemas de alimentos se muestran en la Tabla 3, con los que se buscará hacer el ajuste a los datos experimentales.

Tabla 3. Modelos empíricos para la cinética de secado

\begin{tabular}{|cc|}
\hline Ecuación del Modelo & Nombre \\
\hline$\left(X-X_{e} / X_{0}-X_{e}\right)=\exp (-k t)$ & Newton \\
\hline$\left(X-X_{e} / X_{0}-X_{e}\right)=\exp \left(-k t^{n}\right)$ & Page \\
\hline
\end{tabular}

\subsubsection{Modelos Teóricos}

\subsubsection{Solución de la 2ạ. Ley de Fick con Coeficiente de Difusión constante}

En el caso de ausencia de reacción química, en condiciones de difusión en estado no estacionario, los cuales se presentan con mayor frecuencia durante el secado en materiales sólidos, se utiliza la 2a‥ Ley de Fick.

La 2a Ley de Fick con difusividad constante se puede expresar para una geometría esférica, Treybal (1988) (ecuación 11), con sus respectivas condiciones de frontera (ecuación 12).

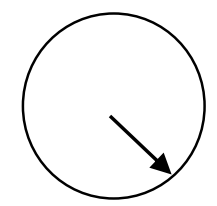

$$
\frac{\partial X}{\partial t}=\frac{D}{r^{2}} \frac{\partial}{\partial r}\left(r^{2} \frac{\partial X}{\partial r}\right)
$$

Con las siguientes condiciones de frontera:

$$
\begin{array}{lll}
\forall r & t=0 & \\
& r=0 & \\
\forall t & & \frac{d X}{d r}=0 \\
& r=R & X=X_{e}
\end{array}
$$

Si se considera una distribución inicial de humedad uniforme y la ausencia de cualquier resistencia externa, la solución de las ecuaciones diferenciales parciales de 2a Ley de Fick, para geometría esférica de radio (r), está descrita por la ecuación (13) (Rao y Rizvi, 1986).

$$
\frac{X-X_{e}}{X_{0}-X_{e}}=\frac{6}{\pi^{2}} \sum_{1}^{\infty} \frac{1}{n^{2}} \exp \left(-\frac{(n \pi)^{2} D \cdot t}{r^{2}}\right)
$$


Esta expresión es utilizada para estimar la difusividad con los datos del periodo decreciente de velocidad de secado o para estimar la velocidad de secado y el tiempo si el valor de la difusividad es conocida (Mujumdar, 2000). El coeficiente de difusión $D$, se emplea como medida de la velocidad de secado.

Para tiempos relativamente largos, r muy pequeño, y Xe como cero, la solución de la ecuación (13) se simplifica haciendo uso sólo del primer término de la serie, en su forma lineal sería:

$$
\ln \frac{X}{X_{0}}=\ln \left(\frac{6}{\pi^{2}}\right)-\left(\frac{\pi}{r}\right)^{2} D \cdot t
$$

Hawlader (1991) propuso que la longitud del sólido, se toma como una función del contenido de humedad, de acuerdo a la ecuación (15).

$$
r^{\prime}=\frac{r}{r_{0}}=\left(\frac{X_{t}}{X_{0}}\right)^{n}
$$

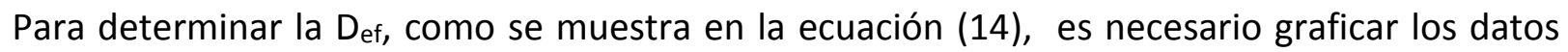

experimentales del $\ln \left(X / X_{0}\right)$ contra $t / r^{\prime 2}$, en donde se busca que el valor de $\mathrm{n}$ de la ecuación (11) ajuste la línea a una recta. Con el valor de la pendiente de la recta se obtiene el coeficiente de la $D_{\text {ef. }}$

\subsubsection{Solución de la 2ạ. Ley de Fick con Coeficiente de Difusión Variable Problema de frontera móvil}

La migración del agua en un sólido poroso en el que existe una variación de sus dimensiones, es considerado como un proceso controlado por la difusión, el cual se lleva a cabo en un sistema binario constituido por A una fase líquida que estará cambiando, y por B la fase sólida cuya masa permanecerá constante. La ecuación de Fick se puede aplicar para describir el movimiento de la humedad en un sólido poroso de forma esférica, es necesario establecer las siguientes suposiciones:

- los cambios en las dimensiones sólo se deben a la migración de contenido de humedad, en la misma dirección que se lleva a cabo la difusión, 
- el proceso difusivio de la humedad ocurre bajo condiciones isotérmicas (Aguerre, y col., 2008)

Para un sólido con forma esférica, la 2a Ley de Fick se presenta en la ecuación (16)

$$
\frac{\partial X}{\partial t}=\frac{1}{r^{2}} \frac{\partial}{\partial r}\left(r^{2} D \frac{\partial X}{\partial r}\right)
$$

Si existe cambio de volumen es necesario hacer la evaluación de la derivada total de $\mathrm{X}_{\mathrm{A}}$,

$$
\frac{d X_{A}}{d t}=\frac{\partial X_{A}}{\partial t}+\frac{\partial X_{A}}{\partial r} \cdot \frac{d r}{d t}
$$

Introduciendo (16) en (17)

$$
\frac{d X_{A}}{d t}=\frac{1}{r^{2}} \frac{\partial}{\partial r}\left(r^{2} D \frac{\partial X_{A}}{\partial r}\right)+\frac{\partial X_{A}}{\partial r} \cdot \frac{d r}{d t}
$$

Para resolver la ecuación (18) se tiene la condición inicial y de frontera siguientes:

$$
\begin{array}{lll}
\forall r & t=0 & X=X_{0} \\
& r=0 & \frac{d X}{d r}=0 \\
\forall t & & X=X_{e}
\end{array}
$$

Las ecuaciones (18) y (94) no pueden ser resueltas de forma analítica debido al movimiento de la frontera del sólido con respecto al eje coordenado. Se realizar un cambio de variable de la forma siguiente, donde Z varía entre cero y uno (Landau, 1950),

$$
z=\frac{r}{R}
$$

Haciendo el cambio de variable en la (18), la cuál será la ecuación de trabajo

$$
\frac{d X_{A}}{d t}=\frac{1}{(z \cdot R)^{2}} \frac{\partial}{\partial z}\left(z^{2} D \frac{\partial X_{A}}{\partial z}\right)+\frac{1}{R} \frac{\partial X_{A}}{\partial z} \cdot z \cdot \frac{d R}{d t}
$$

Debido a que la ecuación (21) esta indeterminada en el centro del sólido, z=0, se aplica la regla de L'Hopital para obtener,

$$
\frac{\partial X_{A}}{\partial t}=3 \frac{D}{R^{2}} \frac{\partial^{2} X_{A}}{\partial z^{2}}
$$


Aguerre y col., (2008) realizaron un modelo matemático a partir de la ecuación de difusión, para la transferencia de masa durante el secado y la rehidratación de un sólido esférico y poroso con ciertas características iniciales, para el que toman en cuenta su cambio de volumen, sin embargo no hay una validación con datos experimentales.

\section{Características del programa}

- El software utilizado para la realización del programa fue Berkeley Madona.

- El problema de frontera móvil se transformó en un problema de frontera fija mediante un cambio de variable (Crank 1979),

- La coordenada espacial se dicretizó por medio de diferencias finitas. Se emplearon diferencias finitas centrales para el interior del dominio y en la frontera se utilizaron diferencias finitas hacia atrás. Mediante la discretización se transformó la ecuación en derivadas parciales en un conjunto de ecuaciones diferenciales ordinarias.

- El conjunto de ecuaciones diferenciales ordinarias se integró con el método de Rosenbrock.

- La $D_{\text {ef }}$ se calculó como una función de la concentración de acuerdo a la correspondiente en cada nodo en cada instante de tiempo. En estas simulaciones se utilizaron 60 nodos.

- Para incluir el efecto del encogimiento, se hizo uso de los datos obtenidos experimentalmente de la variación del radio. Como el objetivo es estimar la $D_{\text {ef }}$ se introdujo en el programa el ajuste experimental del radio como una función del tiempo. A partir de la derivada de esta expresión se obtiene la ecuación para la rapidez de encogimiento.

- Mediante un proceso de prueba y error se ajustaron los coeficientes de $D_{\text {ef }}$ para obtener una buena reproducción de los datos experimentales. Las curvas de secado obtenidas con la simulación fueron comparadas con los datos experimentales visualmente, y mediante una medida del error en cada nodo. 


\section{CAPÍTULO IV}

\section{RESULTADOS Y DISCUSIÓN}

Se presentan los resultados obtenidos del diseño experimental planteado en el Capítulo III, las curvas de secado y variación de volumen. Se analizó la influencia de factores involucrados en la operación de secado ( $T$ y Q). Se realizó el ajuste de las curvas de secado con modelos empíricos y teóricos. Por último se presentan los parámetros termodinámicos obtenidos.

Para el cálculo del contenido de humedad (b.s.) para cada muestra, fue necesario determinar la proporción de sólido seco, siguiendo la metodología mencionada en la sección anterior. Se realizaron tres repeticiones con lo cual se obtuvo que el $95.4 \%$ correspondía al contenido de agua (humedad) y el $4.6 \%$ a la masa de sólido seco, con un intervalo de variación de $\pm 0.3 \%$. Con estos valores se procedió a manejar las cinéticas de secado en función del contenido de humedad (b.s.).

\subsection{Cinéticas de Secado}

En la Figura 6 se muestran las cinéticas de secado obtenidas tanto en termobalanza (a), como en túnel en capa fina (b), en ambos casos el lote de muestras parte de las mismas condiciones, la diferencia recae en el tipo de secador utilizado, en el segundo caso existe un flujo de aire a diferencia del primero. Ambas curvas de secado muestran perfiles parecidos, y debido a la forma que presentan se infiere que el efecto predominante es el difusivo, sin embargo existe una diferencia considerable en el tiempo necesario para llegar al equilibrio.
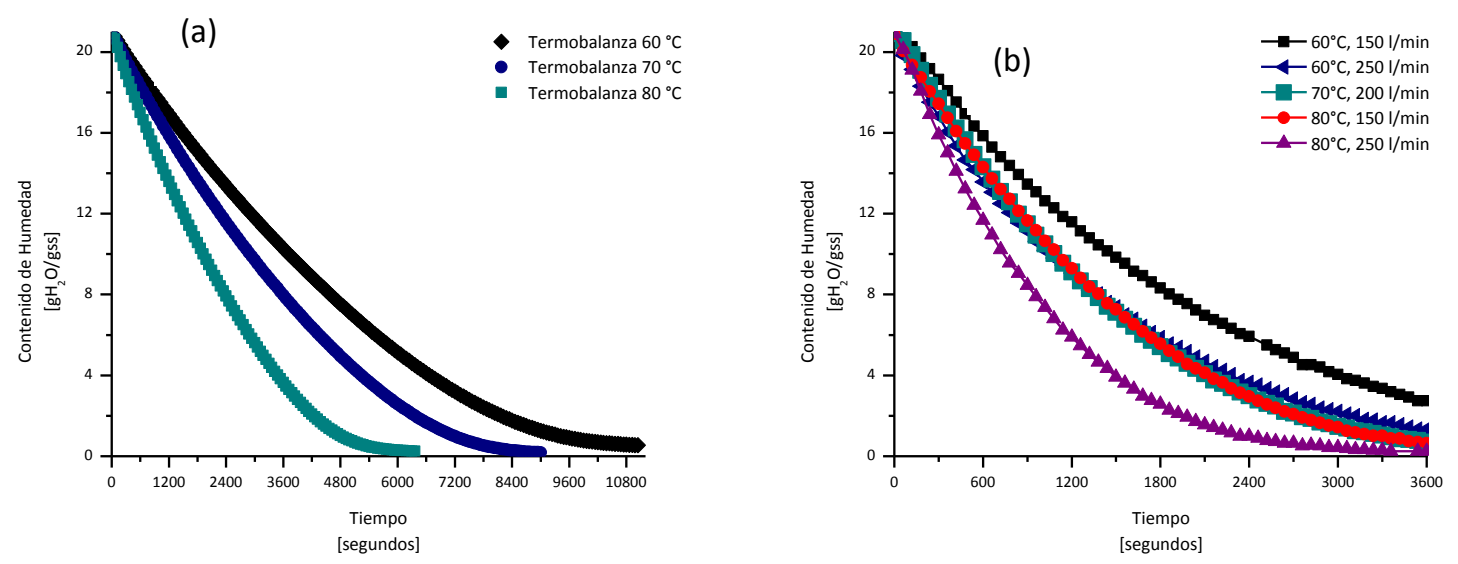

Figura 6. Curvas de secado en termobalanza (a) y en túnel de viento (b). 
Al realizar las curvas de velocidad de secado, graficando $d X / d t$ contra $\mathrm{X}$, se verídica que no existe un periodo de secado constante y que este proceso es independiente de las condiciones de operación del secador, las curvas de secado solo presentan periodo de velocidad decreciente de secado. Lo cual indica que el mecanismo que controla el proceso es difusivo. Sin embargo, el efecto que la velocidad del aire tiene sobre la misma cinética de secado, se puede explicar al combinar dos aspectos que lo favorecen, uno, el alto contenido de humedad del sólido y el otro, el secado en capa delgada.

Ambos aspectos, independientemente del control difusivo, facilitan la transferencia de masa a la corriente de aire que pasa a través del túnel.

Al realizar el análisis de varianza teniendo como variable respuesta el contenido de humedad, para el diseño experimental presentado para el secado en túnel, se obtuvo que tanto la temperatura como el flujo de aire tienen un efecto significativo $(p<0.05)$ sobre la pérdida del contenido de humedad. Se corroboró con la prueba de Shapiro-Wilk W. la distribución normal de los datos.

Para visualizar estos efectos en las Figuras 7 y 8 se puede observar el efecto de la velocidad de aire de secado con una misma temperatura (60 y $80^{\circ}$ respectivamente), al aumentar el flujo del aire disminuye el tiempo de secado.

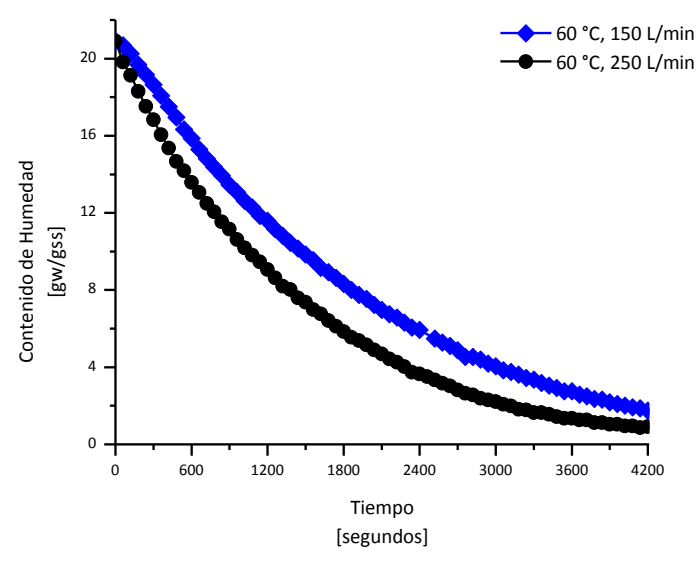

Figura 7. Curvas de secado a $60^{\circ} \mathrm{C}$ con 150 y $250 \mathrm{~L} / \mathrm{min}$.

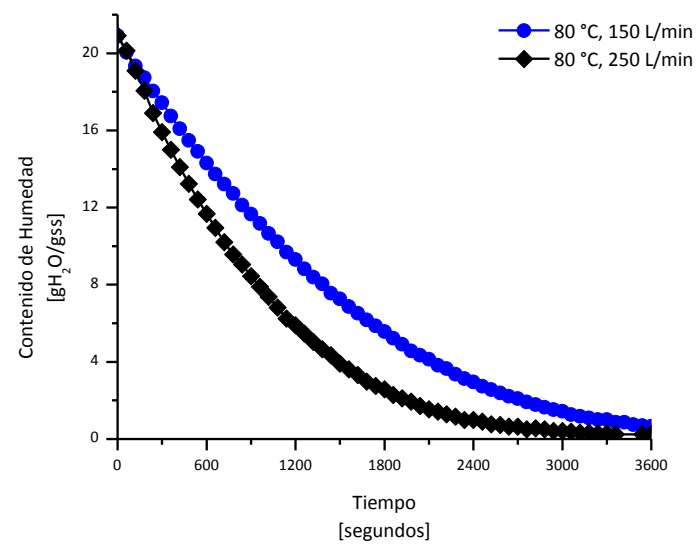

Figura 8. Curvas de secado a $80{ }^{\circ} \mathrm{C}$ con 150 y $250 \mathrm{~L} / \mathrm{min}$

Para observar el efecto de la temperatura, se presentan las Figuras 9 y 10, en donde a un mismo valor de $Q$ existe una diferencia notable en la reducción de los tiempos de secado al 
aumentar la temperatura, entonces con el nivel superior tanto de temperatura como de flujo de aire se tiene el menor tiempo de secado.

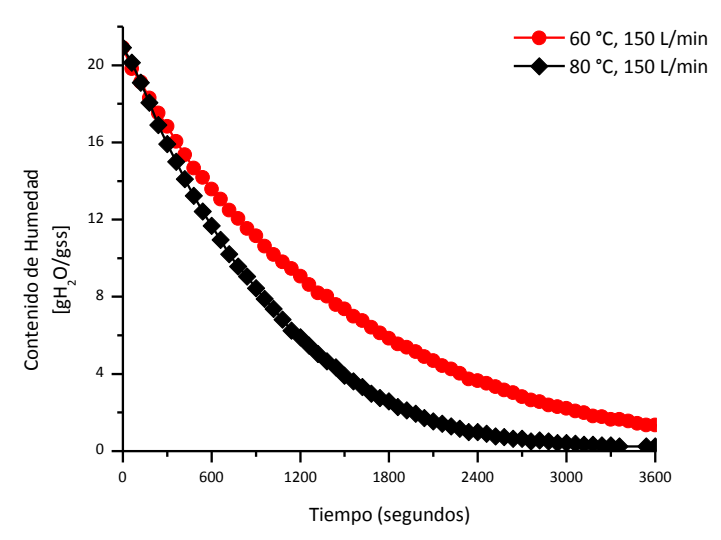

Figura 9. Curvas de secado a 60 y $80^{\circ} \mathrm{C}$ con un flujo de $150 \mathrm{~L} / \mathrm{min}$.

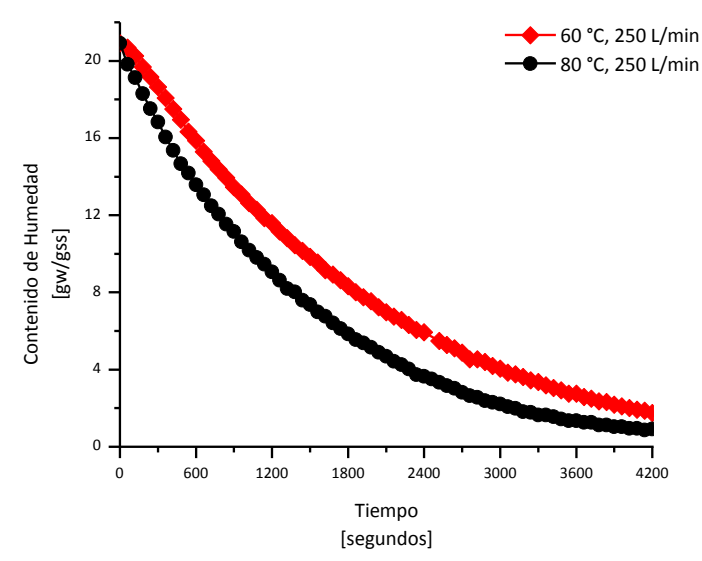

Figura 10. Curvas de secado a 60 y $80^{\circ} \mathrm{C}$ con un flujo de $250 \mathrm{~L} / \mathrm{min}$.

Tabla 4. Humedad de equilibrio para las diferentes condiciones de secado

\begin{tabular}{|c|c|}
\hline Condiciones de Secado & $\begin{array}{c}\text { Humedad de } \\
\left.\text { equilibrio (g } \mathrm{g}_{\mathrm{H} 2 \mathrm{O}} / \mathrm{gss}\right)\end{array}$ \\
\hline $60^{\circ} \mathrm{C}$ & 0.54 \\
\hline $70^{\circ} \mathrm{C}$ & 0.18 \\
\hline $80^{\circ} \mathrm{C}$ & 0.25 \\
\hline $60^{\circ} \mathrm{C}, 150 \mathrm{~L} / \mathrm{min}$ & 0.57 \\
\hline $60^{\circ} \mathrm{C}, 250 \mathrm{~L} / \mathrm{min}$ & 0.78 \\
\hline $70^{\circ} \mathrm{C}, 200 \mathrm{~L} / \mathrm{min}$ & 0.35 \\
\hline $80^{\circ} \mathrm{C}, 150 \mathrm{~L} / \mathrm{min}$ & 0.39 \\
\hline $80^{\circ} \mathrm{C}, 250 \mathrm{~L} / \mathrm{min}$ & 0.25 \\
\hline
\end{tabular}

A partir de análisis de varianza (Anexo 3) se obtiene que el efecto combinado de temperatura y flujo de aire no es significativo, esto se puede observar en la Figura 6 (b) se observa que las curvas obtenidas a $60{ }^{\circ} \mathrm{C}-250 \mathrm{~L} / \mathrm{min}, 70^{\circ} \mathrm{C}-200 \mathrm{~L} / \mathrm{min}$ y $80^{\circ} \mathrm{C}-150 \mathrm{~L} / \mathrm{min}$ se superponen y están localizadas entre los valores extremos de estos parámetros.

Comparado con los tiempos de secado que reporta (Giovanelli y col., 2002) para pulpa de tomate, van desde los 170 hasta los 420 minutos con una velocidad del aire de $1.5 \mathrm{~m} / \mathrm{s}$ y un rango de temperaturas entre 60 y $110{ }^{\circ} \mathrm{C}$, en este trabajo los tiempos de secado están entre los 60 y los 120 minutos. En el caso del trabajo de Brooks y col.,( 2008) en el que tenían diferentes geometrías $\left(1 / 2,1 / 4\right.$ y $1 / 8$ de pieza) con temperaturas de secado de 55 y $65{ }^{\circ} \mathrm{C}$, el 
tiempo necesario dependiendo de cada caso, el cual varió entre las 13 y las 36 horas, en este caso el proceso se realizó en un horno de convección forzada. Por lo que, en efecto existe un efecto importante tanto de la geometría del sólido como de las condiciones de secado.

\subsection{Modelo para el cálculo del radio equivalente durante el proceso de encogimiento}

En este trabajo se plantea un modelo empírico para seguir el encogimiento experimental de los cubos de tomate durante el secado. En la Tabla 5 se presenta el porcentaje de reducción del volumen para cada condición de secado, el valor máximo fue del 85.7 \%. Se adoptó un modelo tipo Ley de Potencia, ecuación (23), para relacionar la variación del radio equivalente de los cubos de tomate.

$$
r_{e q}=a \cdot X^{b}
$$

En la Tabla 6 se muestran los valores de las constantes de la ecuación (23), la cual fue ajustada a los valores experimentales y agrupados en los tres niveles de flujo, de acuerdo al diseño factorial propuesto. En las Figuras 11-13 se muestran los datos experimentales y el ajuste de la variación del radio con respecto al contenido de humedad.

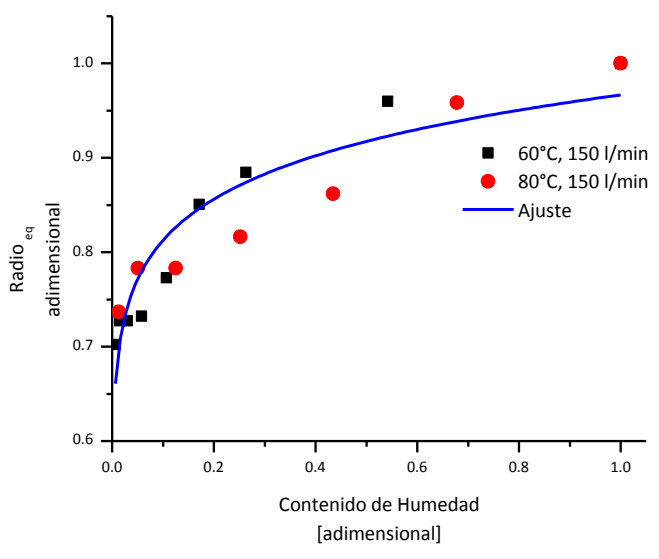

Figura 11. Ajuste modelo tipo potencia para flujo de

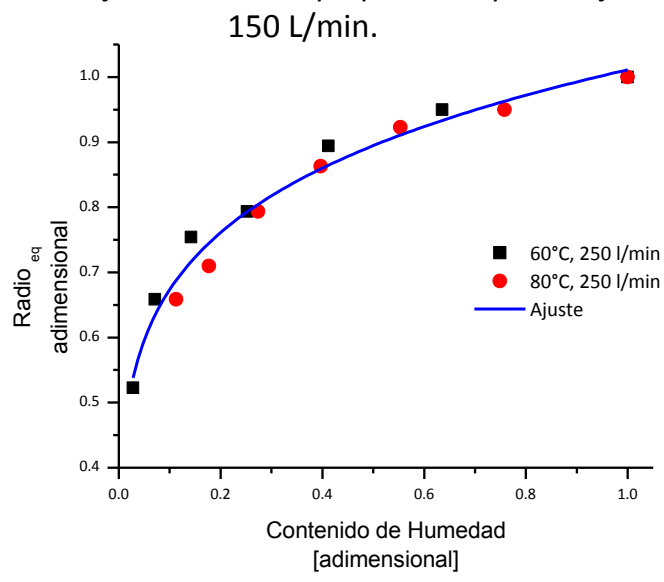

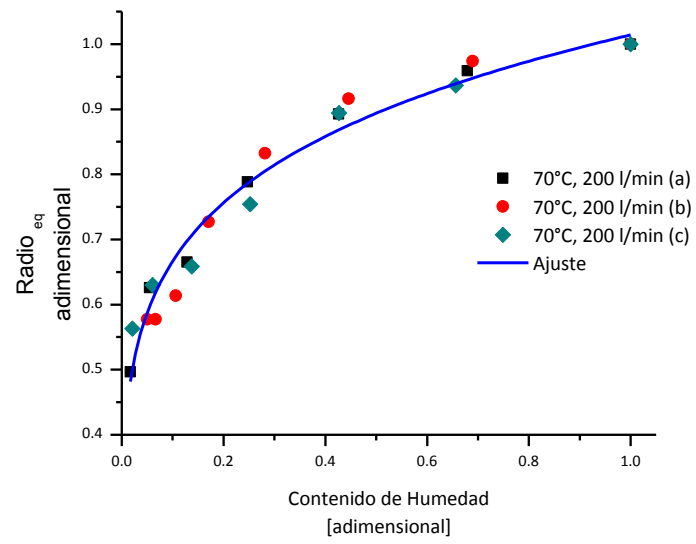

Figura 12. Ajuste modelo tipo potencia para flujo de $200 \mathrm{~L} / \mathrm{min}$.
Figura 13. Ajuste modelo tipo potencia con flujo de $250 \mathrm{~L} / \mathrm{min}$. 
Tabla 5. Porcentaje de encogimiento final.

\begin{tabular}{|c|c|}
\hline $\begin{array}{l}\text { Condiciones de } \\
\text { Secado }\end{array}$ & $\begin{array}{l}\text { \% de Encogimiento } \\
\text { (volumen final) }\end{array}$ \\
\hline $60^{\circ} \mathrm{C}, 150 \mathrm{~L} / \mathrm{min}$ & $65.38 \%$ \\
\hline $60^{\circ} \mathrm{C}, 250 \mathrm{~L} / \mathrm{min}$ & $85.71 \%$ \\
\hline $70^{\circ} \mathrm{C}, 200 \mathrm{~L} / \mathrm{min}$ & $87.75 \%$ \\
\hline $70^{\circ} \mathrm{C}, 200 \mathrm{~L} / \mathrm{min}$ & $80.77 \%$ \\
\hline $70^{\circ} \mathrm{C}, 200 \mathrm{~L} / \mathrm{min}$ & $82.14 \%$ \\
\hline $80^{\circ} \mathrm{C}, 150 \mathrm{~L} / \mathrm{min}$ & $60.00 \%$ \\
\hline $80^{\circ} \mathrm{C}, 250 \mathrm{~L} / \mathrm{min}$ & $71.43 \%$ \\
\hline
\end{tabular}

Tabla 6. Valores de las constantes de la ecuación (22).

\begin{tabular}{|cccc|}
\hline $\begin{array}{c}\text { Condiciones de } \\
\text { Secado }\end{array}$ & $\mathbf{a}$ & $\mathbf{b}$ & $\mathbf{R}^{\mathbf{2}}$ \\
\hline $\mathbf{1 5 0} \mathrm{L} / \mathbf{m i n}$ & 0.96661 & 0.07533 & 0.868 \\
\hline $\mathbf{2 0 0} \mathrm{L} / \mathbf{m i n}$ & 1.01412 & 0.18223 & 0.963 \\
\hline $\mathbf{2 5 0} \mathrm{L} / \mathbf{m i n}$ & 1.01112 & 0.17652 & 0.975 \\
\hline
\end{tabular}

A manera de ejemplo, en la Tabla 77 se muestran fotografías tomadas para el flujo de 250 $\mathrm{L} / \mathrm{min}$ a dos temperaturas de secado $\left(60\right.$ y $80^{\circ} \mathrm{C}$ ) en donde se puede observar la variación de las dimensiones de los cubos.

Tabla 7. Fotografías de cubos de tomate secados a $250 \mathrm{l} / \mathrm{min}$ a 60 y $80^{\circ} \mathrm{C}$.

\begin{tabular}{|c|c|c|}
\hline $\begin{array}{c}\text { Contenido de Humedad } \\
{\left[\mathrm{gH}_{2} \mathrm{O} / \mathrm{gss}\right]}\end{array}$ & $60^{\circ} \mathrm{C}$ & $80^{\circ} \mathrm{C}$ \\
\hline$X=10$ & & \\
\hline
\end{tabular}




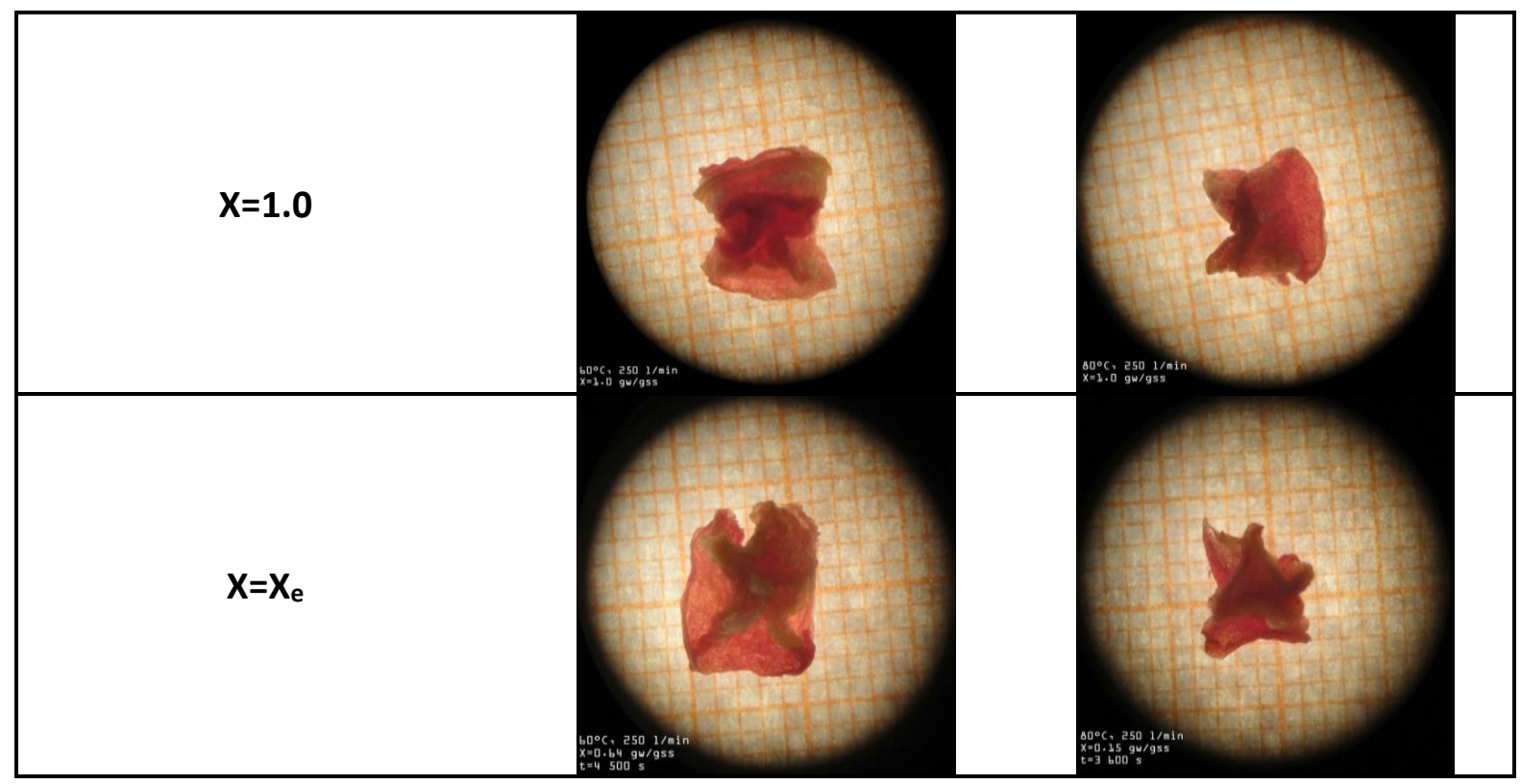

\subsection{Modelos empíricos}

Utilizando los modelos empíricos de Newton y Page (Tabla 3), se modelaron las curvas cinéticas presentadas en la Figura 6 (b) correspondientes al secado en túnel en capa delgada. En las Figuras 14-18 se muestran ajustes realizados con estos modelos.

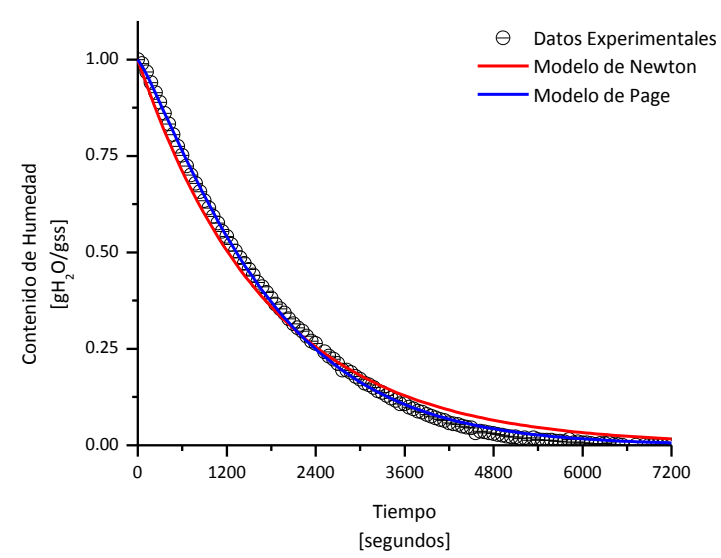

Figura 14. Datos Experimentales $\left(60^{\circ} \mathrm{C}, 150 \mathrm{~L} / \mathrm{min}\right)$ ajustados a los modelos de Newton y Page.

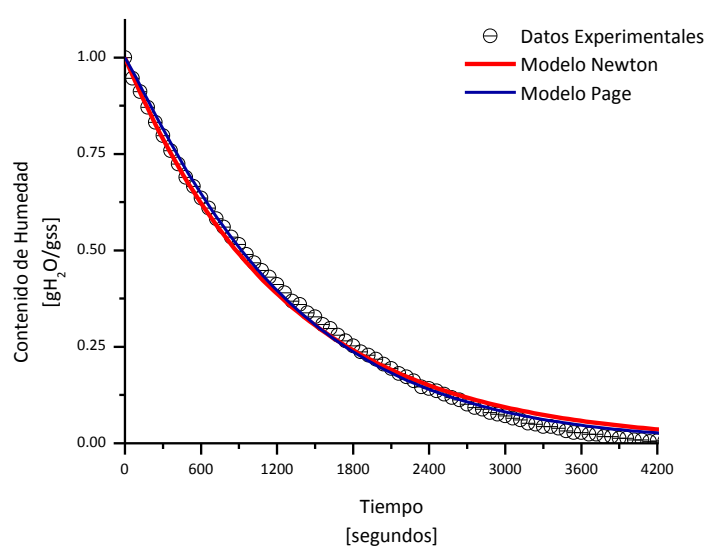

Figura 15. Datos Experimentales $\left(60^{\circ} \mathrm{C}, 250 \mathrm{~L} / \mathrm{min}\right.$ ) ajustados a los modelos de Newton y Page. 


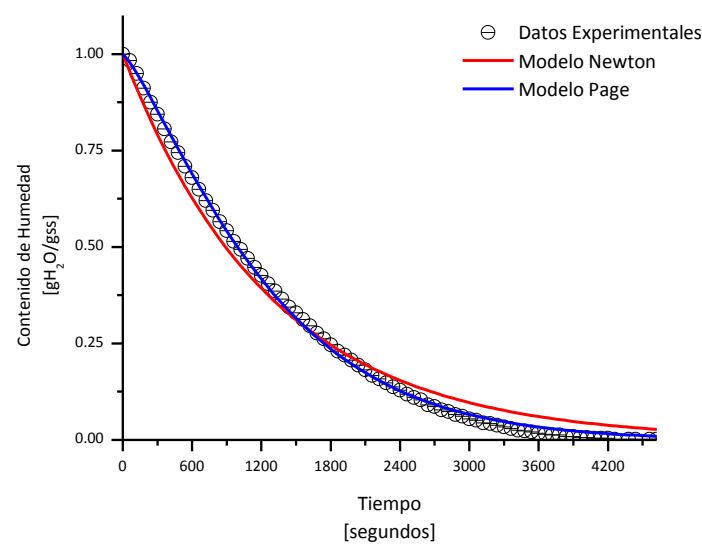

Figura 16. Datos Experimentales $\left(70^{\circ} \mathrm{C}, 200 \mathrm{~L} / \mathrm{min}\right)$ ajustados a los modelos de Newton y Page.

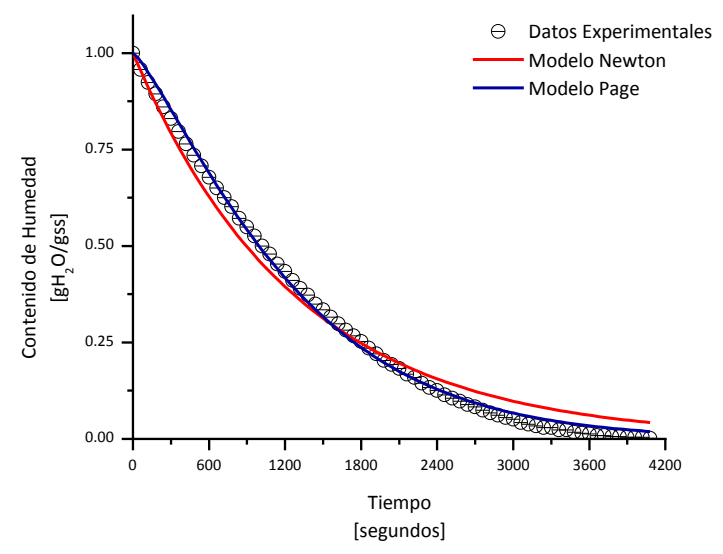

Figura 17. Datos Experimentales $\left(80^{\circ} \mathrm{C}, 150 \mathrm{~L} / \mathrm{min}\right)$ ajustados a los modelos de Newton y Page.

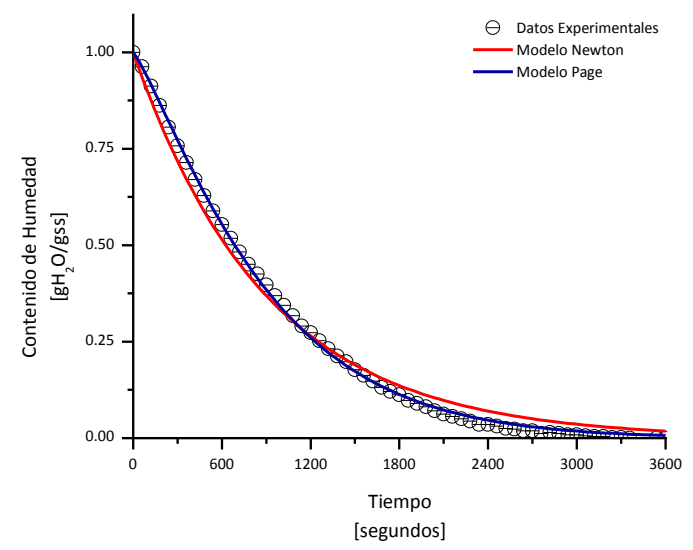

Figura 18. Datos Experimentales $\left(80^{\circ} \mathrm{C}, 250 \mathrm{~L} / \mathrm{min}\right)$ ajustados a los modelos de Newton y Page.

En todos los casos se puede observar un buen ajuste de los datos experimentales con los modelos de la literatura con factores de correlación superiores al 0.98, el modelo de Page es el que muestra mejor ajuste en todos los casos. Sin embargo como estos modelos están basados sólo en parámetros de ajuste, no cuentan con un sustento teórico que permita hacer interpretaciones sobre el fenómeno que se está modelando.

En la Tabla 8 se muestran los valores de las constantes del Modelo de Newton a las diferentes condiciones de secado, y de igual forma en la

Tabla 9 se muestran los valores de las constantes obtenidas para el Modelo de Page. 
Tabla 8. Valores de la constante y correlación para el Modelo de Newton a diferentes condiciones de secado.

\begin{tabular}{|ccc|}
\hline Condiciones de Secado & $\mathbf{k}\left[\mathrm{min}^{-1}\right]$ & $\mathbf{R}^{\mathbf{2}}$ \\
\hline $\mathbf{6 0}{ }^{\circ} \mathbf{C}, \mathbf{1 5 0} \mathrm{L} / \mathrm{min}$ & $7.89 \times 10^{-4}$ & 0.990 \\
\hline $\mathbf{6 0} 0^{\circ} \mathbf{C}, \mathbf{2 5 0} \mathrm{L} / \mathrm{min}$ & $7.90 \times 10^{-4}$ & 0.994 \\
\hline $\mathbf{7 0}{ }^{\circ} \mathbf{C}, \mathbf{2 0 0} \mathrm{L} / \mathrm{min}$ & $7.78 \times 10^{-4}$ & 0.985 \\
\hline $\mathbf{8 0} 0^{\circ} \mathbf{C}, \mathbf{1 5 0} \mathrm{L} / \mathrm{min}$ & $7.75 \times 10^{-4}$ & 0.983 \\
\hline $\mathbf{8 0} 0^{\circ} \mathbf{C}, \mathbf{2 5 0} \mathrm{L} / \mathrm{min}$ & $1.11 \times 10^{-3}$ & 0.989 \\
\hline
\end{tabular}

Tabla 9. Valores de la constante y correlación para el Modelo de Page a diferentes condiciones de secado.

\begin{tabular}{|c|c|c|c|}
\hline Condiciones de Secado & $k\left[\mathrm{~min}^{-1}\right]$ & $\mathbf{n}$ & $\mathbf{R}^{2}$ \\
\hline $60^{\circ} \mathrm{C}, 150 \mathrm{~L} / \mathrm{min}$ & $1.43 \times 10^{-4}$ & 1.179 & 0.998 \\
\hline $60^{\circ} \mathrm{C}, 250 \mathrm{~L} / \mathrm{min}$ & $4.12 \times 10^{-4}$ & 1.088 & 0.993 \\
\hline $70^{\circ} \mathrm{C}, 200 \mathrm{~L} / \mathrm{min}$ & $1.37 \times 10^{-4}$ & 1.235 & 0.998 \\
\hline $80^{\circ} \mathrm{C}, 150 \mathrm{~L} / \mathrm{min}$ & $1.41 \times 10^{-4}$ & 1.231 & 0.997 \\
\hline $80^{\circ} \mathrm{C}, 250 \mathrm{~L} / \mathrm{min}$ & $2.94 \times 10^{-4}$ & 1.188 & 0.998 \\
\hline
\end{tabular}

\subsection{Modelo con Difusividad constante}

A partir de estos valores obtenidos, se procede a integrarlos en el modelo propuesto para la determinación del contenido de humedad a partir de la 2a Ley de Fick. Es decir, para cada nivel del flujo se toma la variación del radio con el modelo propuesto para cada caso. En las Figuras 19-23 se muestran los ajustes con el modelo propuesto por Hawlader (ecuación 15) y el de la correlación tipo Ley de Potencia propuesta en este trabajo (ecuación 23).

Ambas correlaciones se introducen en el modelo de la 2a Ley de Fick para poder obtener el valor de coeficientes de difusión y con esto poder predecir las cinéticas de secado, de igual forma, en las Figuras 19-23 se presentan los ajustes alcanzados.

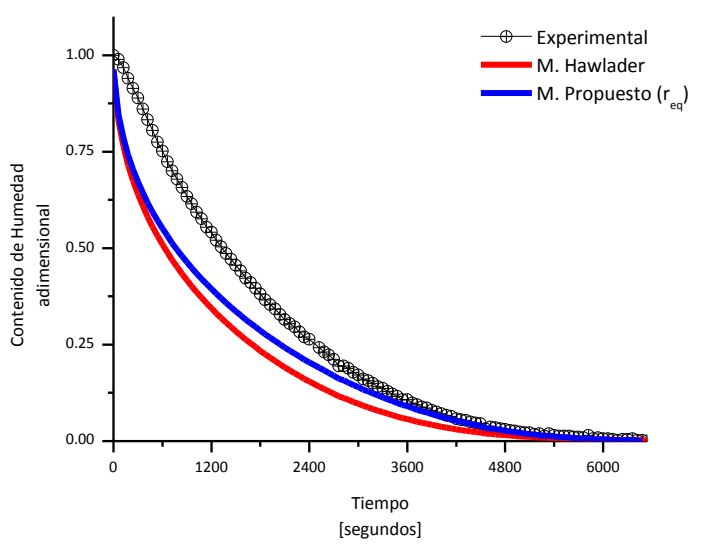

Figura 19. Datos Experimentales (60 ${ }^{\circ} \mathrm{C}, 150 \mathrm{~L} / \mathrm{min}$ ) ajustados a los modelos de Hawlader y propuesto.

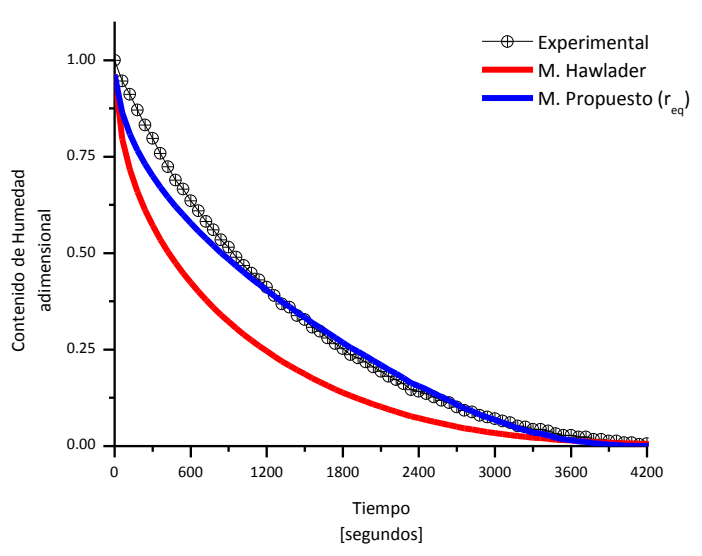

Figura 20. Datos Experimentales $\left(60^{\circ} \mathrm{C}, 250 \mathrm{~L} / \mathrm{min}\right.$ ) ajustados a los modelos de Hawlader y propuesto. 


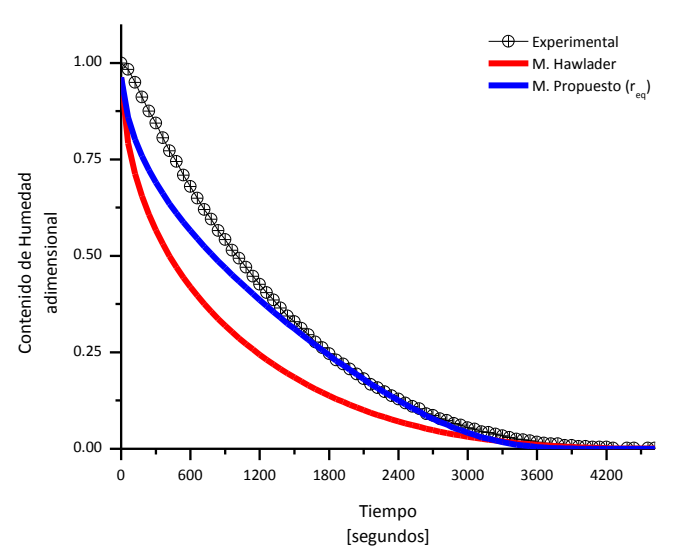

Figura 21. Datos Experimentales $\left(70^{\circ} \mathrm{C}, 200 \mathrm{~L} / \mathrm{min}\right.$ ) ajustados a los modelos de Hawlader y propuesto.

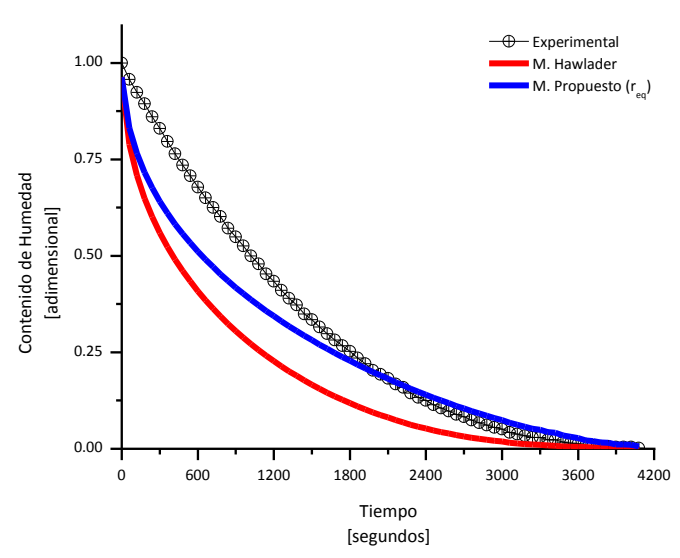

Figura 22. Datos Experimentales $\left(80^{\circ} \mathrm{C}, 150 \mathrm{~L} / \mathrm{min}\right)$ ajustados a los modelos de Hawlader y propuesto

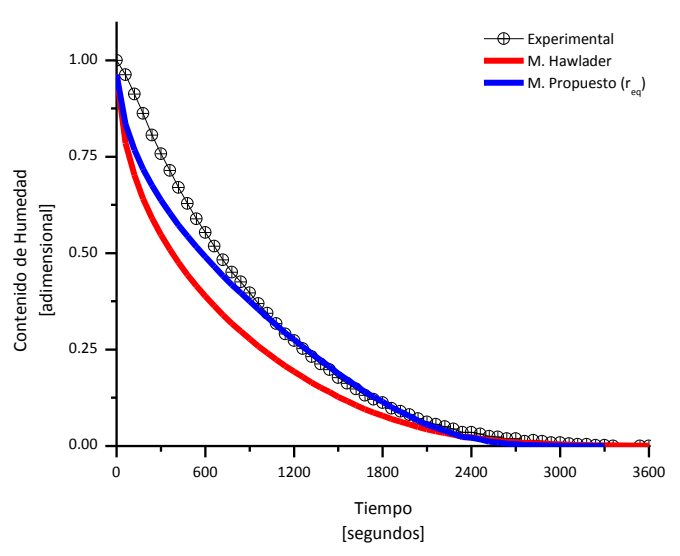

Figura 23. Datos Experimentales $\left(80^{\circ} \mathrm{C}, 250 \mathrm{~L} / \mathrm{min}\right.$ ) ajustados a los modelos de Hawlader y propuesto.

En todos los casos se puede observar una mejoría en el ajuste haciendo uso de las correlaciones propuestas en el presente trabajo, con los valores de los coeficientes de correlación que permiten valorar ambos ajustes en cada caso.

En la

Tabla 1010 se muestran los valores de la Def para las diferentes condiciones de secado, obtenidos con el modelo propuesto por Hawlader, con el valor de la constante $\mathrm{n}$ de la ecuación (15), y los que se obtuvieron a partir del modelo con la modificación propuesta. Los valores de ambos parámetros son consistentes comparados con los reportados por Giovanelli y col., 2002. Se presenta el factor de correlación correspondiente. 
Tabla 10. Valores de la $D_{\text {ef }}$ para las diferentes condiciones de secado.

\begin{tabular}{|c|c|c|c|c|c|}
\hline \multirow{2}{*}{$\begin{array}{c}\text { Condiciones de } \\
\text { Secado }\end{array}$} & \multicolumn{3}{|c|}{ Modelo Hawlader } & \multicolumn{2}{|c|}{ Modelo req } \\
\hline & $\mathrm{D}_{\mathrm{ef}}\left[\mathrm{m}^{2} / \mathrm{s}\right]$ & $\mathrm{n}$ & $\mathrm{R}^{2}$ & $\mathrm{D}_{\mathrm{ef}}\left[\mathrm{m}^{2} / \mathrm{s}\right]$ & $\mathrm{R}^{2}$ \\
\hline $60^{\circ} \mathrm{C}, 150 \mathrm{~L} / \mathrm{min}$ & $1.32 \times 10-9$ & 0.09 & 0.823 & $1.03 \times 10-9$ & 0.898 \\
\hline $60^{\circ} \mathrm{C}, 250 \mathrm{~L} / \mathrm{min}$ & $2.03 \times 10-9$ & 0.08 & 0.803 & $8.84 \times 10-10$ & 0.983 \\
\hline $70^{\circ} \mathrm{C}, 200 \mathrm{~L} / \mathrm{min}$ & $1.72 \times 10-9$ & 0.06 & 0.781 & $7.89 \times 10-10$ & 0.961 \\
\hline $70^{\circ} \mathrm{C}, 200 \mathrm{~L} / \mathrm{min}$ & $2.01 \times 10-9$ & 0.03 & 0.778 & $9.16 \times 10-10$ & 0.957 \\
\hline $70^{\circ} \mathrm{C}, 200 \mathrm{~L} / \mathrm{min}$ & $1.92 \times 10-9$ & 0.07 & 0.791 & $9.99 \times 10-10$ & 0.958 \\
\hline $80^{\circ} \mathrm{C}, 150 \mathrm{~L} / \mathrm{min}$ & $2.03 \times 10-9$ & 0.09 & 0.728 & $1.19 \times 10-9$ & 0.915 \\
\hline $80^{\circ} \mathrm{C}, 250 \mathrm{~L} / \mathrm{min}$ & $2.27 \times 10-9$ & 0.10 & 0.881 & $1.33 \times 10-9$ & 0.970 \\
\hline
\end{tabular}

\subsection{Modelo con la Difusividad en función del contenido de humedad}

Analizando los resultados obtenidos a partir del uso de los modelos presentados anteriormente, el mejor ajuste se obtiene con los modelos de Newton y Page, seguidos de los obtenidos a partir de la $2^{\text {a }}$ Ley de Fick con $D_{\text {ef }}$ constante. El inconveniente que se encuentra en la primera serie de modelos es la falta de un sustento teórico, en cuanto a los restantes se puede observar que al inicio del proceso de secado no se tiene un buen ajuste.

Buscando mejorar estos ajustes, conservando una base teórica, se hizo uso del problema de frontera móvil (sección 3.3.2.2), al ser no lineal se realizó la solución numérica de éste.

Se tomaron coeficientes de difusión dependiendo de las regiones del sólido y de sus concentraciones, los valores fueron más bajas en el interior del sólido y al comienzo del proceso, y más altos en las regiones cercanas a la frontera exterior. Estos niveles de $D_{\text {ef }}$ se aproximaron mediante una función continua que depende de la concentración. La relación propuesta es la siguiente:

$$
D_{e f}=a-\frac{b}{1+\exp \left(-2 k \cdot\left(X-X_{c}\right)\right)}
$$

La ecuación anterior es una función tipo sigmoideal, donde $a$ y b son constantes que se relacionan con el intervalo de variación de la difusividad (amplitud), k es un coeficiente que hace que el cambio de los valores de la Def se más suave o más abrupto, $\mathrm{X}$ el contenido de 
humedad en cada punto, y $\mathrm{X}_{c}$ contenido crítico de huemdad a partir del cual ocurre el cambio en las $D_{\text {ef. }}$

Las constantes de la ecuación (24) se muestran en la Tabla 11. La forma de esta función se muestra en la Figura 24 para diferentes contenidos de humedad del sólido en el tiempo.

Tabla 11. Constantes para la ecuación de Def para diferentes condiciones de operación.

\begin{tabular}{|c|c|c|c|c|}
\hline Condiciones de Secado & $\mathrm{a}\left[\mathrm{m}^{2} / \mathrm{s}\right]$ & b $\left[\mathrm{m}^{2} / \mathrm{s}\right]$ & Xc $\left[g_{H 2 O} / g_{s s}\right]$ & K[gss/gH2O] \\
\hline $60^{\circ} \mathrm{C}, 150 \mathrm{~L} / \mathrm{min}$ & $1.10 \times 10^{-9}$ & $1.06 \times 10^{-9}$ & 17.5 & 1.5 \\
\hline $60^{\circ} \mathrm{C}, 250 \mathrm{~L} / \mathrm{min}$ & $6.00 \times 10^{-10}$ & $5.10 \times 10^{-10}$ & 10.0 & 1.5 \\
\hline $70^{\circ} \mathrm{C}, 200 \mathrm{~L} / \mathrm{min}$ & $9.30 \times 10^{-10}$ & $8.30 \times 10^{-10}$ & 12.5 & 1.5 \\
\hline $80^{\circ} \mathrm{C}, 150 \mathrm{~L} / \mathrm{min}$ & $1.80 \times 10^{-9}$ & $1.74 \times 10^{-9}$ & 17.0 & 1.1 \\
\hline $80^{\circ} \mathrm{C}, 250 \mathrm{~L} / \mathrm{min}$ & $1.20 \times 10^{-9}$ & $1.10 \times 10^{-9}$ & 15.0 & 1.7 \\
\hline
\end{tabular}

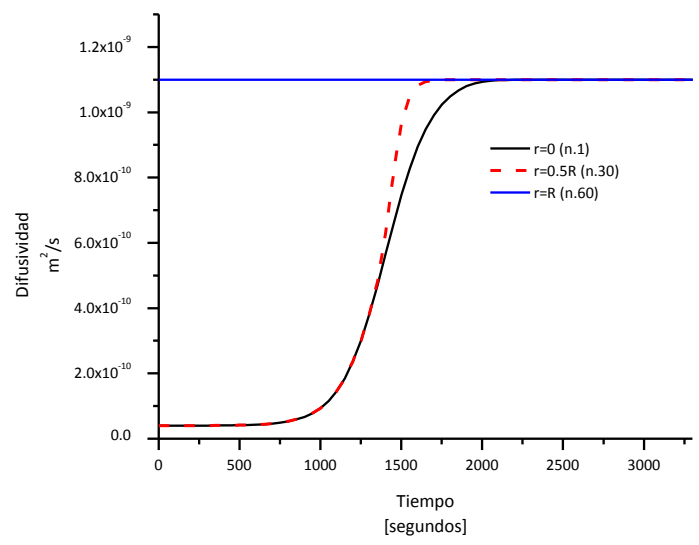

Figura 24. Coeficiente de difusión para $60^{\circ} \mathrm{C}-150 \mathrm{~L} / \mathrm{min}$, para tres puntos del sólido.

Los dos valores de coeficientes de $D_{\text {ef }}$ lo podría indicar la existencia de dos períodos de secado decreciente. La $D_{\text {ef }}$ más baja corresponde al intervalo de concentraciones más altas, y el valor más alto a las concentraciones más bajas. Estos niveles de $D_{\text {ef }}$ se presentan en la Tabla 12 , con el valor de la $\mathrm{R}^{2}$ correspondiente a la calidad del ajuste logrado.

Tabla 12. Coeficiente de $D_{\text {ef }}$ y $R^{2}$ para la simulación de las curvas de secado.

\begin{tabular}{|c|c|c|c|}
\hline \multirow{2}{*}{ Condiciones de Secado } & \multicolumn{2}{|c|}{$D_{\text {ef }}\left[\mathrm{m}^{2} / \mathrm{s}\right]$} & \multirow{2}{*}{$\mathbf{R}^{2}$} \\
\hline & Menor & Mayor & \\
\hline $60{ }^{\circ} \mathrm{C}, 150 \mathrm{~L} / \mathrm{min}$ & $4.00 \times 10^{-11}$ & $1.10 \times 10^{-9}$ & 0.998 \\
\hline $60^{\circ} \mathrm{C}, 250 \mathrm{~L} / \mathrm{min}$ & $9.01 \times 10^{-11}$ & $6.00 \times 10^{-10}$ & 0.996 \\
\hline $70^{\circ} \mathrm{C}, 200 \mathrm{~L} / \mathrm{min}$ & $1.00 \times 10^{-10}$ & $9.30 \times 10^{-10}$ & 0.996 \\
\hline
\end{tabular}




\begin{tabular}{|llll|}
\hline $\mathbf{8 0}{ }^{\circ} \mathrm{C}, \mathbf{1 5 0} \mathrm{L} / \mathrm{min}$ & $6.03 \times 10^{-11}$ & $1.80 \times 10^{-9}$ & 0.997 \\
\hline $\mathbf{8 0} 0^{\circ} \mathrm{C}, \mathbf{2 5 0} \mathrm{L} / \mathrm{min}$ & $1.90 \times 10^{-10}$ & $1.20 \times 10^{-9}$ & 0.997 \\
\hline
\end{tabular}

\subsubsection{Curvas de Secado y Perfiles de Concentración}

En las Figuras 25, 28-31 se muestran las curvas experimentales con el ajuste obtenido, los cuales se puede apreciar, tienen una excelente concordancia entre ellos. En la Tabla 12 se muestra el coeficiente de correlación, para cada condición de secado.

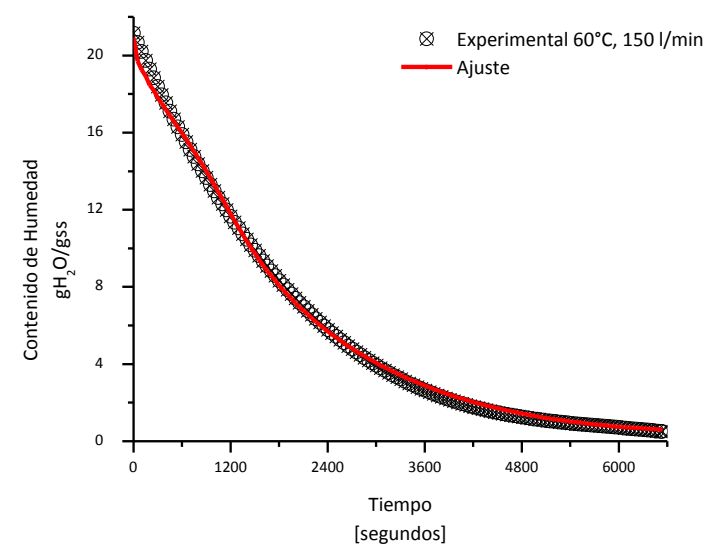

Figura 25. Simulación y datos experimentales de las curvas de secado a $60^{\circ} \mathrm{C}-150 \mathrm{~L} / \mathrm{min}$.

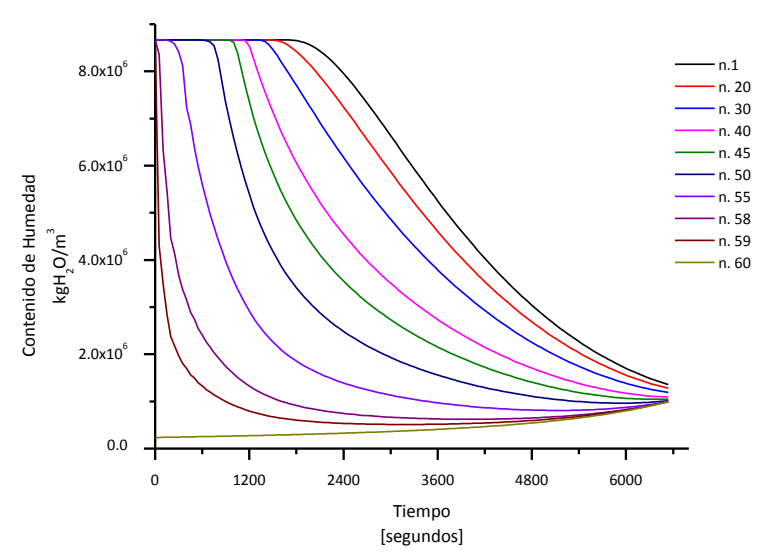

Figura 26. Perfiles de contenido de humedad (b.vol.) $60^{\circ} \mathrm{C}-150 \mathrm{~L} / \mathrm{min}$.

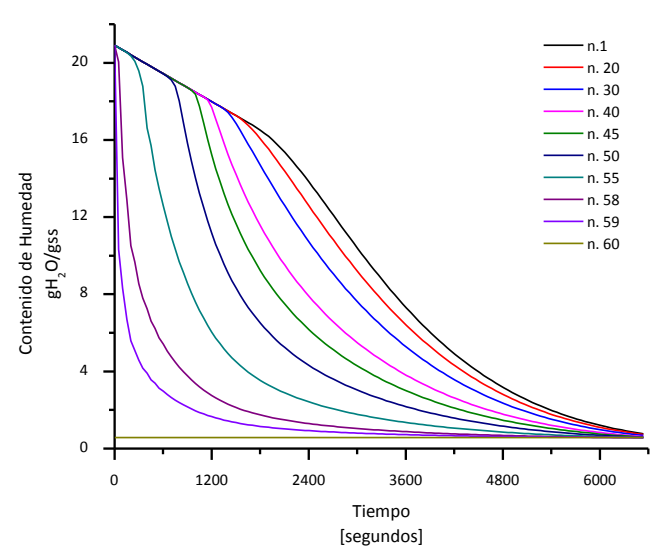

Figura 27 .Perfiles de contenido de humedad (b.s.) a $60{ }^{\circ} \mathrm{C}-150 \mathrm{~L} / \mathrm{min}$

La Figura 26 muestra los perfiles de la concentración contra el tiempo en base volumétrica (b.vol.), los cuales están influenciados en gran parte por la reducción del radio y por lo tanto del volumen. Para el cálculo de las concentraciones, se procede primero a obtener los perfiles de concentración en base volumétrica y la curva promedio, es aquí en donde se incluye en 
efecto del encogimiento medido experimentalmente. Posteriormente se hace el cambio de la concentración $(X)$ a base seca.

En las Figura 27 se muestran los perfiles internos de concentración en base seca, en diferentes puntos del sólido a lo largo del proceso de secado. Siendo el nodo 1 la parte del centro del sólido y el 60 la parte externa de éste. En el Anexo 4 se muestran las gráficas faltantes para cada caso. Se puede observar que en la frontera, $r=R$ (nodo 60), la concentración en base seca se mantienen constante ya que el sistema es isotérmico (ecuación 19).

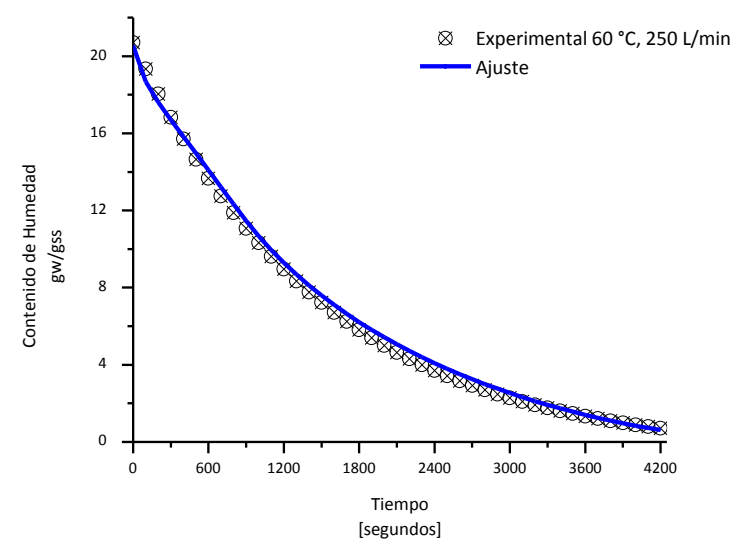

Figura 28. Simulación y datos experimentales de la curva de secado a $60^{\circ} \mathrm{C}-250 \mathrm{~L} / \mathrm{min}$.

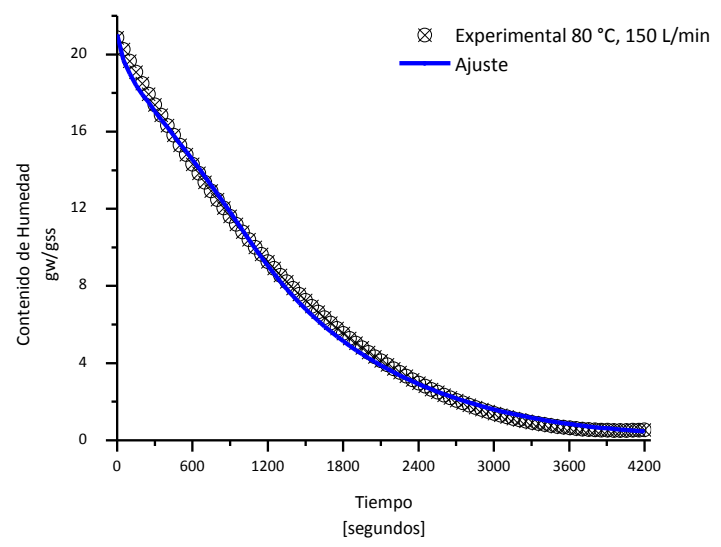

Figura 30. Simulación y datos experimentales de la curva de secado a $80^{\circ} \mathrm{C}-150 \mathrm{~L} / \mathrm{min}$.

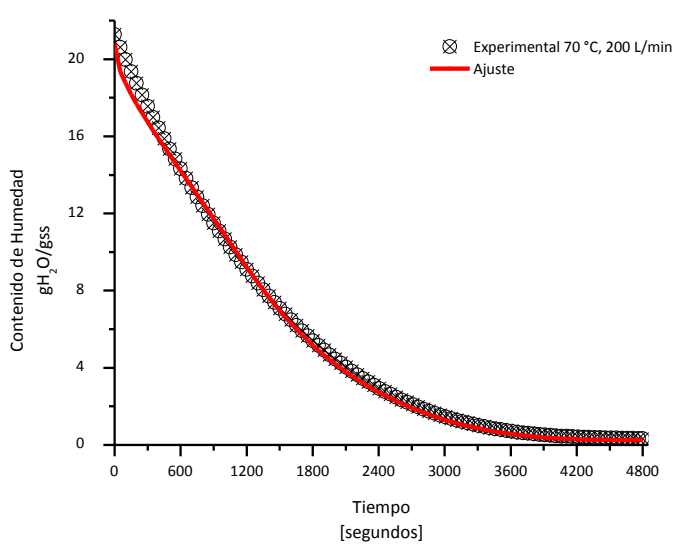

Figura 29. Simulación y datos experimentales de la curva de secado a $70^{\circ} \mathrm{C}-200 \mathrm{~L} / \mathrm{min}$.

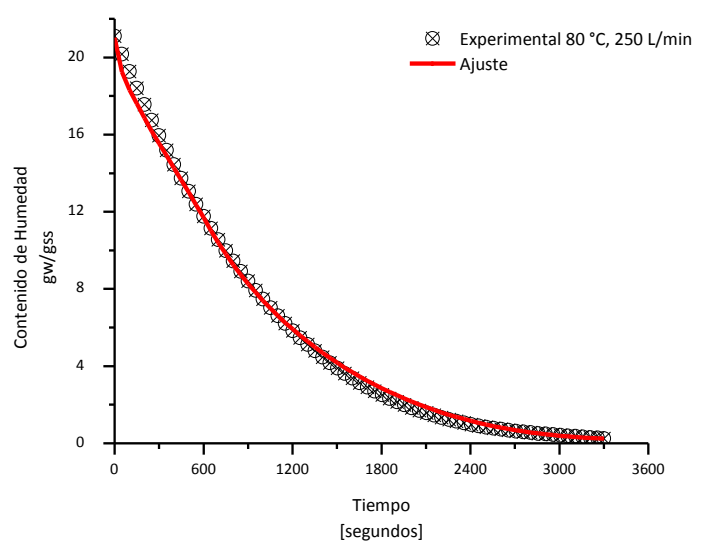

Figura 31. Simulación y datos experimentales de la curva de secado a $80^{\circ} \mathrm{C}-250 \mathrm{~L} / \mathrm{min}$.

Las gráficas 25, 28-31 muestran el ajuste obtenido, en la Tabla 12 se muestran los $\mathrm{R}^{2}$ que están por arriba del 0.996 las cuales pueden ser comparables con las obtenidas con el modelo de Page (Tabla 6), sin embargo están tienen un sustento teórico basado en el modelo de la 2a Ley de Fick. En el Anexo 4, Figuras 37-48 se presentan los perfiles de concentración y los 
coeficientes de difusión para las otras condiciones de secado propuestas en el diseño factorial para este trabajo.

\subsection{Parámetros termodinámicos}

\subsubsection{Actividad de Agua}

A partir de la ecuación (3) se realizó el ajuste de los valores de actividad de agua con respecto al contenido de humedad (b.s.) (medidas a $25^{\circ} \mathrm{C}$ ), esto con el fin de conocer las condiciones de equilibrio del proceso. En la Figura 32 se muestra el ajuste de los puntos experimentales al modelo de GAB, cuyos parámetros se presentan en la Tabla 13, para las otras condiciones de secado se muestran sus isotermas correspondientes en el Anexo 5.

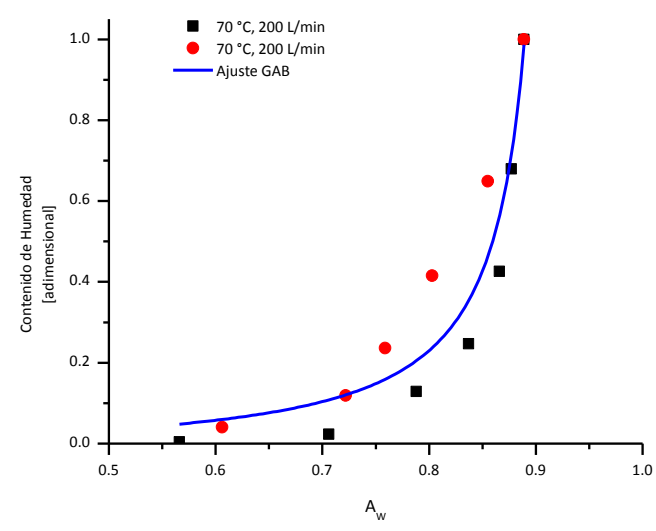

Figura 32. Isoterma del secado a $70^{\circ} \mathrm{C}, 200 \mathrm{~L} / \mathrm{min}$ ajustada al modelo de GAB.

Tabla 13. Valores de las constantes del modelo de GAB para el secado a $70^{\circ} \mathrm{C}$ y $200 \mathrm{l} / \mathrm{min}$.

\begin{tabular}{|ccccc|}
\hline $\begin{array}{c}\text { Condición de } \\
\text { Secado }\end{array}$ & $\begin{array}{c}\mathbf{X}_{\mathbf{0}} \\
\text { [gH } \mathbf{2} \mathbf{O} / \mathbf{g s s}]\end{array}$ & $\mathbf{C}$ & $\mathbf{K}$ & $\mathbf{R}^{\mathbf{2}}$ \\
\hline $\mathbf{7 0}{ }^{\circ} \mathbf{C}, \mathbf{2 0 0} \mathrm{L} / \mathrm{min}$ & 0.03873 & 0.58567 & 1.0834 & 0.90382 \\
\hline
\end{tabular}

\subsubsection{Energía de Activación}

\section{Difusividad Constante}

Los valores calculados de la $D_{\text {ef }}$ como valor constante, para diferentes temperaturas con un flujo de $250 \mathrm{~L} / \mathrm{min}$, se muestran en la Tabla 14. Se puede observar que los valores de la difusividad incrementan al aumentar la temperatura, siendo el valor más alto para la 
temperatura de $80{ }^{\circ} \mathrm{C}$. Los valores de $D_{\text {ef }}$ son similares a los estimados por otros autores para el tomate: $2.3-9.1 \times 10^{-9} \mathrm{~m}^{2} / \mathrm{s}$ para tomates secados en un intervalo de 60 a $110{ }^{\circ} \mathrm{C}$ (Giovanelli y col., 2002), 3.91-7.53×10-10 $\mathrm{m}^{2} / \mathrm{s}$ tomate secado de 55 a $70{ }^{\circ} \mathrm{C}$ (Doymaz, 2005) entre otros. Estos valores de difusividad son consistentes con los estimados en este trabajo.

Tabla 14. Valores de la $D_{\text {ef }}$ a diferentes temperatura con un flujo de $250 \mathrm{l} / \mathrm{min}$.

\begin{tabular}{|cc|}
\hline Temperatura $\left[{ }^{\circ} \mathbf{C}\right]$ & $\mathbf{D}_{\text {ef }}\left[\mathrm{m}^{2} / \mathrm{s}\right]$ \\
\hline $\mathbf{6 0}$ & $8.840 \times 10^{-10}$ \\
\hline $\mathbf{7 0}$ & $1.058 \times 10^{-9}$ \\
\hline $\mathbf{8 0}$ & $1.331 \times 10^{-9}$ \\
\hline
\end{tabular}

El efecto de la temperatura sobre la difusividad puede ser descrito por una ecuación tipo Arrhenius:

$$
D_{e f}=D_{0} \exp \left(-\frac{E_{a}}{R(T+273.15)}\right)
$$

La energía de activación fue calculada graficando el $\mathrm{LnD}_{\text {ef }}$ contra el recíproco de la temperatura $(1 / T+273.15)$, esto es presentado en la Figura 33 .

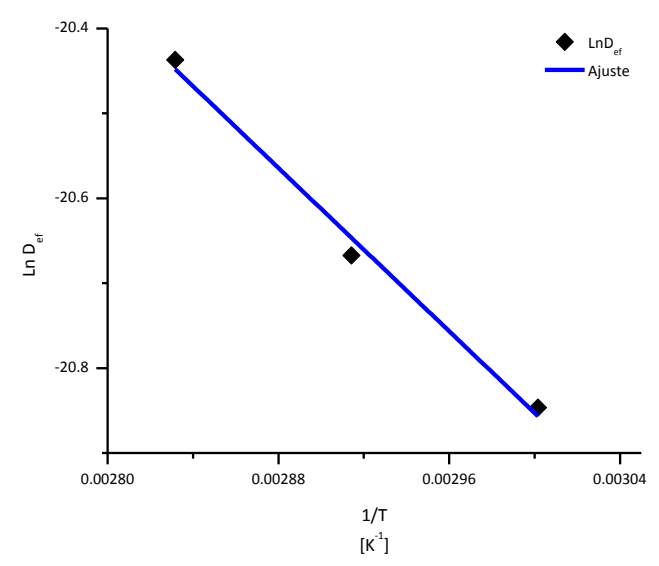

Figura 33. Efecto de la temperatura en el valor de la Difusividad Efectiva.

La $E_{a}$ es una medida de la energía requerida para que el agua libre pueda comenzar a salir del sólido, el valor calculado para el caso de la $D_{\text {ef }}$ constate (sección 4.4), el valor calculado fue de $19.99 \mathrm{~kJ} / \mathrm{mol}$, sustituyendo la ecuación (25) se obtiene la ecuación (26) que representa al 
sistema. Este valor concuerda con los valores reportados por Doymaz (2007) que obtuvó un intervalo de energía de activación de 17.40 a 32.94 kJ/mol.

$$
D_{e f}=1.19 \times 10^{-6} \exp \left(-\frac{19.99}{R(T+273.15)}\right)
$$

\section{Difusividad en función del Contenido de Humedad}

En la sección 4.5 se establecieron dos valores de $D_{\text {ef }}$ para cada condición de secado, que dependían del contenido de humedad. Considerando los casos en lo que se realizó el secado con un flujo de $250 \mathrm{~L} / \mathrm{min}$, se presenta la Tabla 15 retomando los resultados anteriormente presentados, para los dos valores de $D_{\text {ef. }}$

Tabla 15. Valores de la $D_{\text {ef }} f(X)$ a dos temperatura con un flujo de $250 \mathrm{I} / \mathrm{min}$.

\begin{tabular}{|ccc|}
\hline \multirow{2}{*}{ Condiciones de Secado } & \multicolumn{2}{c|}{$D_{\text {ef }}\left[\mathrm{m}^{2} / \mathrm{s}\right]$} \\
& Menor & Mayor \\
\hline $60^{\circ} \mathrm{C}, \mathbf{2 5 0} \mathrm{L} / \mathrm{min}$ & $9.010 \times 10^{-11}$ & $6.000 \times 10^{-10}$ \\
\hline $\mathbf{8 0}{ }^{\circ} \mathrm{C}, \mathbf{2 5 0} \mathrm{L} / \mathrm{min}$ & $1.900 \times 10^{-10}$ & $1.200 \times 10^{-9}$ \\
\hline
\end{tabular}

Las energías de activación fueron calculadas para los valores menores de la $D_{\text {ef }}$ a dos temperaturas (Figura 34) y los para los valores mayores de este coeficiente (Figura 35).

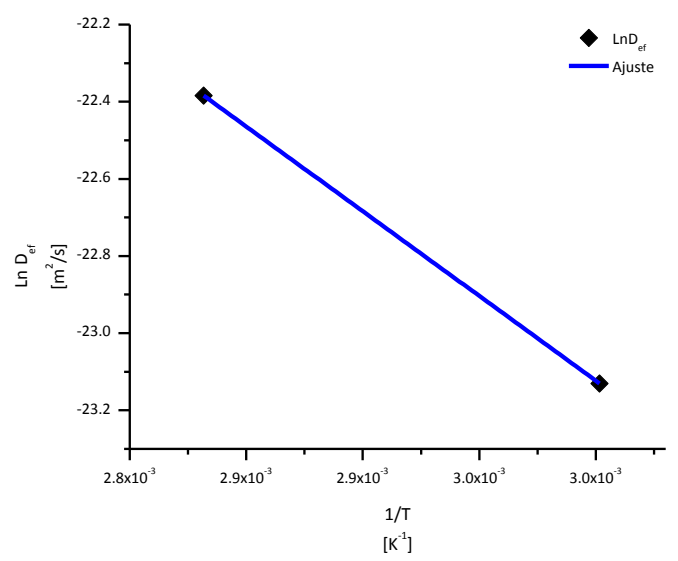

Figura 34. Efecto de la temperatura en el valor bajo de la $D_{\text {ef. }}$

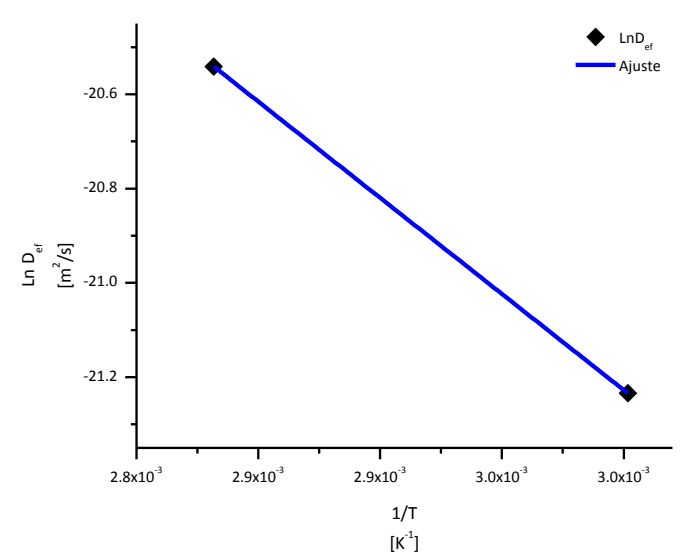

Figura 35. Efecto de la temperatura en el valor alto de la $D_{\text {ef. }}$ 
Las ecuaciones 27 y 28 representan al sistema para bajos y altos valores de la difusividad. Las $E_{a}$ fueron de 36.49 y $33.89 \mathrm{~kJ} / \mathrm{mol}$ respectivamente. Estos valores también muestran la posibilidad de tener dos periodos de secado decrecientes.

$$
\begin{aligned}
& D_{e f}=4.74 \times 10^{-5} \exp \left(-\frac{36.49}{R(T+273.15)}\right) \\
& D_{e f}=1.24 \times 10^{-4} \exp \left(-\frac{33.89}{R(T+273.15)}\right)
\end{aligned}
$$

A pesar de que para obtener la Ea en cada caso solo se consideraron las $D_{\text {ef }}$ de la temperatura menor $\left(60^{\circ} \mathrm{C}\right)$ y las de la mayor $\left(80^{\circ} \mathrm{C}\right)$ del diseño factorial, se esperaría que los valores de las $D_{\text {ef }}$ a $70{ }^{\circ} \mathrm{C}$ se encontraran entre los obtenidos en los extremos, y así las energías de activación fueran cercanas a las ya calculadas.

\subsubsection{Calor Específico}

Los valores experimentales obtenidos, con el método establecido en este trabajo, se hizo un promedio por cada grado de temperatura. En la Figura 36 se muestran los valores experimentales obtenidos, así como el ajuste de los datos a una ecuación polinómica de segundo orden $\left(R^{2}=0.9916\right)$, la cual relaciona el calor específico en función de la temperatura (ecuación 29). La expresión que representa al sistema es:

$$
c p=3.62+0.01 T-6.97 \times 10^{-5} T^{2}
$$

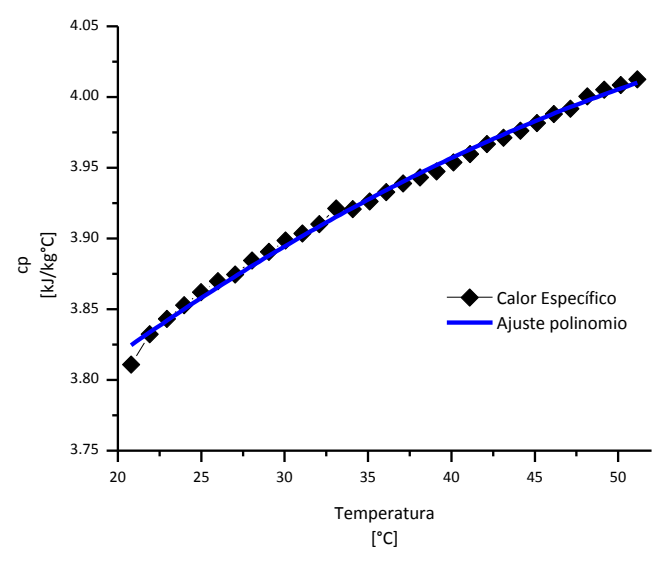

Figura 36. Gráfica del calor específico en función de la Temperatura. 


\section{CONCLUSIONES}

Se analizó experimentalmente el secado de cubos de tomate en balanza de humedad y en túnel de viento. Se encontró que hay diferencias significativas entre estos dos procedimientos de secado, donde el flujo de aire tiene un efecto importante. Esto debido a la ausencia de resistencias externas en el túnel de viento.

Al llevar acabo un diseño factorial $2^{2}$ para estudiar el efecto tanto de la temperatura como del flujo de aire tanto en la cinética de secado como en la tasa de encogimiento para el secado en capa fina de los cubos de tomate en el túnel de viento. Se encontró que ambos factores son significativos para la cinética de secado y también para el caso de la tasa de encogimiento

Sin embargo al utilizar coeficientes constantes, tanto en la solución propuesta por este Hawlader como el de este trabajo, no se logra una descripción adecuada de los datos experimentales, a pesar de que esta última muestra una mayor aproximación. En este caso se parte de una solución analítica a la ecuación de difusión con frontera fija y se modifica para incluir el efecto del encogimiento

Adicionalmente se determinaron coeficientes de difusión en función de la humedad a partir de un procedimiento a prueba y error, introduciendo al modelo la información experimental sobre la tasa de encogimiento. Para mejorar el ajuste se consideró coeficientes de difusión más altos en un cierto intervalo de concentraciones del sólido y más bajos en otro, lo cual podría indicar la existencia de dos períodos de secado decreciente, esta hipótesis es reforzada por los valores obtenidos de le energía de activación, que difieren para cada periodo de secado.

Para cada caso experimental, los dos niveles de $D_{\text {ef }}$ obtenidos se aproximaron mediante una función continua de la concentración. Con los coeficientes de difusión estimados por éste método se logró un excelente ajuste de los datos experimentales ( $R^{2}>.99$ para cada caso). 


\section{TRABAJO A FUTURO}

Extender y proyectar el problema, con el uso de las propiedades termodinámicas obtenidas, a un caso de secado en lecho fluidizado.

Para tener más información sobre el fenómeno del encogimiento es necesario realizar pruebas que permitan obtener información detallada acerca del cambio del área superficial del sólido y su relación con el volumen de este.

Es necesario estudiar y tomar en cuenta el efecto que puedan tener las resistencias externas, y determinar si son significativas. Se podría incluir la búsqueda de resistencias propias del sólido, en este caso la posible formación de costras que limiten la eliminación de humedad.

Aplicar la metodología y estudio realizado en este trabajo, a otras frutas o vegetales con alto contenido de humedad.

Realizar un estudio de los efectos de las condiciones de secado sobre la calidad del producto, basado sobre todo en la retención de licopeno, ya que a este carotenoide se le atribuyen beneficios a la salud. 


\section{BIBLIOGRAFÍA}

Abano, E., Ma, H., \& Qu, W. (2011). Influence of air temperature on the drying kinetics and quality of tomato slices. Journal of Food Process Technologie, 2(123):1-9.

Aguerre, R., Tolaba, M., \& Suarez, C. (2008). Modeling volume changes in food drying and hydration. Latin American Applied Research, 38, 345-349.

Akanbi, C., Adeyemi, R., \& Ojo, A. (2006). Drying characteristics and sorption isotherm of tomato slices. Journal of Food Engineering, 73:157-63.

Akiyama, T., Liu, H., \& Hayakawa, K. (1997). Hygrostress-multicrack formation and propagation in cylindrical viscoelastic food undergoing heat and moisture transfer processes. International Journal of Heat and Mass Transfer, 40(7), 1601-1609.

Akpinar, E., \& Bicer, Y. (2005). Modeling of the drying of eggplants in thin-layers. International Journal of Food Science and Technology, 273-281.

Andritsos, N., Dalampakis, P., \& Kolios, N. (2003). Use of geothermal energy for tomato energy. GMC Bulletin, 9-13.

AOAC. (1990). Official methods of analysis. Washington DC: Association of Official Analytical Chemists.

Askari, G., Emam-Djomeh, Z., \& M., T. (2009). Effect of various drying methods on texture and color of tomato halves. Journal of Texture Studies, 40(4):371-89.

Bizot, H., Buleon, A., N., M.-R., \& Multon, J. (1985). Some Facts Concerning Water Vapour Sorption On Potato Starch . En D. Simato, \& J. Multon, Properties of Water in Foods (págs. 83-93). Dordrecht, Netherlands: Martinus Nijhoff Publishers.

Bouaziz, N., \& Belghith, A. (1998). Heat and mass transfer during the convective drying: from the sample behaviour to the dryer project. Proceedings of the 11th international symposium, $A$, 118-125.

Brennan, J., Butters, J., Cowell, N., \& Lilly, A. (1970). Las operaciones de la ingeniería de los alimentos. España: Acribia.

Brennan, J., J.R., B., Cowell, N., \& Lilly, A. (1986). Las operaciones de la ingeniería en alimentos. España: Acribia.

Brooks, M., Abou El-Hana, N., \& Ghaly, A. (2008). Effects of Tomato Geometries and Air Temperature on the Drying Behavior of Plum Tomato. American Journal of Applied Sciences, 1369-1375.

Chang, C., Lin, H., Chan, C., \& Liu, Y. (2006). Comparisons on the antioxidant properties of fresh, freezedried and hot-air-dried tomatoes. Journal of Food Engineering, 77, 478-485.

Chen, X. (2007). Moisture diffusivity in food and biological materials. Dryin Technologie, 25(7-8):120313. 
Crank, J. (1979). The Mathematics of Diffusion (Segunda ed.). Oxford: Oxford University Press.

Demiray, E., \& Tulek, Y. (2012). Thin-layer drying of tomato (Lycopersicum esculentum Mill. cv. Rio Grande) slices in a convective hot air dryer. Heat and Mass Transfer, 48(5):841-7.

Doymaz, I. (2005). Drying characteristics and kinetics of okra. Journal of Food Engineering, 69, 275-279.

Doymaz, I. (2007). Air-drying characteristics of tomatoes. Journal of Food Engineering, 78, 1291-1297.

Durance, T., \& Wang, J. (2002). Energy consumption, density and rehydration rate of vacuum microwave and hot-air convection dehydrated tomatoes. Journal of Food Science(67), 22122216.

Earle, R. L. (1996). Unit operations in food processing. London: Perganion Press.

Ertekin, C., \& Yaldiz, O. (2004). Drying of eggplant and selection of a suitable thin layer drying model. Journal of Food Engineering, 349-359.

Ertekin, C., \& Yaldiz, O. (2004). Drying of eggplant and selection of a suitable thin layer drying model. Journal of Food Engineering, 63, 349-359.

Félix, A., Robles, T., Santiago, P., \& Vizcarra, M. (1988). Estudio de la Ingeniería de la deshidratación de papa en un secador intermitente de lecho fluidizado. Avances de la ingeniería química de la Universidad Autónoma de Chapingo, 762-777.

Fennema, O. R. (1996). Food Chemistry (Vol. 3a. ). Marcel Dekker Inc.

Foust, A., \& Wenzel, L. (1998). Transferencia simultánea de calor y masa- secado. En Principio de operaciones unitarias. México: CECSA.

Gabas, A. L., Menegalli, F. C., \& Telis-Romero, J. (1999). Effect of chemical pretreatment on the physical properties of dehydrated grapes. Drying Technology, 17(6), 1215-1226.

Gaware, T., Suta, r. N., \& Thorat, B. (2010). Drying of tomato using different methods: comparison of dehydration and rehydration kinetics. Drying Technology, 28(5):651-8.

Geankoplis, C. (1998). Procesos de transporte y operaciones unitarias (3a ed. ed.). México: CECSA.

Gekas, V., \& Lamberg, I. (1991). Determination of difussion coefficients in volume-change systemsApplication in the case of potato drying. Journal of Food Engineering, 14, 317-326.

Giovanelli, G., Zanoni, B., Lavelli, V., \& Nani, R. (2002). Water sorption, drying and antioxidant properties of dried tomato products. Journal of Food Engineering, 52, 135-141.

Hatamipour, M., \& Mowla, D. (2003). Correlations for shrinkage, density and diffusivity for drying of maize and green peas in a fluidized bed with energy carrier. Journal of food Engineering, 59:221-227. 
Hawlader, M., Ho, J., \& Zhang, Q. (1999). A mathematical model for drying of shrinking materials. Drying Technology, 17: 27-47.

Hossain, M., \& Gottschalk, K. (2009). Single layer drying characteristics of half fruit tomato. International Journal of Food Properties, 12(4):871-84.

Hougen, O. A., McCauley, H. J., \& Marshal, W. R. (1940). Transactions of the American Institute of Chemical Engineers, 183.

Hussein, E. (1994). On the limitations of the diffusion equation. Dev Chemical Eng Mineral Process, 2(2-3):149-57.

Jangam, S. V., Law, C. L., \& Mujumdar, A. S. (2010). Drying of Foods, Vegetables and Fruits.

Kaleemullah, S., \& Kailappan, R. (2005). Drying kinetics of red chilies in rotary dryer. Biosystems Engineering, 92, 15-23.

Kaleta, A., \& Górnicki, K. (2010). Some remarks on evaluation of drying models of red beet particles. Energy Conversion and Management, 51: 2967-2978.

Kaya, S., \& Oner, M. (1996). Water activity and moisture sorption isotherms of aziantep cheese. Journal Of Food Quality, 121-132.

Khalloufi, S., Almeida-Rivera, C., Janssen, J., \& Bongers, P. (2012). Pseudo-linearity of the shrinkage coefficient and a sensitivity study of collapse and shrinkage functions. Food Research International, 48, 808-819.

Khazaei, J., Chegini, G. R., Chegini, \& Bakhshiani, M. (2008). A Novel Alternative Method for Modeling the Effects of Air Temperature and Slice Thickness on Quality and Drying Kinetics of Tomato Slices: Superposition Technique. Drying Technology: An International Journal, 26, 759-775.

Kulanthaisami, S., Rajkumar, P., Venkatachalam, P., Subramanian, P., Raghavan, G., Gariepy, Y., y otros. (2010). Drying kinetics of tomato slices in solar cabinet dryer compared with open sun drying. Journal, 97(7-9):287-95.

Labuza, T. P. (1968). Sorption Phenomena in Foods. Food Technology, 22(3), 15-20.

Labuza, T. P. (1980). The effect of water activity on reaction kinetics of food deterioration. Food Technology, 34, 36-41.

Landau, H. (1950). Heat conduction in a melting solid. Quarterly of Applied Mathematics, 81-94.

Lewicki, P., Le, H., \& Pomaranska, W. (2002). Effect of pre-treatment on convective drying of tomatoes. Journal of Food Engineering, 54:141-146.

Liu, G. C., Liu, M., \& Wan, X. (2012). Shrinkage, porosity and densitybehaviour during convectivedrying of bio-porous material. Procedia Engineering, 31:634-640. 
Lozano, J. E., Rotstein, E., \& Urbicain, M. J. (1980). Total porosity and open-pore porosity in the drying of fruits. Journal of Food Science, 45, 1403-1407.

Lozano, J. E., Rotstein, E., \& Urbicain, M. J. (1983). Shrinkage, porosity and bulk density of foodstuffs at changing moisture contents. Journal of Food Science, 48, 1497-1502, 1553.

Machado, M., Oliveira, F., \& Cunha, L. (1999). Effect of milk fat and total solids concentration on the kinetics of moisture uptake by readyto- eat breakfast cereal. International Journal of Food Science and Technology, 34, 47-57.

Maskan, M., \& Gogus, F. (1998). Sorption isotherms and drying characteristics of mulberry (Morus alba). Journal of Food Engineering, 37, 437-449.

Mayor, L., \& Sereno, A. (2004). Modelling shrinkage during convective drying of food materials: a review. Journal of Food Engineering, 61, 373-386.

Mayor, L., \& Sereno, A. (2004). Modelling shrinkage during convective drying of food materials: a review. Journal of Food Engineering, 61, 373-386.

McCabe, W. L., Smith, J. C., \& Harriott, P. (1991). Operaciones Unitarias en Ingeniería Química. Madrid: McGraw-Hill.

McMinn, W. (2006). Thin-layer modeling of the convective, microwave, microwave-convective and microwave-vacuum drying of lactose powder. Journal of Food Engineering, 72, 113-123.

Mcminn, W. A., \& Magee, T. R. (1997). Physical characteristics of dehydrated potatoes-Part I. Journal of Food Engineering, 33, 37-48.

Misra, R. N., \& Young, J. H. (1980). Numerical solution for simultaneous moisture diffusion and shrinkage during soybean drying. Transactions of the ASAE, 1277-1282.

Movagharnejad, K., \& Nikzad, M. (2007). Modeling of tomato drying using artificial neural network. Computers and Electronics in Agriculture, 59(1-2):78-85.

Mujumdar, A. S. (2000). Fundamental principles of drying. Montreal: Dvahastin S.

Mulet, A., Tarrazo, J., García-Reverter, J., \& Berna, A. (1997). Shrinkage of cauliflower florets and stems during drying. En R. (. Jowitt, Engineering and food at ICEF 7 (págs. 97-100). Sheffield, UK: Sheffield Academic Press.

Okos, M. R., Narsimhan, G., Singh, R. K., \& Witnauer, A. C. (1992). Food dehydration. En D. R. Heldman, \& D. B. Lund, Handbook of food engineering. New York: Marcel Dekker.

Ozdemir, M., \& Devres, Y. (1999). he thin layer drying characteristics of hazelnuts during roasting. Journal of Food Engineering, 42, 225-233.

Perry, R. (1992). Manual del ingeniero químico (Sexta edición ed., Vol. II). México: McGraw Hill. 
Queiroz, M. R., \& Nebra, S. A. (2001). Theoretical and experimental analysis of the drying kinetics of bananas. Journal of Food Engineering, 47, 127-132.

Rahman, M. S. (2001). Toward prediction of porosity in foods during drying: A brief review. Drying Technology, 19, 1-13.

Rahman, M. S. (2003). A theoretical model to predict the formation of pores in foods during drying. International Journal of Food Properties, 6, 61-72.

Rahman, M. S., Perera, C. O., Chen, X. D., Driscoll, R. H., \& Potluri, P. (1996). Density, shrinkage and porosity of Calamari Mantle Meat during air drying in a cabinet dryer as a function of water content. Journal of Food Engineering, 30, 135-145.

Rajkumar, P., Kulanthaisami, S., Raghavan, G., Gariépy, Y., \& Orsat, V. (2007). Drying kinetics of tomato slices in vacuum assisted solar and open sun drying methods. Drying Technology, 1349-1357.

Ratti, C. (1994). Shrinkage during drying of foodstuffs. Journal of Food Engineering, 23, 91-105.

Rivera Bahena, D. (2007). Evaluación de la deshidratación de jitomate (Licopersicum esculentum), con atemperado en lecho vibrofluidizado, considerando la retención de licopeno como parámetro de calidad. México, D.F.: Escuela Nacional de Ciencias Biológicas, IPN.

Rizvi, S. S., \& Benado, A. L. (1984). Thermodynamics properties of dehydrated food. Food Technology, 83-92.

Rovedo, C. O., Suárez, C., \& Viollaz, P. E. (1997). Kinetics of forced convective air drying of potato and squash slabs. Food Science and Technology International, 3, 251-261.

Sacilik, K., Keskin, R., \& Elicin, A. (2006). Mathematical modelling of solar tunnel drying of thin layer organic tomato. Journal of Food Engineering, 73, 231-238.

Sacilik, K., Keskin, R., \& Elicin, K. (2006). Mathematical modeling of solar tunnel drying of thin layer organic tomato. Journal of Food Engineering, 73, 231-238.

SAGARPA. (2010). Monografía de Cultivos: Jitomate. Subsecretaría de Fomento a los Agronegocios.

Sahin, A., \& Dincer, I. (2005). Prediction of drying times for irregular shaped multi-dimensional objects. Journal of Food Engineering, 71, 119-126.

Saravacos, G., \& Maroulis, Z. (2001). Transport properties of foods. New York: Marcel Decker Inc.

Schultz, E., Mazzuco, M., Machado, R., \& Bolzan, A. (2007). Effect of pre-treatments on drying, density and shrinkage of apple slices. Journal of food Engineering, 78:1103-1110.

Shi, J., Le Maguer, M., Y., K., Liptay, A., \& Niekamp, F. (1999). Lycopene degradation and isomerization in tomato dehydration. Food Research International, 32:15-21. 
Simal, S., Mulet, A., Catalá, P., \& Rosselló, C. (1996). Moving boundary model for simultaneous moisture movement in grapes. Journal of Food Science, 61: 157-160.

Solís, C., Usami, O., Kirchner, S., Orozco, L., Atilano, D., Medina, F., y otros. (1989). Elaboración de frutas y ortalizas (Segunda Ed. ed.). Mexico: Trillas-SEP.

Souraki, B. A., \& Mowla, D. (2008). Axial and radial moisture diffusivity in cylindrical fresh green beans in a fluidized bed dryer with energy carrier: Modeling with and without shrinkage. Journal of Food Engineering, 88, 9-19.

Souza, J., Medeiros, M., Magalhaes, M., Rodrigues, S., \& Fernandes, F. (2007). Optimization of osmotic dehydration of tomatoes in a ternary system followed by air-drying. Journal of Food Engineering, 83(4):501-9.

St George, S., Cenkowski, S., \& Muir, W. (2004). A review of drying technologies for the preservation of nutritional compounds in waxy skinned fruit. North Central ASAE/CSAE Conference (págs. 2425). Winnipeg, Manitoba, Canada: 24-25.

Suvarnakuta, P., Devahastin, S., \& Mujumdarc, A. S. (2007). A mathematical model for low-pressure superheated steam drying of a biomaterial. Chemical Engineering and Processing: Process Intensification, 46: 675-683.

Toor, R., \& Savage, G. (2006). Effect of semi-drying on the antioxidant components of tomatoes. Food Chemistry, 94, 90-97.

Treybal, R. (1988). Mass transfer operations (Segunda edición ed.). USA: McGraw Hill.

Treybal, R. (1993). Mass transfer operations (Segunda edición ed.). USA: McGraw Hill.

Uddin, M., Hawlader, M., \& M.S., R. (1990). Evaluation of drying characteristics of pineapple in the production of pineapple powder. Journal of Food Processing and Preservation, 14, 375-91.

Vagenas, G. K., \& Marinos-Kouris, D. (1991). Drying kinetics of apricots. Drying Technology, 9(3), 735752.

Viollaz, P., \& Suarez, C. (1985). Drying of shrinking bodies. American Institute of Chemical Engineering Journal, 31, 1566-1568.

Wang, L., \& Sun, D. (2003). Recent developments in numerical modeling of heating and cooling process in the food industry-a review. Trends Food, 14:408-23.

Wang, N., \& Brennan, J. G. (1995). Changes in structure, density and porosity of potato during dehydration. Journal of Food Engineering, 24(1), 61-76.

Wei, X., Jing, D., \& Yi, Z. (2006). Volume Shrinkage Characteristics of Porous M aterials in Drying Process. Journal of South China University of Technology , 34(8):61-65. 
Yaldiz, O., \& Ertekin, C. (2001). Thin layer solar drying of some different vegetables. Drying Technologie, 19, 583-596.

Yong, C. K., Islam, M., \& Mujumdar, A. (2006). Mechanical means of enhancing drying rates: Effect on drying kinetics and quality. Drying Technology, 24, 397-404.

Zanoni, B., Peri, C., Nani, R., \& Lavelli, V. (1999). Oxidative heat damage of tomato halves as affected by drying. Food Research International, 31(5):395-401.

Zeng, L., Zhao, S., \& Xiong, S. (2008). Modeling and moisture diffusion properties of salted silver carp during hot-air drying. Transactions of the Chinese society of agricultural engineering, 2008,24(7):280-283.

Zielinska, M., \& Markowski, M. (2007). Drying behavior of carrots dried in a spout-fluidized bed dryer. Drying Technology, 25, 261-270.

Zogzas, N. P., Maroulis, Z. B., \& Marinos-Kouris, D. (1994). Densities, shrinkage and porosity of some vegetables during air drying. Drying Technology, 12(7), 1653-1666. 


\section{ANEXOS}

\section{Anexo 1}

\section{Escaldado}

El escaldado es un tratamiento térmico importante para la preparación de legumbres destinadas al enlatado, congelación o deshidratación. El escaldado se lleva a cabo para inactivar enzimas o destruir los sustratos de las enzimas como los peróxidos. El escalde se lleva a cabo calentando el alimento rápidamente hasta una temperatura predeterminada, manteniéndolo a esta temperatura durante un tiempo igualmente predeterminado, la temperatura y tiempo depende de la especie, de su estado de madurez y de su tamaño, luego se enfría rápidamente o se turna al siguiente proceso de manufactura sin hacer una interrupción en el tiempo. El escaldado por inmersión se lleva a cabo pasando el alimento a velocidad controlada, a través de un tambor perforado contenido en un depósito de agua con temperatura de escalde $\left(75-95^{\circ} \mathrm{C}\right)$ controlada (Brennan y col., 1970) (Solís y col., 1989).

El escaldado produce los siguientes cambios:

- Limpia la materia prima y reduce la cantidad de bacterias.

- Los gases celulares se desprenden, con lo que se reduce la corrosión de los envases y facilita la obtención del vacío en la parte superior durante el enlatado.

- Puede mejorar la textura especialmente de los productos deshidratados.

- Inactivación de enzimas, lo cual mejora la calidad del producto, reduciendo los cambios indeseables de sabor y color.

- Fijación y acentuación del color natural.

- Desarrollo del sabor característico.

- Eliminación de una parte del agua contenida en los tejidos. 


\section{Anexo 2}

Datos Experimentales Tunel de Secado para el diseño factorial propuesto

\begin{tabular}{|c|c|c|c|c|c|}
\hline $\begin{array}{l}\text { Temperatura= } \\
\text { Flujo de Aire= }\end{array}$ & $\begin{array}{c}60 \\
150 \\
\end{array}$ & $\begin{array}{c}{ }^{\circ} \mathrm{C} \\
\mathrm{L} / \mathrm{min}\end{array}$ & $\begin{array}{l}\text { Temperatura= } \\
\text { Flujo de Aire= }\end{array}$ & $\begin{array}{c}60 \\
250\end{array}$ & $\begin{array}{l}{ }^{\circ} \mathrm{C} \\
\mathrm{L} / \mathrm{min}\end{array}$ \\
\hline Masa seca= & 0.229 & g & Masa seca= & 0.230 & g \\
\hline $\begin{array}{l}\text { tiempo } \\
\text { segundos }\end{array}$ & $\begin{array}{l}\text { Peso } \\
\text { gramos }\end{array}$ & $\begin{array}{c}X \\
g_{\mathrm{H} 2 \mathrm{O} / g s \mathrm{gS}}\end{array}$ & $\begin{array}{l}\text { tiempo } \\
\text { segundos }\end{array}$ & $\begin{array}{c}\text { Peso } \\
\text { gramos }\end{array}$ & $\begin{array}{c}X \\
g_{\mathrm{H} 2 \mathrm{O}} / \mathrm{gss}\end{array}$ \\
\hline 0 & 5.03 & 20.908 & 0 & 5.05 & 20.908 \\
\hline 60 & 4.98 & 20.690 & 60 & 4.8 & 19.823 \\
\hline 120 & 4.88 & 20.254 & 120 & 4.64 & 19.129 \\
\hline 180 & 4.75 & 19.688 & 180 & 4.45 & 18.305 \\
\hline 240 & 4.63 & 19.166 & 240 & 4.27 & 17.524 \\
\hline 300 & 4.51 & 18.643 & 300 & 4.11 & 16.830 \\
\hline 360 & 4.38 & 18.077 & 360 & 3.93 & 16.049 \\
\hline 420 & 4.25 & 17.510 & 420 & 3.77 & 15.355 \\
\hline 480 & 4.12 & 16.944 & 480 & 3.61 & 14.661 \\
\hline 540 & 3.98 & 16.334 & 540 & 3.5 & 14.183 \\
\hline 600 & 3.87 & 15.855 & 600 & 3.36 & 13.576 \\
\hline 660 & 3.74 & 15.289 & 660 & 3.24 & 13.056 \\
\hline 720 & 3.63 & 14.810 & 720 & 3.11 & 12.492 \\
\hline 780 & 3.53 & 14.375 & 780 & 3.01 & 12.058 \\
\hline 840 & 3.43 & 13.939 & 840 & 2.89 & 11.537 \\
\hline 900 & 3.32 & 13.460 & 900 & 2.8 & 11.147 \\
\hline 960 & 3.23 & 13.068 & 960 & 2.68 & 10.626 \\
\hline 1020 & 3.13 & 12.632 & 1020 & 2.58 & 10.192 \\
\hline 1080 & 3.05 & 12.284 & 1080 & 2.49 & 9.802 \\
\hline 1140 & 2.95 & 11.848 & 1140 & 2.41 & 9.455 \\
\hline 1200 & 2.89 & 11.587 & 1200 & 2.32 & 9.064 \\
\hline 1260 & 2.79 & 11.151 & 1260 & 2.22 & 8.630 \\
\hline 1320 & 2.71 & 10.803 & 1320 & 2.12 & 8.197 \\
\hline 1380 & 2.63 & 10.455 & 1380 & 2.08 & 8.023 \\
\hline 1440 & 2.56 & 10.150 & 1440 & 1.98 & 7.589 \\
\hline 1500 & 2.49 & 9.8452 & 1500 & 1.93 & 7.372 \\
\hline 1560 & 2.42 & 9.540 & 1560 & 1.84 & 6.982 \\
\hline 1620 & 2.33 & 9.148 & 1620 & 1.79 & 6.765 \\
\hline 1680 & 2.28 & 8.930 & 1680 & 1.71 & 6.418 \\
\hline 1740 & 2.21 & 8.625 & 1740 & 1.64 & 6.114 \\
\hline 1800 & 2.14 & 8.320 & 1800 & 1.58 & 5.854 \\
\hline 1860 & 2.07 & 8.015 & 1860 & 1.51 & 5.550 \\
\hline 1920 & 2.01 & 7.754 & 1920 & 1.47 & 5.377 \\
\hline 1980 & 1.96 & 7.536 & 1980 & 1.42 & 5.160 \\
\hline 2040 & 1.89 & 7.231 & 2040 & 1.36 & 4.900 \\
\hline 2100 & 1.83 & 6.970 & 2100 & 1.31 & 4.683 \\
\hline 2160 & 1.78 & 6.752 & 2160 & 1.25 & 4.422 \\
\hline 2220 & 1.74 & 6.578 & 2220 & 1.21 & 4.249 \\
\hline
\end{tabular}




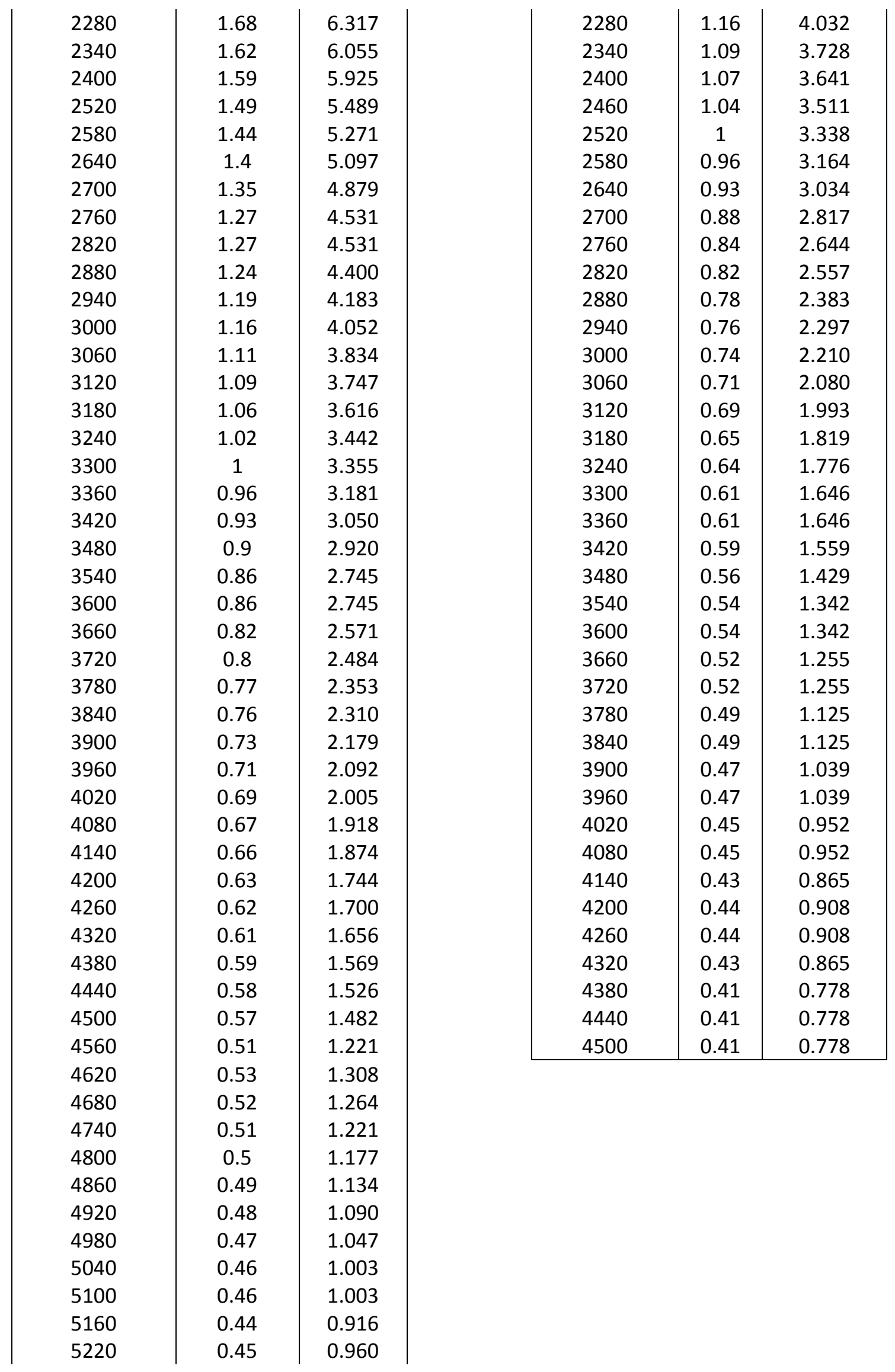




\begin{tabular}{|c|c|c|c|c|c|c|c|c|c|}
\hline 5280 & & 0.42 & 0.829 & & & & & & \\
\hline 5340 & & 0.45 & 0.960 & & & & & & \\
\hline 5400 & & 0.43 & 0.872 & & & & & & \\
\hline 5460 & & 0.42 & 0.829 & & & & & & \\
\hline 5520 & & 0.42 & 0.829 & & & & & & \\
\hline 5580 & & 0.42 & 0.829 & & & & & & \\
\hline 5640 & & 0.41 & 0.785 & & & & & & \\
\hline 5700 & & 0.41 & 0.785 & & & & & & \\
\hline 5760 & & 0.4 & 0.742 & & & & & & \\
\hline 5820 & & 0.43 & 0.872 & & & & & & \\
\hline 5880 & & 0.39 & 0.698 & & & & & & \\
\hline 5940 & & 0.4 & 0.742 & & & & & & \\
\hline 6000 & & 0.39 & 0.698 & & & & & & \\
\hline 6060 & & 0.39 & 0.698 & & & & & & \\
\hline 6120 & & 0.38 & 0.655 & & & & & & \\
\hline 6300 & & 0.38 & 0.655 & & & & & & \\
\hline 6420 & & 0.37 & 0.611 & & & & & & \\
\hline 6480 & & 0.37 & 0.611 & & & & & & \\
\hline 6540 & & 0.36 & 0.568 & & & & & & \\
\hline $\begin{array}{l}\text { Temp.= } \\
\text { Flujo = }\end{array}$ & $\begin{array}{c}70 \\
200 \\
\end{array}$ & $\begin{array}{c}{ }^{\circ} \mathrm{C} \\
\mathrm{L} / \mathrm{min}\end{array}$ & & $\begin{array}{c}\text { Temp.= } \\
\text { Flujo= }\end{array}$ & $\begin{array}{c}70 \\
200 \\
\end{array}$ & $\begin{array}{c}{ }^{\circ} \mathrm{C} \\
\mathrm{L} / \mathrm{min}\end{array}$ & $\begin{array}{l}\text { Temp.= } \\
\text { Flujo = }\end{array}$ & $\begin{array}{c}70 \\
200 \\
\end{array}$ & $\begin{array}{c}{ }^{\circ} \mathrm{C} \\
\mathrm{L} / \mathrm{min} \\
\end{array}$ \\
\hline M.seca= & 0.230 & g & & M.seca= & 0.229 & g & M.seca= & 0.232 & g \\
\hline \begin{tabular}{c|} 
tiempo \\
segundos
\end{tabular} & $\begin{array}{c}\text { Peso } \\
\text { gramos }\end{array}$ & $\begin{array}{c}\mathrm{X} \\
\mathrm{g}_{\mathrm{H} 2 \mathrm{O}} / \mathrm{gSS}\end{array}$ & & \begin{tabular}{|c|} 
tiempo \\
segundos
\end{tabular} & $\begin{array}{c}\text { Peso } \\
\text { gramos }\end{array}$ & \begin{tabular}{|c|}
$X$ \\
$\mathrm{~g}_{\mathrm{H} 2 \mathrm{O}} / \mathrm{gSS}$ \\
\end{tabular} & \begin{tabular}{|c|} 
tiempo \\
segundos
\end{tabular} & $\begin{array}{c}\text { Peso } \\
\text { gramos }\end{array}$ & \begin{tabular}{|c|}
$\mathrm{X}$ \\
$\mathrm{g}_{\mathrm{H} 2 \mathrm{O}} / \mathrm{gsS}$ \\
\end{tabular} \\
\hline 0 & 5.05 & 20.908 & & 0 & 5.03 & 20.908 & 0 & 5.09 & 20.908 \\
\hline 60 & 4.97 & 20.561 & & 60 & 5.02 & 20.864 & 60 & 4.98 & 20.434 \\
\hline 120 & 4.81 & 19.867 & & 120 & 4.82 & 19.993 & 120 & 4.77 & 19.530 \\
\hline 180 & 4.63 & 19.086 & & 180 & 4.59 & 18.991 & 180 & 4.55 & 18.584 \\
\hline 240 & 4.46 & 18.348 & & 240 & 4.46 & 18.425 & 240 & 4.35 & 17.723 \\
\hline 300 & 4.31 & 17.697 & & 300 & 4.36 & 17.990 & 300 & 4.17 & 16.948 \\
\hline 360 & 4.13 & 16.917 & & 360 & 4.09 & 16.814 & 360 & 4.04 & 16.388 \\
\hline 420 & 3.97 & 16.222 & & 420 & 3.97 & 16.291 & 420 & 3.84 & 15.528 \\
\hline 480 & 3.84 & 15.658 & & 480 & 3.82 & 15.638 & 480 & 3.71 & 14.968 \\
\hline 540 & 3.67 & 14.921 & & 540 & 3.69 & 15.071 & 540 & 3.56 & 14.322 \\
\hline 600 & 3.53 & 14.314 & & 600 & 3.54 & 14.418 & 600 & 3.44 & 13.806 \\
\hline 660 & 3.39 & 13.706 & & 660 & 3.43 & 13.939 & 660 & 3.32 & 13.289 \\
\hline 720 & 3.25 & 13.099 & & 720 & 3.3 & 13.373 & 720 & 3.27 & 13.074 \\
\hline 780 & 3.13 & 12.578 & & 780 & 3.17 & 12.807 & 780 & 3.11 & 12.386 \\
\hline 840 & 2.99 & 11.971 & & 840 & 3.03 & 12.197 & 840 & 3.01 & 11.955 \\
\hline 900 & 2.88 & 11.494 & & 900 & 2.96 & 11.892 & 900 & 2.86 & 11.309 \\
\hline 960 & 2.75 & 10.930 & & 960 & 2.82 & 11.282 & 960 & 2.76 & 10.879 \\
\hline 1020 & 2.65 & 10.496 & & 1020 & 2.69 & 10.716 & 1020 & 2.68 & 10.535 \\
\hline 1080 & 2.54 & 10.019 & & 1080 & 2.55 & 10.106 & 1080 & 2.6 & 10.190 \\
\hline 1140 & 2.43 & 9.542 & & 1140 & 2.49 & 9.845 & 1140 & 2.45 & 9.545 \\
\hline 1200 & 2.33 & 9.108 & & 1200 & 2.37 & 9.322 & 1200 & 2.34 & 9.071 \\
\hline 1260 & 2.23 & 8.674 & & 1260 & 2.3 & 9.017 & 1260 & 2.26 & 8.727 \\
\hline 1320 & 2.14 & 8.283 & & 1320 & 2.23 & 8.712 & 1320 & 2.16 & 8.297 \\
\hline 1380 & 2.04 & 7.850 & & 1380 & 2.12 & 8.233 & 1380 & 2.05 & 7.823 \\
\hline
\end{tabular}




\begin{tabular}{|c|c|c|}
1440 & 1.94 & 7.416 \\
1500 & 1.87 & 7.112 \\
1560 & 1.79 & 6.765 \\
1620 & 1.71 & 6.418 \\
1680 & 1.62 & 6.028 \\
1740 & 1.55 & 5.724 \\
1800 & 1.48 & 5.420 \\
1860 & 1.4 & 5.073 \\
1920 & 1.35 & 4.856 \\
1980 & 1.29 & 4.596 \\
2040 & 1.23 & 4.336 \\
2100 & 1.17 & 4.075 \\
2160 & 1.1 & 3.772 \\
2220 & 1.06 & 3.598 \\
2280 & 1.01 & 3.381 \\
2340 & 0.96 & 3.164 \\
2400 & 0.92 & 2.991 \\
2460 & 0.87 & 2.774 \\
2520 & 0.83 & 2.600 \\
2580 & 0.8 & 2.470 \\
2640 & 0.74 & 2.210 \\
2700 & 0.72 & 2.123 \\
2760 & 0.68 & 1.950 \\
2820 & 0.66 & 1.863 \\
2880 & 0.62 & 1.689 \\
2940 & 0.6 & 1.603 \\
3000 & 0.57 & 1.472 \\
3060 & 0.55 & 1.386 \\
3120 & 0.52 & 1.255 \\
3180 & 0.51 & 1.212 \\
3240 & 0.49 & 1.125 \\
3300 & 0.47 & 1.039 \\
3360 & 0.45 & 0.952 \\
420 & 0.43 & 0.865 \\
3480 & 0.42 & 0.822 \\
3540 & 0.41 & 0.778 \\
3600 & 0.39 & 0.691 \\
3660 & 0.38 & 0.648 \\
3720 & 0.37 & 0.605 \\
3780 & 0.37 & 0.605 \\
3840 & 0.35 & 0.518 \\
3900 & 0.35 & 0.518 \\
3960 & 0.34 & 0.475 \\
4020 & 0.34 & 0.475 \\
4080 & 0.33 & 0.431 \\
4140 & 0.33 & 0.431 \\
4200 & 0.33 & 0.431 \\
4260 & 0.32 & 0.388 \\
4320 & 0.31 & 0.344 \\
\hline & &
\end{tabular}

\begin{tabular}{|c|c|c|c|c|c|}
\hline 1440 & 2.07 & 8.015 & 1440 & 1.98 & 7.522 \\
\hline 1500 & 1.95 & 7.493 & 1500 & 1.93 & 7.307 \\
\hline 1560 & 1.91 & 7.319 & 1560 & 1.84 & 6.919 \\
\hline 1620 & 1.81 & 6.883 & 1620 & 1.72 & 6.403 \\
\hline 1680 & 1.72 & 6.491 & 1680 & 1.65 & 6.101 \\
\hline 1740 & 1.65 & 6.186 & 1740 & 1.59 & 5.843 \\
\hline 1800 & 1.58 & 5.881 & 1800 & 1.5 & 5.456 \\
\hline 1860 & 1.52 & 5.620 & 1860 & 1.45 & 5.241 \\
\hline 1920 & 1.46 & 5.359 & 1920 & 1.39 & 4.982 \\
\hline 1980 & 1.39 & 5.054 & 1980 & 1.33 & 4.724 \\
\hline 2040 & 1.37 & 4.967 & 2040 & 1.31 & 4.638 \\
\hline 2100 & 1.3 & 4.662 & 2100 & 1.22 & 4.251 \\
\hline 2160 & 1.25 & 4.444 & 2160 & 1.14 & 3.906 \\
\hline 2220 & 1.21 & 4.270 & 2220 & 1.08 & 3.648 \\
\hline 2280 & 1.13 & 3.921 & 2280 & 1.06 & 3.562 \\
\hline 2340 & 1.09 & 3.747 & 2340 & 0.98 & 3.218 \\
\hline 2400 & 1.05 & 3.573 & 2400 & 0.95 & 3.089 \\
\hline 2460 & 1 & 3.355 & 2460 & 0.9 & 2.873 \\
\hline 2520 & 0.96 & 3.181 & 2520 & 0.85 & 2.658 \\
\hline 2580 & 0.93 & 3.050 & 2580 & 0.8 & 2.443 \\
\hline 2640 & 0.91 & 2.963 & 2700 & 0.79 & 2.400 \\
\hline 2700 & 0.87 & 2.789 & 2760 & 0.71 & 2.056 \\
\hline 2760 & 0.83 & 2.615 & 2820 & 0.67 & 1.883 \\
\hline 2820 & 0.8 & 2.484 & 3000 & 0.61 & 1.625 \\
\hline 2880 & 0.77 & 2.353 & 3120 & 0.58 & 1.496 \\
\hline 2940 & 0.76 & 2.310 & 3300 & 0.48 & 1.066 \\
\hline 3000 & 0.74 & 2.223 & 3360 & 0.45 & 0.936 \\
\hline 3060 & 0.71 & 2.092 & 3540 & 0.43 & 0.850 \\
\hline 3120 & 0.68 & 1.961 & 3600 & 0.42 & 0.807 \\
\hline 3180 & 0.67 & 1.918 & 3780 & 0.43 & 0.850 \\
\hline 3240 & 0.65 & 1.831 & 3960 & 0.41 & 0.764 \\
\hline 3300 & 0.62 & 1.700 & 4080 & 0.39 & 0.678 \\
\hline
\end{tabular}




\begin{tabular}{|c|c|c|c|c|c|}
\hline $\begin{array}{c}\text { Temperatura= } \\
\text { Flujo Aire= }\end{array}$ & $\begin{array}{c}80 \\
150 \\
\end{array}$ & $\begin{array}{c}{ }^{\circ} \mathrm{C} \\
\mathrm{L} / \mathrm{min}\end{array}$ & $\begin{array}{c}\text { Temperatura= } \\
\text { Flujo Aire= }\end{array}$ & $\begin{array}{c}80 \\
250 \\
\end{array}$ & $\begin{array}{c}{ }^{\circ} \mathrm{C} \\
\mathrm{L} / \mathrm{min}\end{array}$ \\
\hline Masa seca= & 0.230 & g & Masa seca= & 0.231 & g \\
\hline $\begin{array}{c}\text { tiempo } \\
\text { segundos }\end{array}$ & $\begin{array}{c}\text { Peso } \\
\text { gramos }\end{array}$ & $\begin{array}{c}X \\
g_{\mathrm{H} 2 \mathrm{O} / g s S}\end{array}$ & $\begin{array}{c}\text { tiempo } \\
\text { segundos }\end{array}$ & $\begin{array}{c}\text { Peso } \\
\text { gramos }\end{array}$ & $\begin{array}{c}X \\
g_{\mathrm{H} 2 \mathrm{O}} / \mathrm{gSS}\end{array}$ \\
\hline 0 & 5.04 & 20.908 & 0 & 5.08 & 20.908 \\
\hline 60 & 4.84 & 20.038 & 60 & 4.9 & 20.132 \\
\hline 120 & 4.68 & 19.343 & 120 & 4.66 & 19.096 \\
\hline 180 & 4.54 & 18.734 & 180 & 4.42 & 18.061 \\
\hline 240 & 4.38 & 18.039 & 240 & 4.15 & 16.897 \\
\hline 300 & 4.24 & 17.430 & 300 & 3.92 & 15.905 \\
\hline 360 & 4.08 & 16.735 & 360 & 3.71 & 14.999 \\
\hline 420 & 3.93 & 16.083 & 420 & 3.5 & 14.094 \\
\hline 480 & 3.79 & 15.474 & 480 & 3.3 & 13.231 \\
\hline 540 & 3.66 & 14.909 & 540 & 3.11 & 12.412 \\
\hline 600 & 3.52 & 14.301 & 600 & 2.94 & 11.679 \\
\hline 660 & 3.39 & 13.735 & 660 & 2.77 & 10.946 \\
\hline 720 & 3.27 & 13.214 & 720 & 2.6 & 10.212 \\
\hline 780 & 3.16 & 12.736 & 780 & 2.45 & 9.566 \\
\hline 840 & 3.02 & 12.127 & 840 & 2.33 & 9.048 \\
\hline 900 & 2.91 & 11.649 & 900 & 2.19 & 8.444 \\
\hline 960 & 2.8 & 11.171 & 960 & 2.06 & 7.884 \\
\hline 1020 & 2.68 & 10.649 & 1020 & 1.94 & 7.366 \\
\hline 1080 & 2.58 & 10.214 & 1080 & 1.81 & 6.805 \\
\hline 1140 & 2.46 & 9.6933 & 1140 & 1.68 & 6.245 \\
\hline 1200 & 2.37 & 9.302 & 1200 & 1.6 & 5.900 \\
\hline 1260 & 2.26 & 8.823 & 1260 & 1.5 & 5.469 \\
\hline 1320 & 2.16 & 8.389 & 1320 & 1.4 & 5.037 \\
\hline 1380 & 2.08 & 8.041 & 1380 & 1.31 & 4.649 \\
\hline 1440 & 1.97 & 7.563 & 1440 & 1.24 & 4.347 \\
\hline 1500 & 1.9 & 7.259 & 1500 & 1.14 & 3.916 \\
\hline 1560 & 1.81 & 6.867 & 1560 & 1.07 & 3.614 \\
\hline 1620 & 1.73 & 6.520 & 1620 & 1 & 3.312 \\
\hline 1680 & 1.65 & 6.172 & 1680 & 0.92 & 2.967 \\
\hline 1740 & 1.58 & 5.868 & 1740 & 0.87 & 2.752 \\
\hline 1800 & 1.51 & 5.563 & 1800 & 0.83 & 2.579 \\
\hline 1860 & 1.43 & 5.216 & 1860 & 0.76 & 2.277 \\
\hline 1920 & 1.36 & 4.911 & 1920 & 0.72 & 2.105 \\
\hline 1980 & 1.28 & 4.564 & 1980 & 0.68 & 1.932 \\
\hline 2040 & 1.23 & 4.346 & 2040 & 0.63 & 1.717 \\
\hline 2100 & 1.18 & 4.129 & 2100 & 0.59 & 1.544 \\
\hline
\end{tabular}




\begin{tabular}{|c|c|c|c|c|c|}
\hline 2160 & 1.11 & 3.825 & 2160 & 0.56 & 1.415 \\
\hline 2220 & 1.07 & 3.651 & 2220 & 0.53 & 1.285 \\
\hline 2280 & 1 & 3.346 & 2280 & 0.5 & 1.156 \\
\hline 2340 & 0.95 & 3.129 & 2340 & 0.46 & 0.983 \\
\hline 2400 & 0.91 & 2.955 & 2400 & 0.46 & 0.983 \\
\hline 2460 & 0.86 & 2.738 & 2460 & 0.44 & 0.897 \\
\hline 2520 & 0.82 & 2.564 & 2520 & 0.41 & 0.768 \\
\hline 2580 & 0.78 & 2.390 & 2580 & 0.4 & 0.725 \\
\hline 2640 & 0.74 & 2.216 & 2640 & 0.38 & 0.638 \\
\hline 2700 & 0.71 & 2.086 & 2700 & 0.38 & 0.638 \\
\hline 2760 & 0.67 & 1.912 & 2760 & 0.35 & 0.509 \\
\hline 2820 & 0.64 & 1.782 & 2820 & 0.36 & 0.552 \\
\hline 2880 & 0.61 & 1.651 & 2880 & 0.35 & 0.509 \\
\hline 2940 & 0.58 & 1.521 & 2940 & 0.33 & 0.423 \\
\hline 3000 & 0.56 & 1.434 & 3000 & 0.33 & 0.423 \\
\hline 3060 & 0.52 & 1.260 & 3060 & 0.32 & 0.380 \\
\hline 3120 & 0.5 & 1.173 & 3120 & 0.31 & 0.336 \\
\hline 3180 & 0.48 & 1.086 & 3180 & 0.31 & 0.336 \\
\hline 3240 & 0.46 & 0.999 & 3240 & 0.3 & 0.293 \\
\hline 3300 & 0.46 & 0.999 & 3300 & 0.3 & 0.293 \\
\hline 3360 & 0.43 & 0.869 & 3360 & 0.29 & 0.250 \\
\hline 3420 & 0.43 & 0.869 & 3420 & 0.3 & 0.293 \\
\hline 3480 & 0.4 & 0.738 & 3480 & 0.27 & 0.164 \\
\hline 3540 & 0.39 & 0.695 & 3540 & 0.29 & 0.250 \\
\hline 3600 & 0.38 & 0.651 & 3600 & 0.29 & 0.250 \\
\hline 3660 & 0.36 & 0.564 & & & \\
\hline 3720 & 0.36 & 0.564 & & & \\
\hline 3780 & 0.35 & 0.521 & & & \\
\hline 3840 & 0.35 & 0.521 & & & \\
\hline 3900 & 0.34 & 0.477 & & & \\
\hline 3960 & 0.34 & 0.477 & & & \\
\hline 4020 & 0.34 & 0.477 & & & \\
\hline 4080 & 0.33 & 0.434 & & & \\
\hline 4140 & 0.32 & 0.391 & & & \\
\hline 4200 & 0.32 & 0.391 & & & \\
\hline
\end{tabular}




\section{Anexo 3}

Análisis de Varianza y Pruebas de Normalidad para el diseño factorial $\mathbf{2}^{\mathbf{2}}$

Variable respuesta: Contenido de Humedad adimensional a los 3000 segundos

\begin{tabular}{|ccccccc|}
\hline Fuente & $\begin{array}{c}\text { Suma de } \\
\text { Cuadrados } \\
\text { Tipo III }\end{array}$ & GL & $\begin{array}{c}\text { Cuadrado } \\
\text { Medio }\end{array}$ & F & Sig. \\
\hline Modelo Corregido & $.015^{\mathrm{a}}$ & 4 & .004 & 95.361 & .010 \\
\hline Intercepto & .031 & 1 & .031 & 782.836 & .001 \\
\hline Temperatura & .008 & 1 & .008 & 211.651 & .005 \\
\hline Flujo de Aire & .005 & 1 & .005 & 128.236 & .008 \\
\hline Temperatura * Flujo de Aire & .001 & 1 & .001 & 21.068 & .044 \\
\hline Error & $7.929 \mathrm{E}-5$ & 2 & $3.964 \mathrm{E}-5$ & & & \\
\hline Total & .046 & 7 & & & & \\
\hline Total Corregido & .015 & 6 & & & & \\
\hline
\end{tabular}

a. $\mathrm{R}$ Squared $=.995$ (Adjusted R Squared $=.984$ ); b. Computed using alpha $=.05$

Prueba de Igualdad de Error de Varianzas de Levene ${ }^{a}$

\begin{tabular}{|c|c|c|c|}
\hline$F$ & $d f 1$ & $d f 2$ & Sig. \\
\hline 1.045 & 4 & 2 & .543 \\
\hline
\end{tabular}

a. Design: Intercept + Temperatura + Flujo de Aire + Temperatura * Flujo de Aire

Se probó la distribución normal de los datos mediante la prueba de Shapiro-Wilk W. con una tolerancia del $5 \%$

- Variable respuesta: Tamaño de Sólido a los 1800 segundos

\begin{tabular}{|ccccrr|}
\hline Fuente & $\begin{array}{c}\text { Suma de } \\
\text { Cuadrados } \\
\text { Tipo III }\end{array}$ & GL & $\begin{array}{c}\text { Cuadrado } \\
\text { Medio }\end{array}$ & F & Sig. \\
\hline Modelo Corregido & $.162^{\mathrm{a}}$ & 4 & .040 & 11.628 & .081 \\
\hline Intercepto & 1.860 & 1 & 1.860 & 534.851 & .002 \\
\hline Temperatura & .067 & 1 & .067 & 19.155 & .048 \\
\hline Flujo de Aire & .091 & 1 & .091 & 26.242 & .036 \\
\hline Temperatura * Flujo de Aire & .002 & 1 & .002 & .559 & .533 \\
\hline Error & .007 & 2 & .003 & & \\
\hline Total & 2.132 & 7 & & & \\
\hline Total Corregido & .169 & 6 & & & \\
\hline
\end{tabular}

a. R Squared $=.959$ (Adjusted R Squared $=.876$ )

Prueba de Igualdad de Error de Varianzas de Levene ${ }^{a}$

\begin{tabular}{|c|c|c|c|}
\hline$F$ & $d f 1$ & $d f 2$ & Sig. \\
\hline 1.570 & 4 & 2 & .425 \\
\hline
\end{tabular}

a. Design: Intercept + Temperatura + Flujo de Aire + Temperatura * Flujo de Aire

Se probó la distribución normal de los datos mediante la prueba de Shapiro-Wilk W. con una tolerancia del $5 \%$. 


\section{Anexo 4}

Gráficas de la Simulación de las cinéticas de secado

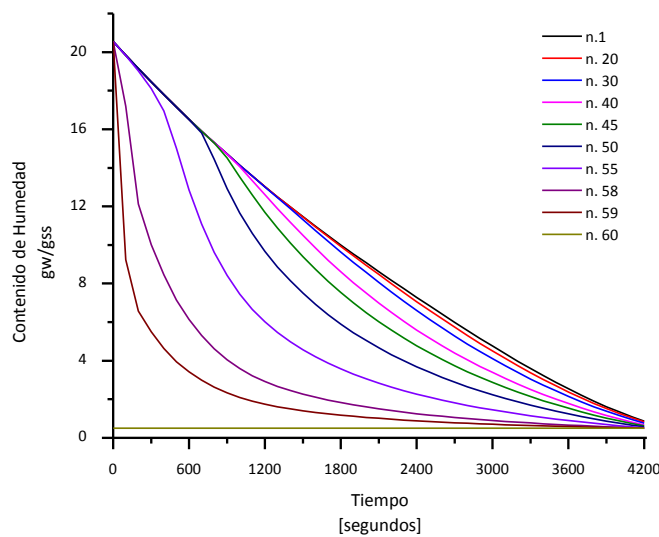

Figura 37. Perfiles de contenido de humedad (b.s.) a $60^{\circ} \mathrm{C}-250 \mathrm{l} / \mathrm{min}$.

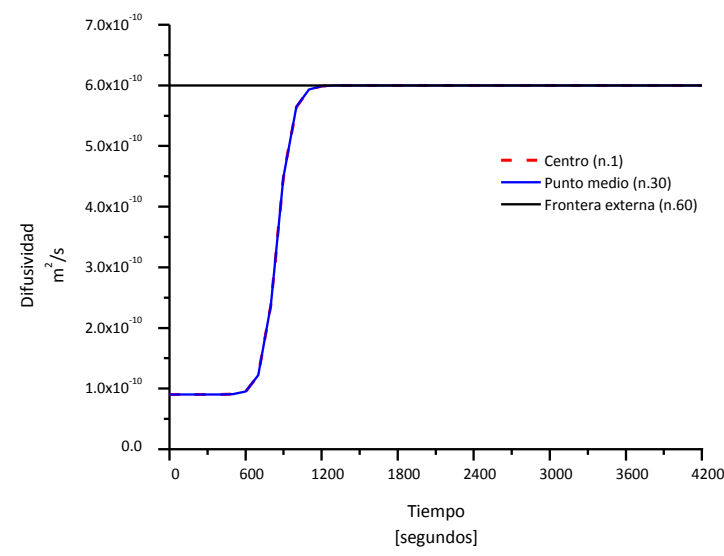

Figura 39. Coeficiente de difusión (función continua) para $60^{\circ} \mathrm{C}-250 \mathrm{~L} / \mathrm{min}$, para tres puntos del sólido.

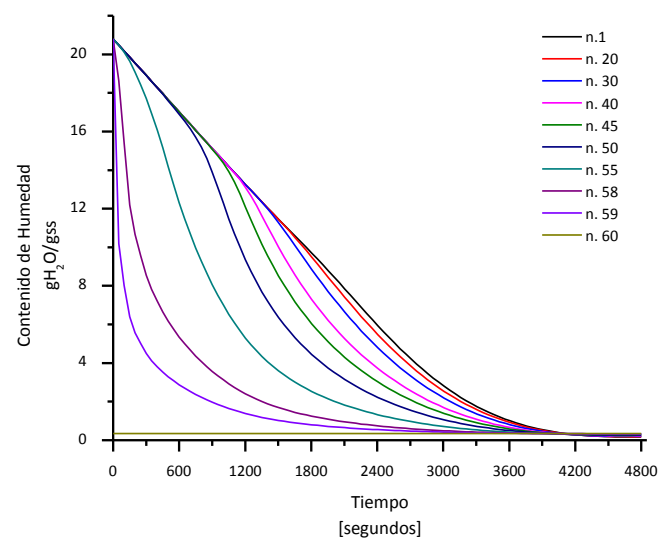

Figura 41. Perfiles de contenido de humedad (b.s.) a $70{ }^{\circ} \mathrm{C}-200 \mathrm{~L} / \mathrm{min}$.

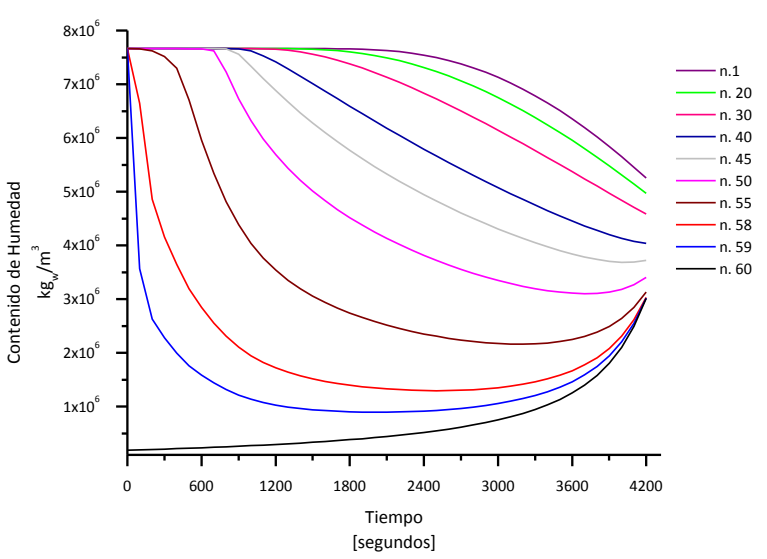

Figura 38. Perfiles de contenido de humedad (b. vol.) $60^{\circ} \mathrm{C}-250 \mathrm{l} / \mathrm{min}$.

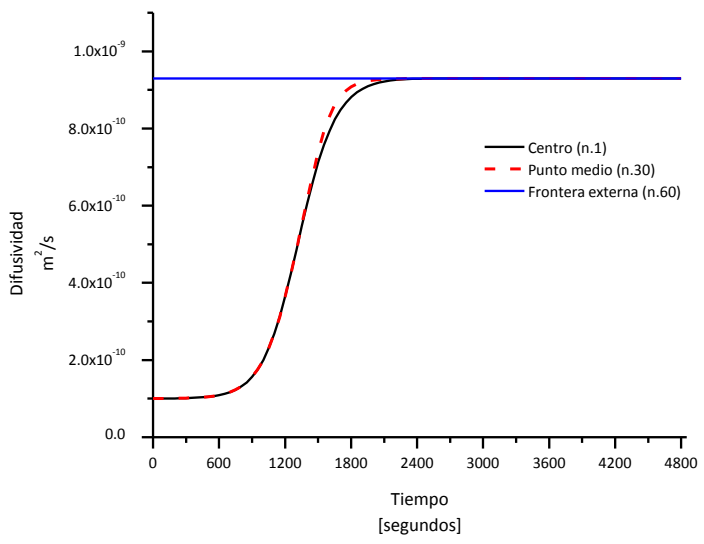

Figura 40. Coeficiente de difusión (función continua) para $70{ }^{\circ} \mathrm{C}-200 \mathrm{~L} / \mathrm{min}$, para tres puntos del sólido.

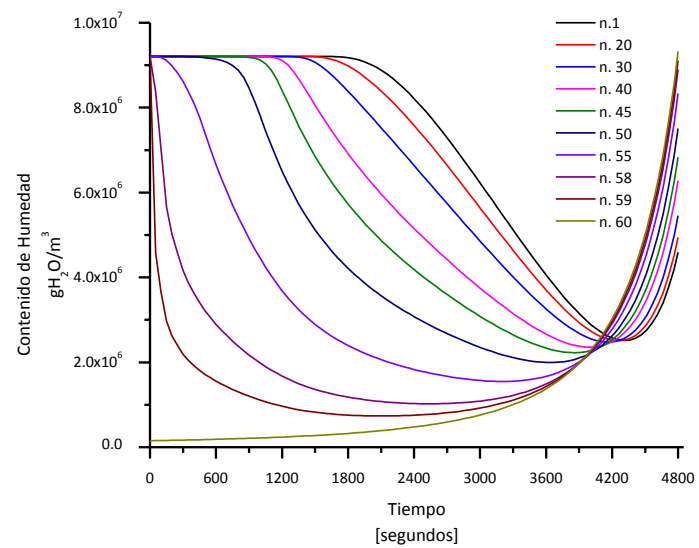

Figura 42. Perfiles de contenido de humedad (b. vol.) $70{ }^{\circ} \mathrm{C}-200 \mathrm{~L} / \mathrm{min}$. 


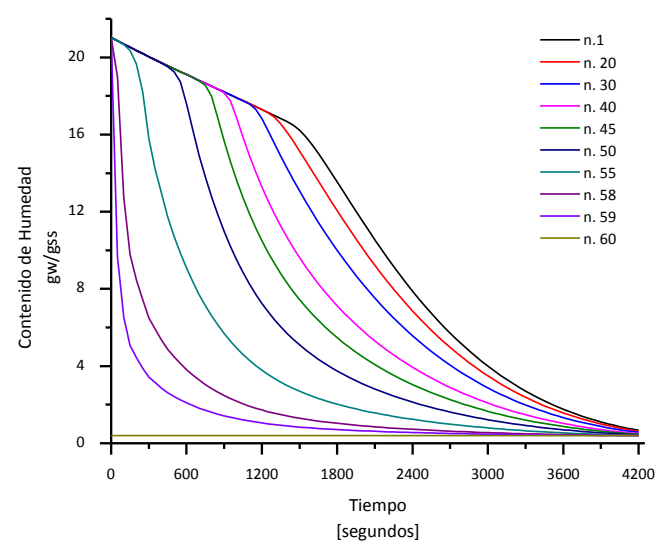

Figura 43. Perfiles de contenido de humedad (b.s.) a $80^{\circ} \mathrm{C}-150 \mathrm{l} / \mathrm{min}$.

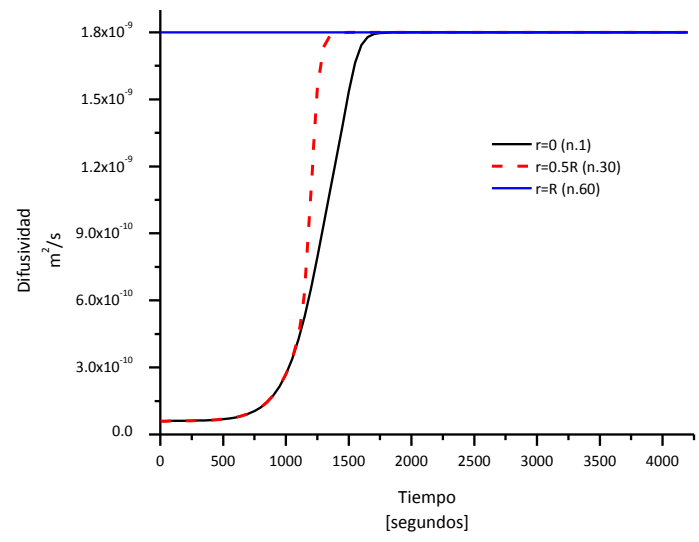

Figura 45 . Coeficiente de difusión para $80^{\circ} \mathrm{C}-150$ I/min, para tres puntos del sólido.

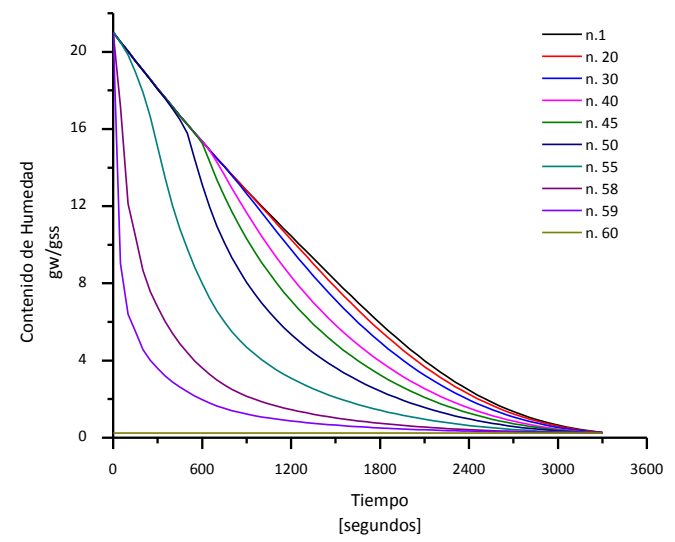

Figura 47. Perfiles de contenido de humedad (b.s.) a $80^{\circ} \mathrm{C}-250 \mathrm{l} / \mathrm{min}$.

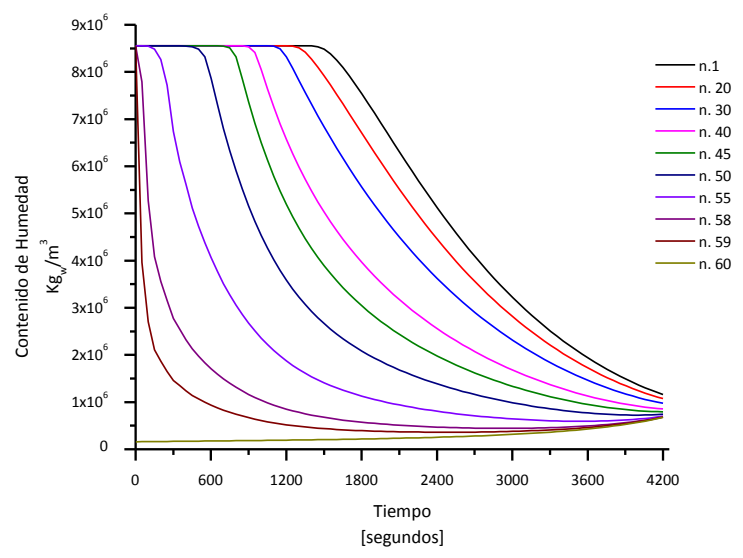

Figura 44. Perfiles de contenido de humedad (b. vol.) $80^{\circ} \mathrm{C}-150 \mathrm{l} / \mathrm{min}$.

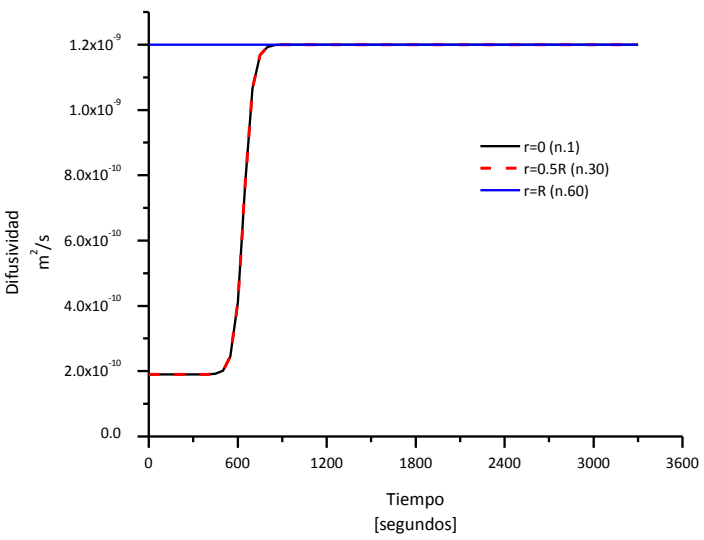

Figura 46. Coeficiente de difusión (función continua) para $80^{\circ} \mathrm{C}-250 \mathrm{l} / \mathrm{min}$, para tres puntos del sólido.

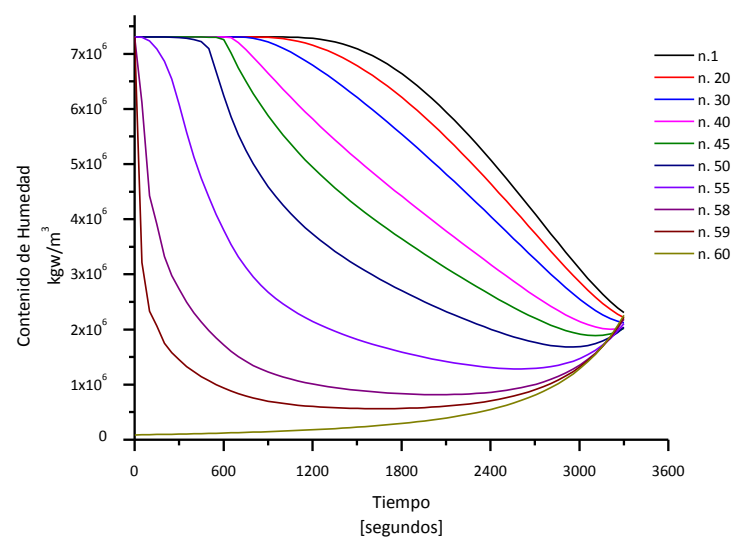

Figura 48 . Perfiles de contenido de humedad (b. vol.) $80^{\circ} \mathrm{C}-250 \mathrm{l} / \mathrm{min}$ 


\section{Anexo 5}

Isotermas del secado d cubos de tomate a 60 y $80^{\circ} \mathrm{C}$ con flujos de aire de 150 y $250 \mathrm{I} / \mathrm{min}$ ajustadas con el modelo de GAB.

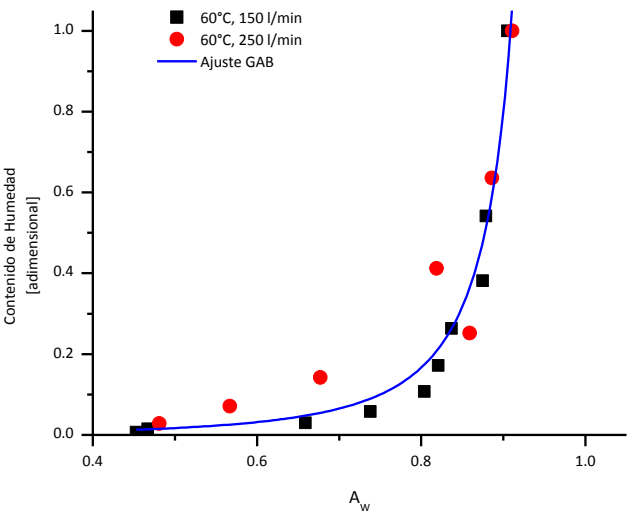

Figura 49. Isoterma del secado a $60^{\circ} \mathrm{C}, 150-250$ $\mathrm{I} / \mathrm{min}$ ajustada al modelo de

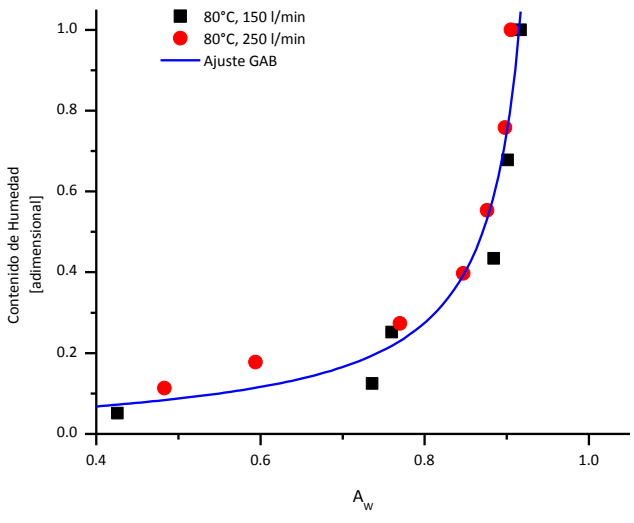

Figura 50. Isoterma del secado a $80^{\circ} \mathrm{C}, 150-250$ I/min ajustada al modelo de GAB

\begin{tabular}{|ccccc|}
\hline $\begin{array}{c}\text { Condiciones de } \\
\text { Secado }\end{array}$ & $\mathbf{X}_{\mathbf{0}}$ & $\mathbf{C}$ & $\mathbf{K}$ & $\mathbf{R}^{\mathbf{2}}$ \\
\hline $\mathbf{6 0} \mathbf{0}^{\circ} \mathbf{C} \mathbf{1 5 0 - 2 5 0} \mathrm{I} / \mathbf{m i n}$ & 0.08457 & 0.09808 & 1.04134 & 0.93425 \\
\hline $\mathbf{8 0 ^ { \circ } \mathbf { C } , \mathbf { 1 5 0 - 2 5 0 } \mathrm { I } / \mathrm { min }}$ & 0.04702 & 7.5247 & 1.04176 & 0.93356 \\
\hline
\end{tabular}

Tabla 16. Valores de las constantes del modelo de GAB para el secado a 60 y $80^{\circ} \mathrm{C}$ y $150-250 \mathrm{I} / \mathrm{min}$.

\section{Anexo 6}

Determinación de la Capacidad Calorífica en Calorimetría Diferencial de Barrido (DSC) 2920,

\section{TA Instruments}

En la interface del programa Thermal Advantage se introduce la siguiente secuencia de comandos:

1. Equilibrate al $20.00^{\circ} \mathrm{C}$

2. Data Storage: off

3. Modulate $+/-0.500^{\circ} \mathrm{C}$ every $80 \mathrm{sec}$

4. Isothermal for $10 \mathrm{~min}$

5. Data Storage: on

6. Isothermal for $5.00 \mathrm{~min}$

7. Data Storage: off

8. Increment $1.00^{\circ} \mathrm{C}$

9. Repeat segment 4 for 30 times 
Anexo 7

Equipo Experimental del Secador de Túnel

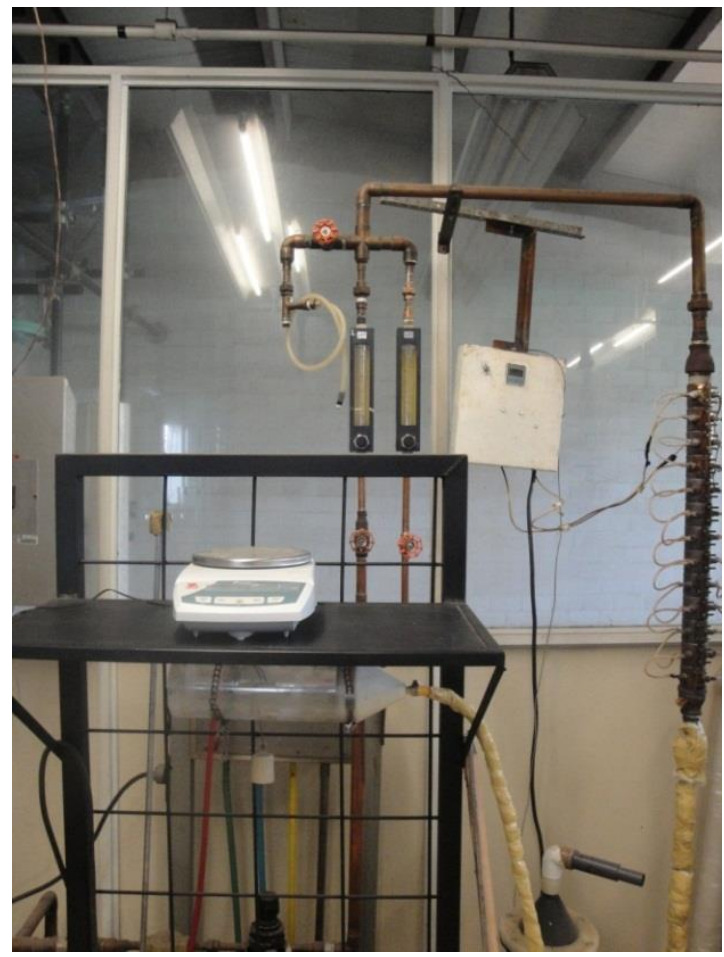

